\title{
2. Kapitel
}

\section{Rückkehr nach Leipzig und Heirat}

Nach meiner Rückkehr nach Leipzig wohnte ich zunächst bei meinen Eltern. Da inzwischen meine Schwester die Dachkammer bezogen hatte, schlief ich nachts auf einem Diwan im Arbeitszimmer meines Vaters. Ich stand in lebhaftem Briefwechsel mit Anna Elbert. ${ }^{1}$ Bei meinem letzten Besuch in Frankfurt waren wir übereingekommen, im Sommer zu heiraten, obgleich wir uns klar darüber waren, daß es sehr knapp zugehen würde. Ich wurde mehrfach zu ihren Eltern in der Riederwaldsiedlung eingeladen. Ihr Vater hatte in Frankfurter Schachkreisen einen Namen als starker Spieler. Bei einem der Besuche erzählte ich beiläufig, daß ich auch Schach spielte, was ihn veranlaßte, mich sofort ans Schachbrett zu setzen. Anna sah zu in freudiger Erwartung, daß ich abgeschlachtet werden würde, aber ich gewann die Partie, was bei ihm Verblüffung, bei ihr lautes Triumphgeschrei hervorrief. Übrigens habe ich nicht so rasch wieder eine Partie gegen ihn gewonnen. Auch bei meinem letzten Besuch in Frankfurt vor meiner Heirat spielte ich mit ihm Schach. Mitten in einer Partie knurrte er: "Wollen meine Tochter heiraten?" Ich antwortete: „Ich hoffe, daß Sie nichts dagegen haben", worauf er erwiderte: "Das ist Eure Angelegenheit. Sie müssen ja wissen, was Sie tun." Von Ersparnissen war weder bei mir noch bei ihr die Rede, aber sie besaß viel Wäsche und sehr viele schöne und elegante Kleider. In Frankfurt galt sie zusammen mit ihrer jüngeren Schwester als eine der Frankfurter Schönheiten. Sie erzählte voll Stolz, welches Aufsehen sie erregt hatte, als sie im Frankfurter Opernhaus im brennend roten Abendkleid langsam die große Treppe heruntergestiegen war. Sie verkehrte in Frankfurter literarischen Kreisen und war mit Hermann Wendel ${ }^{2}$ befreundet. Mit ihrem kastanienroten Haar und ihrer vollen Figur war sie eine auffallende Erscheinung. Ihre betonte Eleganz gab bei den innerparteilichen Auseinandersetzungen, an denen sie auf das Lebhafteste teilnahm, ihren Gegnern stets Anlaß zu bissigen und selbst ungezogenen Bemerkungen.

$[\ldots]$

Vor ihrer endgültigen Übersiedlung nach Leipzig besuchten wir zu Pfingsten 1917 gemeinsam Weimar. Ausgerechnet vor Goethes Gartenhaus hatten wir unseren ersten soliden Krach. Es war das erste Mal, daß ihr Selbstbewußtsein energisch mit dem meinen zusammenstieß. Es war auch nicht das letzte Mal. Sie hatte eine viel zu starke Vorstellung von ihrer Persönlichkeit, als daß sie mir erlaubt hätte, eine bestimmende Rolle zu übernehmen. ${ }^{3}$

Anna war zweieinhalb Jahre jünger als ich, aber sie war abgeschlossener und reifer. Das, was man den stillen Machtkampf in einer Ehe nennen kann, war vom ersten

1 Anna Geyer, geb. Elbert (1893-1973), Besuch der Mittel- und Handelsschule und Gaststudium an der Universität in Franlsfurt a. M., 1919 MdL Sachsen (USPD), dann Redakteurin am „Volksblatt" Halle, Mitarbeit am „Vorwärts", 1933 Emigration zunächst nach Prag und Paris, dann nach USA.

2 Hermann Wendel (1884-1936), sozialdemokratischer Schriftsteller, Redakteur der Frankfurter „Volksstimme“, 1912-1918 MdR, 1933 Emigration nach Frankreich.

3 Der nachfolgende Absatz steht im Original (Ms. S. 92) an späterer Stelle; er wurde wegen des Zusammenhangs und um Wiederholungen zu vermeiden hier eingefügt. Vgl. Anm. 6. 
Tage an im Gange. Sie war ehrgeizig für sich selbst, und sie setzte ihren Ehrgeiz daran, mich politisch aufsteigen zu sehen. Sie paßte schlecht in die graue Leipziger Arbeiterwelt. Aber der Kontrast ihrer Erscheinung mit dem, was man im Leipziger Arbeiterparteileben gewohnt war, gab ihr einen Vorteil, als sie später in Versammlungen redete. In der Leipziger Parteihierarchie war sie ein krasser Außenseiter, obgleich sie aus einer angesehenen Frankfurter Parteifamilie stammte und gewissermaßen ein Veteran des Kampfes gegen die rechtssozialistische Kriegspolitik war. Sie verstand sich schön anzuziehen, mit einem Zug ins Künstlerische im Stile der damaligen Mode. Einer ihrer Hüte von damals ist mir heute noch als Symbol von Eleganz in Erinnerung. Und doch fehlte etwas, was ich intellektuell nicht erfassen und was ich nicht benennen konnte. Ich blicke heute aus sehr großer zeitlicher Entfernung auf diese Anfänge einer Ehe zurück, die bis zum Jahre 194.0 weitergeführt wurde, unter mancherlei, zum Teil heftigen Krisen.

Nach ihrer Übersiedlung nach Leipzig nahmen wir zunächst eine möblierte Einzimmerwohnung in Leipzig-Thonberg, einer Vorstadt in der Nähe des Völkerschlachtdenkmals, nicht allzu weit von der Wohnung meiner Eltern entfernt. Thr Vater hatte ihr beim Abschied dreihundert Mark in die Hand gedrückt. Außerdem brachte sie ebenso viele Bücher mit wie ich selbst besaß, ihre Unterbringung in der gemieteten Wohnung war ein Problem. Der Juli des Jahres 19.17 war nicht gerade eine Zeit für traditionelle Hochzeitsreisen, so gingen wir zusammen mit einem meiner Freunde, der eine Freundin besuchen wollte, nach Dresden. Wir hatten dort ein sehr merkwürdiges Erlebnis. Wir besuchten das Café „Italienisches Dörfchen“ am Elbufer, einen Lieblingsplatz der Dresdner Gesellschaft. Anna trug ein weißes, bis zum Halse geschlossenes Kleid und dazu einen außerordentlich breiten weißen Hut, der ihre schöne Haarfarbe besonders hervorhob. Als wir durch das Café gingen, erhoben sich viele Gäste zu unserer Verblüffung neugierig von ihren Plätzen. Wir setzten uns an einen Tisch, und vom Nebentisch hörte ich, was die Sensation war: „Die Frau Kronprinzessin besucht Dresden." Die Dresdner Bürger glaubten, in ihr die Kronprinzessin zu sehen, die vor vierzehn Jahren in einem großen Skandal ihren Mann, den späteren König Friedrich August von Sachsen, verlassen hatte und bei Nacht und Nebel aus Sachsen geflüchtet war.

In meinen Ferien besuchten wir Frankfurt. Wir fuhren in einem Nachtzug, natürlich dritter Klasse. Es war kalt, und ich war viel zu leicht angezogen. Das Ergebnis war eine Rippenfellentzündung, verbunden mit einer Bronchitis, die ich lange Zeit nicht loswerden konnte, besonders da ich sie einfach mit Codein zu unterdrücken suchte. Nach unserer Rückkehr wurde die möblierte Wohnung zu unbequem. Wir nahmen noch weiter draußen, praktisch am Stadtrand, im zweiten Stock eines neu gebauten Hauses eine Mietswohnung von zweieinhalb Zimmern, die wir auf das Notdürftigste möblierten. Die Kosten der Wohnung wie die ständig steigenden Lebenshaltungskosten erforderten es, daß Anna eine Stellung als Sekretärin in einem Versicherungsbüro annahm. Wir aßen mittags zusammen in einem scheußlichen Privatmittagstisch in der inneren Stadt. Um dies vorwegzunehmen: in dem Hungerwinter 1917 auf 1918, in dem die Ernährungsverhältnisse in den sächsischen Industriegebieten die schlechtesten im ganzen Reich waren, haben wir redlich mit der Masse der Leipziger Bevölkerung mitgehungert und mitgefroren.

[...]

Der Weg zur Arbeit brachte mich jeden Morgen in Berührung mit der Leipziger Arbeiterwelt, und zwar nicht nur in der völlig überfüllten Straßenbahn. Auf beiden 
Seiten der langen und engen Straße, die von den Vorstädten zum Stadtinneren führte, ergossen sich die grauen Ströme der Arbeitenden stadtwärts, die Bürgersteige völlig ausfüllend. Die Hauptmasse schwenkte halbwegs zum Stadtinneren nach rechts, nach Osten ab und wurde von den Großdruckereien für Buch- und Kunstdruck aufgenommen. [...]

\section{Wachsender Einfluß in der Leipziger Arbeiterbewegung}

Meine Stellung in der Leipziger Arbeiterbewegung war anders als die eines von außerhalb der Pewegung gekommenen Intellektuellen. Nicht nur meine Herkunft, sondern auch meine vorhergehende intensive Tätigkeit in der Leipziger Arbeiterjugend trugen dazu bei. Diese Tätigkeit übertrug ich nun auf die Parteiorganisation, in weit ausgedehnterem Maße als in Würzburg. Ich war zwar „der Doktor" oder der „Doktor Geyer" - aber ich wurde von den sozialistischen Arbeitern als einer der ihren angesehen, der von vornherein dazugehört hatte. Die Schwierigkeiten, denen die meisten von außerhalb der Bewegung gekommenen Intellektuellen begegneten, obwohl sie tatsächliche Opfer an Einkommen und gesellschaftlichem Status für ihre Tätigkeit in der Sozialdemokratischen Partei brachten, bestanden in Leipzig für mich nicht. So war es mir möglich, meine Anschauungen immer stärker der Organisation der USPD im Leipziger Bezirk aufzudrücken. Ich kann heute nicht mehr sagen, wie viele Mitgliederversammlungen ich damals pro Woche abgehalten habe, aber es waren jedenfalls so viele, daß ich beträchtlich weniger Zeit zum Nachdenken und zu freien Überlegungen hatte als zuvor in Würzburg. Neben meiner Vortrags- und Versammlungstätigkeit stand ein zentraler Rednerausbildungskursus, den ich leitete. Auf diese Weise wuchs ich in eine Stellung hinein, die über die der meisten Mitglieder der Leipziger Parteileitung hinausging, und erwarb ein Ansehen und ein Vertrauen, das in dieser Form nur wenige der führenden Mitglieder der Leipziger USPD besaßen. Es war eine besondere Position, gewissermaßen eine Kronprinzenposition; denn zu allem kam hinzu, daß ich der Sohn meines Vaters war und daß dessen große Beliebtheit sich auf mich übertrug. [...] Aber diese Position mußte einigen der Mitglieder der Leipziger Parteileitung mißfallen. Dieses Mißfallen ist später in der Form von Differenzen über sachlich politische Fragen zum Ausdruck gekommen. Damals war ich mir über diese Konsequenz keineswegs im klaren. Mein Gefühl der Solidarität mit ihnen und der Loyalität ihnen gegenüber war so stark, daß mir daneben keine kühl abwägende Analyse meiner eigenen Stellung und der möglichen Konsequenzen möglich gewesen wäre. Aus großer Distanz zurückblickend weiß ich heute, daß ich mir damals schon - also etwa von der Mitte des Jahres 1917 bis zur Mitte des Jahres 1918 - nicht nur Freunde, sondern auch Gegner in den führenden Kreisen der Leipziger Partei gemacht habe.

Diese Parteiorganisation hatte eine repräsentative Verfassung. Die Grundlage bildeten die eingetragenen Parteimitglieder, die ihren Willen in den Mitgliederversammlungen der einzelnen Wohnbezirke zum Ausdruck bringen konnten. Zwischen ihnen und der gewählten Parteileitung wie dem von dieser kontrollierten Sekretariat stand „die Capora“. Dieser Name, der durch Jahrzehnte unverändert gebraucht wurde, war die sächsische Verballhornung der Worte „die in corpore versammelten Funktionäre", die natürlich aus den unbeholfenen Anfängen der Partei stammten. Die Funktionäre, etwa 1500 an der Zahl, waren die eigentlichen Parteiarbeiter, die 
kleinere Werbe- und Organisationsfunktionen ehrenamtlich versahen. Aus ihnen wurde "die kleine Capora" gebildet, die in Zusammenarbeit mit der Parteileitung das eigentlich entscheidende Organ darstellte. In beiden Körperschaften gewann ich beträchtlichen Anhang, obgleich dies an diesem Zeitpunkt noch nicht offen in Erscheinung trat. Dies beruhte nicht nur auf meiner Kronprinzenstellung, sondern sehr stark auch auf einer für die Leipziger Arbeiterbewegung eigentümlichen Haltung intellektueller Führung gegenüber. Die alte, von Marx und Engels gepflegte Hochachtung vor der Wissenschaft war hier besonders lebendig, und die Leipziger Parteifunktionäre haben stets mit Hochachtung zu den Intellektuellen aufgesehen, die ihre Zeitung redigierten - auf Schönlank, ${ }^{4}$ Stampfer, ${ }^{5}$ Mehring, Dr. Lensch. Obgleich ich nur einer der Redakteure der „Leipziger Volkszeitung “ war, kam ich immer stärker in die Position des führenden Intellektuellen der Leipziger Organisation. Aber mir wurde nicht nur die Hochachtung entgegengebracht, die diese Männer erhalten hatten, sondern ich wurde zugleich von den Leipziger Funktionären als einer der ihren angesehen. So wuchsen die Voraussetzungen heran, unter denen ich später bewußt nach der Führung griff und sie verwirklichte.

$[\ldots]^{6}$

Rein körperlich gesehen, litten wir alle unter der Unterernährung. Der Leipziger Industriebezirk wie ganz Sachsen überhaupt gehörte zu den Gebieten, in denen die Lebensmittelversorgung am niedrigsten war. Das verbundene Einkommen von Anna und mir war nach späteren Begriffen sehr niedrig - aber auch wenn es höher gewesen wäre, hätten wir angesichts der strengen Kriegsrationierung und der allgemeinen Warenknappheit nicht viel damit anfangen können. Es war für uns Ehrensache, innerhalb der Rationierung zu leben und das hieß vom Ersatz. Wir teilten die Not und den Hunger der Leipziger Arbeiterbevölkerung, aber wir hatten nicht die Vergünstigungen, die für Munitionsarbeiter durchgesetzt worden waren. Besonders fehlten uns Obst und frisches Gemüse. Eines Tages entdeckte Anna in einem Geschäft im alten Rathaus eine Glasflasche mit Apfelmus. Das hatten wir seit vielen Monaten nicht gegessen. Wir kauften die Flasche und aßen sie am gleichen Abend aus. Solange es Kartoffeln gab, wechselte das Abendessen zwischen Kartoffelbrei mit weißer Sauce und Kartoffelbrei mit brauner Sauce. Ein baltischer Student, mit dem ich bereits vor Kriegsausbruch befreundet war, kam nahezu täglich anderthalb Stunden weit angelaufen, um in den Genuß dieses Menus zu kommen. Er verrichtete kriegswichtige Arbeit in einer chemischen Fabrik - das heißt, er trug Packkisten von den Waggons zum Lagerhaus. Mein körperlicher Zustand war sehr schlecht, und ich erlitt zwei Anfälle der spanischen Grippe. Der erste war leichter, immerhin war mein Zustand so, daß bei einer Nachmusterung der untersuchende Arzt sagte: „Gehen Sie nachhause, legen Sie sich ins Bett, kommen Sie in acht Wochen wieder." Der zweite Grippeanfall überfiel mich morgens in der Straßenbahn, als ich zur Redaktion fuhr. Ich stand im Mittelgang einer völlig überfüllten Straßenbahn - fast ausschließlich Frauen - und ich fiel plötzlich um. Einige hilfreiche Frauen sagten sofort „Grippe“ und ließen mich niedersetzen. Ich fuhr noch nach der Redaktion, mußte aber nach-

4 Bruno Schönlank (1859-1901), 1893-1901 leitender Redalkteur der LVZ.

5 Friedrich Stampfer (1874-1957), 1900-1902 Redakteur der LVZ, 1917-1933 Chefredalteur des "Vorwärts“, 1920-1933 MdR, 1933 Emigration, stand auf dem rechten Flügel der SPD.

6 Die gekürzten Passagen (Ms. S. 89-92) enthalten außer einigen Bemerkungen über seine junge Ehe Schilderungen der fränkischen Mainlandschaft, in der sich Curt Geyer in jener Zeit zum Besuch von Verwandten seiner Frau öfters aufhielt. 
hause zurückkehren und mich ins Bett legen. Von diesem Anfall erholte ich mich schwer, ich hatte ihn gerade bis auf die letzten Spuren überwunden, als die vorrevolutionären Wochen begannen, so daß ich wieder eine Rednertätigkeit in größtem Stil aufnehmen konnte. Anfang Oktober 1918 wurde ich wieder nachgemustert und diesmal k. v. Feld geschrieben - aber an diesem Zeitpunkt hätte ich selbstverständlich einem Einberufungsbefehl keine Folge geleistet. Ich erhielt auch keinen.

Ich will mich nicht mit einer Chronik des politischen Geschehens zwischen dem Sommer 1917 und dem November 1918 aufhalten. Die Zeitung mußte unter der Vorzensur sehr vorsichtig lavieren; dennoch war es möglich herauszuarbeiten, daß die Kluft zwischen der SPD und der USPD sich nicht schloß, sondern sich im Gegenteil erweiterte. Die Hauptstreitpunkte waren zunächst die Friedensresolution ${ }^{7}$ und die Weigerung der sozialdemokratischen Fraktion im Reichstag, offen auf jede Annexion Belgiens zu verzichten, wodurch unserer Ansicht nach die Friedensresolution entwertet wurde. Dazu kamen die auf der Stockholmer Sozialistenkonferenz ${ }^{8}$ hervortretenden Differenzen. Seit der russischen Revolution vom Februar 1917 und erst recht seit der russischen Oktoberrevolution stand die Parole: „Frieden ohne Entschädigungen und Annexionen" im Mittelpunkt unserer Parteipropaganda. Sie gab der Partei das Gesicht der ausgesprochenen Friedenspartei, aber ein erheblicher Teil ihrer Führer verband mit dieser Friedenspropaganda das revolutionäre Ziel. Sie hatten das Beispiel der Bolschewiki vor Augen, welche die Friedensparole benutzt hatten, um ihre Revolution zu entfesseln und zum Siege zu führen. Im Grunde war es diese Doppelgesichtigkeit der USPD, die ihrer späteren Spaltung zugrunde lag.

\section{Vorrevolutionäre Situation in Deutschland unter dem Eindruck der russischen Oktoberrevolution}

Das Geschehen in Rußland war ein mächtiger Antrieb für die revolutionären Illusionen auf der Linken der deutschen Arbeiterbewegung. Es war in gewissem Sinne eine Wiederholung des Prozesses, der durch die Fernwirkung der russischen Revolution von 1905 hervorgerufen worden war. Aber waren es damals die Anschauungen und Lehren Rosa Luxemburgs gewesen, welche die Doktrin der Linken beeinflußten, so waren es jetzt die Lehren Lenins und Trotzkis von der Weltrevolution, die zwangs-

7 Ausgehend von einer Forderung des Zentrumsabgeordneten Erzberger im Hauptausschuß des Reichstags am 6. Juli 1917 brachten am 17. Juli anläßlich einer Kriegskredit-Debatte Zentrum, SPD und Fortschrittliche Volkspartei eine Resolution im Reichstag ein, in der ein Friedensschluß ohne Annexionen verlangt wurde. Die Friedensresolution bildete den Ausgangspunkt dex Zusammenarbeit der drei Parteien im Interfraktionellen Ausschuß und in der späteren "Weimarer Koalition". Die Nationalliberalen hatten sich nach anfänglicher Zusammenarbeit wieder zurückgezogen und stimmten gegen die Resolution, die USPD übte Stimmenthaltung.

8 Auf Initiative der holländischen und skandinavischen Sektionen der alten (II.) Intemationale sollte mit dem Ziel einer gemeinsamen Erklärung aller sozialistischen Parteien der kriegführenden und neutralen Länder im Sommer 1917 eine Konferenz in Stockholm stattfinden, die aber von den alliierten Regierungen einerseits und den Bolschewiki andererseits verhindert worden war. Statt dieser von der europäischen Arbeiterbewegung mit großen Hoffnungen erwarteten Friedenskundgebung tagte vom 5.-12. September 1917 in Stockholm die dritte Konferenz der Zimmerwalder Bewegung, dem internationalen Zusammenschluß der oppositionellen Gruppen und Parteien der Arbeiterbewegung. Vgl. Julius Braunthal, Geschichte der Internationale, Bd. 2, Hannover 1963, S. 78 ff. 
läufig dem Weltkriege nachfolgen würde. Die Lehren Lenins über das revolutionäre Machtproblem waren einfach - sie hatten keinen Raum für komplizierte Probleme des Übergangs und der Umschaltung in einer Revolution, sondern rieten ganz einfach: zerschlagt alle bisherigen Staatsorgane und schafft völlig neue. Theoretisch geriet ich in diesen Monaten immer stärker in den Bann dieser Anschauungen. Und doch war in dieser Erwartung der Revolution auf Grund des russischen Vorbildes und der Lehren der Bolschewiki etwas von dem Warten auf das große Wunder.

Bei verschiedenen Gelegenheiten veranstaltete die Leipziger Parteileitung im Einklang mit den Anweisungen des USPD-Parteivorstandes politische Demonstrationen. Nahezu alle diese Demonstrationen waren nicht viel mehr als glorifizierte Parteitreffen, einige von ihnen hatten nur den Umfang großer Mitgliederversammlungen. Es war klar, daß es uns nicht gelang, die Masse der Arbeiterbevölkerung, die damals vorwiegend aus Frauen, Munitionsarbeitern und unabkömmlichen Arbeitern bestand, wirklich in Bewegung zu bringen, was immer auch ihre Gefühle über den Krieg und die Not und den H.unger waren. Damals begegnete ich den Fragen, die mich späterhin bei der kritischen Überprüfung der marxistischen Doktrin theoretisch stark beschäftigt haben: Warum kommen die Massen nicht in Bewegung? Was bringt die Massen in Bewegung? Was müssen wir tun, um sie in Bewegung zu bringen? Im Grunde lief dies auf die Frage hinaus: „Wie macht man eine Revolution?" Die Antwort auf diese Frage schien uns gegeben durch das Beispiel der bolschewistischen Revolution, nämlich in geeigneter Situation die Forderung des Friedens zu benutzen, um mit ihr in die Macht zu reiten und dann die Macht für sozialistische Zielsetzungen zu gebrauchen. Wir rückten damit nicht nur näher an die bolschewistische Doktrin heran und nährten die durch sie vermittelten Illusionen, wir begannen auch, in den Bolschewiki unsere natürlichen Verbündeten zu sehen. Damit kam die Ostorientierung des radikalen Flügels der USPD in Gang, und mit ihr das Bekenntnis zum revolutionären Defätismus. ${ }^{9}$ Ich habe bereits erwähnt, daß wir uns in den ersten Kriegswochen in die Erwägung geflüchtet hatten, daß der Krieg ohne Sieger und Besiegte, ohne Annexionen und Entschädigungen enden müßte. Zwischen dem revolutionären Defätismus auf der äußersten Linken und dem unbedingten Siegeswillen bei den Vertretern der äußersten Rechten in der Sozialdemokratischen Partei gab es viele Nuancen und Meinungsschwankungen je nach der Kriegslage. Noch nach dem Ausbruch der Februarrevolution in Rußland bis zur Oktoberrevolution, welche die Bolschewiki an die Macht brachte, lag der Haltung der USPD die Erwägung zugrunde, daß Wilhelm II. nicht als Sieger durch das Brandenburger Tor zurückkehren dürfe, weil dies nach der Ansicht aller führenden USP-Mitglieder den Beginn einer europäischen Reaktionsperiode, die Verewigung des Scheinkonstitutionalismus der deutschen Verfassung und der Machtstrukturen des wilhelminischen Kaiserreichs und vor allem den endgültigen Sieg der nationalistischen Ideen über die Volksmassen bedeutet hätte. Aber sollte man darum den Sieg der anderen wünschen, den Sieg des englischen und französischen Nationalismus? Dieses Problem wurde namentlich unter den jüngeren intellektuellen Anhängern der USPD sehr vorsichtig, aber immer wieder diskutiert, ohne daß von der Bildung einer ein-

9 Lenin hatte nach Kriegsausbruch eine Politik des Defätismus propagiert: „Die Sozialisten müssen den Massen klar machen, daß es für sie kein Heil ohne die revolutionäre Niederwerfung der, eigenen' Regierungen gibt und daß ihre Kriegsverlegenheiten eben zu diesem Zwecke ausgenützt werden müssen." Vgl. W. J. Lenin, Sozialismus und Krieg, in: Lenin, Werke, Bd. 21, Berlin (O) 1974, S. 317. 
heitlichen Meinung unter ihnen gesprochen werden konnte. [. . . Obwohl ich schon vor dem Ersten Weltkrieg nicht verkannte, wie stabil die Machtverhältnisse im wilhelminischen Kaiserreich waren, hatte ich mich doch dem Glauben an die Revolution verschrieben. Während der ersten beiden Kriegsjahre jedoch hätte ich nicht gewagt, mir selber zu sagen: die deutsche Niederlage ist die Voraussetzung einer deutschen Revolution. Auch ich habe damals wie die Mehrheit der Kriegsopposition auf die Frage, wie der von uns geforderte Frieden aussehen sollte, mit der Formel geantwortet: ohne Sieger und Besiegte. Unter innenpolitischem Gesichtspunkt - und die Kriegsopposition von damals wie die USPD in ihren ersten Anfängen war vorwiegend innenpolitisch orientiert als Vertreterin intransigenter Opposition gegen das wilhelminische System - schien uns, daß das Scheitern des deutschen Angriffs, ein Kriegsausgang, der die Realisierung aller deutschen Machtforderungen und Annexionswünsche verhinderte, dem Prestige des Kaisertums und der herrschenden Volksschichten genügend Abbruch tun würde, um den Boden für revolutionäre Entwicklungen vorzubereiten. Auf dieser Grundlage konnte die USPD in ihrem Vorläuferstadium wie in ihren ersten Anfängen eine vollwertige Antwort geben auf die Frage, wie sie sich den Frieden vorstellte, nachdem sie einmal die Forderung des Friedens auf ihr Banner geschrieben hatte.

Aber nach der russischen Oktoberrevolution vom Jahre 1917 war in dieser Hinsicht die Ideologie der USPD nicht mehr einheitlich. Die Friedensforderung und die sozialrevolutionäre Zielsetzung fielen auseinander, als die entschiedensten Anhänger der sozialrevolutionären Richtung sich dem Standpunkt annäherten, daß die Friedenssehnsucht der Massen - auch wenn es ein Frieden nach einer Niederlage sein würde - benutzt werden müßte, um revolutionäre Bewegungen mit sozialrevolutionärer Zielsetzung gegen das bestehende Regime in Gang zu bringen. Das war die Lehre, welche die Propaganda der Sowjetregierung während der Friedensverhandlungen von Brest-Litowsk, ${ }^{10}$ deren oberster Sprecher Leo Trotzki war, den deutschen Arbeitern, die sich zur USPD bekannten, und ihren Führern einhämmerte.

Diese Entwicklung war in Berlin deutlicher als in Leipzig, diese Anschauungen beherrschten in Berlin die sogenannten „revolutionären Obleute“, ${ }^{11}$ jene Organisation von Betriebsvertretern, die später eine entscheidende Rolle bei den Berliner revolutionären Vorgängen spielte. In unserer Zeitung wie in der Leipziger Parteileitung hatten wir bisher Leipzig für den Vorort der USPD gehalten. Daß wir es nicht waren und daß die Führung in Berlin konzentriert wurde, konnten wir aus Anlaß des

10 Die Friedensverhandlungen mit Rußland hatten am 20.12.1917 begonnen, waren am 10.2. 1918 unterbrochen worden und erst nach dem deutschen Vormarsch (18.2.1918) abgeschlossen worden. Der Diktatfriede von Brest-Litowsk vom 3.3. 1918 wurde im Reichstag gegen die Stimmen der USPD ratifiziert. Vgl. Winfried Baumgart, Deutsche Ostpolitik 1918. Von Brest-Litowsk bis zum Ende des Ersten Weltkrieges, Wien/München 1966. - Leo Trotzki (1879-1940), führender Organisator der Oktoberrevolution, als Volkskommissar für Àueres (1917-1918) anfänglich Leiter der russischen Delegation bei den Friedensverhandlungen, stand als Gegner des Friedensschlusses in Opposition zu Lenin.

11 Die Revolutionären Obleute entstanden unter Führung von Richard Müller (neben den später E. Däumig und G. Ledebour traten) als oppositionelle Gruppe gegen die Burgfriedenspolitik der SPD und der Gewerkschaften. Die Revolutionären Obleute kamen überwiegend aus der Dreher-Branche des Berliner Metallarbeiterverbandes, hatten den Schwerpunkt in Berlin und verstanden sich innerhalb der USPD als (locker organisierte) Sondergruppe, die einen strikten Rätekurs steuerte. Vgl. Peter von Oertzen, Betriebsräte in der Novemberrevolution, Düsseldorf 1963, S. 71 ff. 
Januar-Generalstreiks von $1918^{12}$ erkennen, der die Reichsregierung von einem Diktatfrieden gegen Sowjetrußland abhalten sollte. Bei dieser Gelegenheit trat die Ostorientierung scharf hervor. Den Anweisungen der USPD-Zentrale folgend, riefen auch wir in Leipzig zum Generalstreik auf, aber es war klar, daß das Zentrum revolutionärer Aktivität und Vorbereitungen in Berlin lag. Der Streik verhinderte den Frieden von Brest-Litowsk nicht, aber er schuf als erste große Aktion eine Kampftradition und er stellte engere Verbindungen zwischen der Organisation der Obleute und der zentralen Parteileitung der USPD und den Bolschewiki her. Die von den Friedensverhandlungen in Brest-Litowsk ausgehende politische Friedenspropaganda für die Völker aller kriegführenden Mächte schuf eine wichtige Grundlage für unsere kommenden revolutionären Organisationen. Heute bin ich mir theoretisch und praktisch vollkommen darüber im klaren, wo die Grenzen der Wirksamkeit von Propaganda liegen und daß es Ereignisse und Erlebnisse sind, die große Volksmassen in Bewegung bringen. Dann kann Propaganda wirksam werden - der Prozeß verläuft nicht umgekehrt.

Die Stimmungen in der deutschen Arbeiterschaft von damals im allgemeinen wie auch in Leipzig waren durchaus abhängig von der jeweiligen Kriegslage. Die revolutionäre Aufwallung, die sich im Januarstreik gezeigt hatte, verebbte beim Beginn der Märzoffensive. ${ }^{13}$ Der Zusammenhang der Stimmung der Soldaten an der Front mit der Stimmung in der Heimat war sehr eng. Solange von der Front die Anschauung ausging, daß Frieden durch den Sieg möglich wäre, blieb die Propaganda des Friedens ohne Sieger und Besiegte auf breiteste Volksmassen ohne Eindruck. Nach dem Ende der Märzoffensive folgten die Monate der Erwartung neuer Offensiven. In diesen Monaten suchte die Reichsregierung die Stimmung zu heben mithilfe der sogenannten Durchhalte-Propaganda. Ich fuhr im Auftrag der Redaktion zu einer der Sitzungen, die in Dresden für die Chefredakteure der sächsischen Zeitungen veranstaltet wurden, und hörte mir dort einen optimistischen Vortrag eines Majors an, der das Thema "Wir schaffen's" - nämlich den Frieden durch den Endsieg - abhandelte. [...]

In diesen Wochen nach der Märzoffensive trat in Leipzig die zum Kampfe gegen die Friedensresolutionsmehrheit des Reichstages gegründete Vaterlandspartei ${ }^{14}$ besonders stark hervor und wurde sehr aktiv - die Friedensschlüsse von Brest-Litowsk [3. März 1918] und von Bukarest ${ }^{15}$ schienen zu zeigen, daß die Friedensresolution überholt und nicht mehr als Richtlinie der Politik des Reiches anzusehen sei. Der Führer der Vaterlandspartei in Leipzig war mein früherer Lehrer, Professor Erich Brandenburg. Das Leipziger Bürgertum, das in seiner großen Mehrheit nationallibe-

12 Vom 28. 1. - 4.2.1918 kam es von Berlin ausgehend in zahlreichen Städten zum ersten politischen Massenstreik in Deutschland, bei dem für einen Frieden ohne Annexionen, für die Demokratisierung, gegen den Belagerungszustand und für bessere Ernährung demonstriert wurde.

13 Die erste deutsche Offensive des Jahres 1918 erfolgte zwischen 21.3. und 6. 4. mit drei Axmeen in der Picardie.

14 Die Deutsche Vaterlandspartei propagierte unter dem Vorsitz von A. v. Tirpitz und Wolfgang Kapp seit September 1917 die alldeutschen Annexionsziele (Belgien, Luxemburg, Holland, Teile Polens und Frankreichs, baltische Ostseeprovinzen, Gebiete in Westrußland und der Ukraine) und ein großes deutsches Kolonialreich in Afrika. Die Partei, die sich als Sammlungsbewegung für eine ,kraftvolle Reichspolitik“ verstanden hatte, löste sich Ende 1918 auf.

15 Im Frieden von Bukarest (7. Mai 1918) hatte Rumänien Gebietsabtretungen hinnehmen und weitgehende wirtschaftliche und handelspolitische Zugeständnisse an Deutschland machen müssen. 
ral war, trat angesichts der neuen Hoffnungen auf den Endsieg auf den Boden der Vaterlandspartei. Diese veranstaltete eine Massenversammlung im großen Saal des Leipziger Zoo mit Professor Brandenburg als Redner. Das war für mich eine willkommene Gelegenheit. Ich besuchte die Versammlung mit einer beträchtlichen Anzahl unserer Parteianhänger und Mitglieder der Arbeiterjugend. Wir bildeten in dieser Versammlung eine sehr starke Minderheit. Ich verlangte das Wort nach Brandenburgs Rede und erhielt es, als ich darauf hinwies, daß uns öffentliche Versammlungen nicht erlaubt waren. Ich begann die Illusionen der Siegeshoffnungen aufzuzeigen und zu widerlegen und Brandenburgs Anschauungen anzugreifen. Seine empörte Gefolgschaft hörte einige Zeit zu, dann schrie sie mich nieder. Wir sprengten darauf regelrecht die Versammlung. Ich hatte damit die öffentliche Aufmerksamkeit auf mich gezogen und sie wandte sich von mir nicht mehr ab.

Dann kam die Julioffensive [15.-17. Juli 1918], deren Anfangserfolge beim Leipziger Bürgertum Siegesjubel hervorriefen, der mit dem Siegesjubel der ersten Kriegswochen durchaus vergleichbar war. Am Abend des dritten Tages dieser Offensive hatte ich an einer Parteisitzung teilgenommen und hatte mir dann die letzten Telegramme angesehen, die es deutlich machten, daß die Offensive steckengeblieben war und eine gefährliche Gegenoffensive eingesetzt hatte. Aber an diesem Tage standen die Leipziger Bürger unter dem Eindruck der Tatsache, daß deutsche Truppen wieder die Marne überschritten hatten. Im Siegesjubel flossen Bier und Wein in Strömen. Die Straßenbahn war überfüllt mit braven Leipziger Bürgern, alle angetrunken, sie lachten und sangen und schlugen sich gegenseitig auf die Schultern. Ich hing im Mittelgang eingekeilt an der Strippe, als auch mir plötzlich jemand auf die Schulter schlug. Ich sah mich um, es war mein Hauswirt, ein nationalliberaler Stadtverordneter, der ebenfalls an der Strippe hing. Auch er war völlig betrunken und strahlte über das ganze dicke Gesicht. Er gröhlte: „Herr Doktor, wir siegen, wir siegen! Jetzt ist der Krieg bald aus, und wir sind die Sieger. Wir sind wieder über der Marne, wir sind wieder über der Marne, wissen Sie, was das heißt, natürlich wissen Sie, was das heißt, wir haben's geschafft. Erst der Sieg, dann der Frieden! Nun werden wir alle reich, ich werde reich, Sie, Herr Doktor, werden reich, jedermann wird reich", und in dieser Tonart redete er während der ganzen Zwanzigminutenfahrt auf mich ein. Ich habe mich oft gefragt, welche Gefühle er gehabt haben muß, als er am anderen Morgen in der Zeitung die offiziellen Beschwichtigungsnachrichten las. Der Vorfall ist mir visuell und wörtlich so stark im Gedächtnis geblieben, weil er den kommenden Stimmungszusammenbruch erklärt. [. . .]

Ich verfolgte in den nächsten Tagen genau die Telegramme. Sie vermittelten den Eindruck eines Rückschlags und eines strategischen Rückzugs der Offensivtruppen, der nicht einmal bis zu ihrer Ausgangsstellung zurückführte, aber nicht mehr. Dann kam der 8. August. ${ }^{16}$ Am nächsten Tage blieb ich zuhause, weil ich noch unter Grippenachwirkungen litt. Anna holte ein Abendblatt, sie kam zurück und sagte: "Das verstehe ich nicht, was ist denn geschehen?" Ich sah mir die Zeitung an und wog die offiziellen Formulierungen ab : ernste Lage, bedauerlich, unerwarteter Einbruch, kein Grund zur Panik. Panik! Was war denn geschehen? Am anderen Tage ging ich auf die Zeitung, sah mir die Telegramme an und sprach mit den Kollegen.

16 In der Schlacht bei Amiens (8.-11. August 1918) brachen britische Panzer tief in die deutschen Linien ein. Ludendorff nannte den 8. August den „schwarzen Tag des deutschen Heeres". 
Wir waren uns darüber einig, daß die Kriegslage sich entscheidend geändert habe und daß die Hoffnung der Regierung, doch noch zum Frieden durch Sieg zu kommen, endgültig dahin sei. Es ist für die damaligen Stimmungen und Erschöpfungszustände bezeichnend, daß wir zunächst nicht an Revolution dachten, sondern daran, daß die kaiserliche Regierung sich nun zum Frieden würde bequemen müssen. Wir sahen den Frieden wirklich herannahen. Am Nachmittag dieses Tages ging ich mit Anna vor dem Eingang zum Südfriedhof im Sommersonnenschein spazieren. Wir redeten über die Befreiung vom Druck des Krieges durch den nun unvermeidlich gewordenen Frieden, und dann begannen wir uns vorzustellen, was sein würde und wie es sein würde, in der primitivsten Form, und wie es uns und jeden berühren würde. Anna sagte träumerisch: „Es wird also wieder so etwas Märchenhaftes wie Schokolade geben", und dann zählten wir auf, was wir am meisten entbehrt hätten. Es war wirklich kein revolutionäres Gespräch.

Aber bald hatten wir das Gefühl der herannahenden Katastrophe, nachdem wir von der Erregung in Berlin und der Stimmung im Reichstag unterrichtet worden waren. Es war offenkundig, daß mindestens ein Regimewechsel erfolgen würde und da $\beta$ die Kriegsdiktatur zu zerbrechen begann. ${ }^{17}$ Auf mich und meinen Vater machte es größ. ten Eindruck, als wir in einem Brief meines Bruders, der an der Ostfront in der Nähe von Luck stand, das Wort "Revolution" lasen. Mit dürren Worten stand darin, daß die Truppe überzeugt sei, daß nun die Revolution in Deutschland gänzlich unvermeidlich sei. Das ließ uns aufhorchen und aufwachen!

Es war nicht ganz einfach, einem größeren Kreis als unseren engsten Parteifunktionären das Verständnis dafür zu vermitteln, daß die kritische Stunde gekommen war und daß der Augenblick wirklicher politischer Aktivität der Arbeiterschaft herannahte. Die Wandlung in der Situation war so drastisch, daß die nackten Berichte darüber, so wie sie die Zeitung über die Vorgänge und Beratungen und den kommenden Regierungswechsel in Berlin geben konnte, einer Erläuterung und propagandistischer Auswertung bedurften. Wir standen vor der Aufgabe, die arbeitende Bevölkerung aus dem lethargischen Gefühl zu wecken, daß es immer so weitergehen werde, und ihr zu sagen, daß für sie die Stunde des aktiven Eingreifens herannahe. In der unter Zensur erscheinenden Zeitung war dies nicht möglich, große öffentliche Versammlungen wurden uns nicht erlaubt, so blieb uns nur der Weg, erlaubte und anmeldungspflichtige Mitgliederversammlungen abzuhalten, und zwar so viele wie möglich. Ein erheblicher Teil dieser Versammlungen wurde von mir gehalten. Die Erfahrungen, die ich dabei machte, zeigten mir, daß offenbar die Frontsoldaten im Westen und Osten die Lage und die sich aus ihr ergebenden Konsequenzen weit deutlicher erkannten als unsere Arbeiterbevölkerung, selbst als unsere Parteimitglieder in Leipzig. Mit allem, was ich über die Vorgänge vor und hinter den Kulissen in Berlin wußte, vermittelten die meisten dieser Versammlungen mir einen merkwürdigen und enttäuschenden Eindruck. Vor fünfzig bis hundertfünfzig eben von der Arbeit gekommenen müden Menschen in einem kleinen Saal von großen Dingen, vom Sturz

17 Angesichts der sich im Sommer 1918 abzeichnenden militärischen Niederlage forderte die Oberste Heeresleitung die Beteiligung der Mehrheitsparteien (SPD, Zentrum, Fortschrittliche Volkspartei) an der Reichsregierung, um Waffenstillstandsverhandlungen die Wege zu ebnen. Mit der am 3. Oktober 1918 gebildeten Regierung Max von Baden vollzog sich der Übergang vom konstitutionellen zum parlamentarischen System in Deutschland. Vgl. Heinrich Potthoff, Der Parlamentarisierungserlaß vom 30. September 1918, in: VfZ 20 (1972), S.319-332 (dort weitere Literaturangaben). 
der Monarchie und Revolution zu reden, selbst in verhüllten Ausdrücken, erschien dabei als eine nicht adäquate Aufgabe. In manchen der Versammlungen erlebte ich, daß die Zuhörer mir einfach nicht glauben wollten, als ich ihnen die tatsächlichen Berliner Vorgänge um die Neubildung der Reichsregierung, die Panik der Obersten Heeresleitung und den völligen Stimmungszusammenbruch der bürgerlichen Parteiführer und deren Entsetzen vortrug. Eine dieser Versammlungen - sie waren alle polizeilich überwacht - ist mir besonders im Gedächtnis geblieben. Sie fand in einem südlichen Vorort Leipzigs in einem kleinen Saal eines kleinen Gasthofs statt. Meine Absicht war, die Zuhörer aufzurütteln und sie auf revolutionäre Ereignisse vorzubereiten. Nach meiner Rede erbat ein älterer Arbeiter das Wort - eines unserer geschätzten Parteimitglieder - und nach einigen Komplimenten für mich kam die Frage, ob ich nicht eine sehr gefährliche Rede gehalten hätte. Ich antwortete, das beste Zeichen dafür, daß ich die Lage und die Auflösung des alten Systems richtig dargestellt hätte, sei die Tatsache, daß der überwachende Polizeibeamte nicht einzugreifen gewagt habe. Der Beamte sah mich erstaunt an, dann beugte er sich wieder über seine Notizen und nahm auch diese Äußerung von mir in sie auf. In allen diesen Versammlungen war es ganz offensichtlich, daß Anweisung an die Polizei ergangen war, sie nicht zu stören. Es war eine merkwürdige Lage. Es war ganz offensichtlich eine vorrevolutionäre Situation - aber die Leute, die sie zu einer revolutionären verwandeln sollten, mußten mühevoll zum Verständnis der Situation gebracht werden, während die Staatsgewalt selbst es begriffen hatte und deutlich zu resignieren begann. Da aber von Tag zu Tag die Ereignisse sich überstürzten, wurde unseren Mitgliedern klarer und klarer, daß es wirklich so weit war. Besonders nach der Amnestie für Karl Liebknecht und Rosa Luxemburg ${ }^{18}$ - Frau Luxemburg war vor ihrer Verhaftung eine Hauptmitarbeiterin der Zeitung gewesen - wurde es deutlich spürbar, daß auf der einen Seite die Niedergeschlagenheit des Bürgertums, auf der anderen die Unruhe der Leipziger Arbeiter, die allmählich in Bewegung kamen, anwuchs. Noch ein Vierteljahr zuvor hatten wir mit kleinsten Mitteln arbeiten müssen. Ich erinnere mich, daß der Lokalredakteur der Zeitung, der spätere sächsische Innenminister Hermann Liebmann, ${ }^{19}$ der neben mir das jüngste und aktivistischste Mitglied der Parteileitung war, und ich selber einst zehntausend Handzettel, die zu einer Demonstration aufriefen, selber drucken mußten. Jeder druckte fünftausend, und zwar jeder auf einer ganz kleinen Handdruckerei in Privatwohnungen, er in einem nördlichen, ich in einem südlichen Arbeitervorort. Den Satz hatte uns nach Arbeitsschluß heimlich und verbotenerweise ein Setzer in der Zeitung hergestellt. Die Geschäftsleitung hätte nicht gewagt, sich darauf einzulassen.

Jeden Tag diskutierten wir in der Redaktion der Zeitung, wie wir uns verhalten sollten. Die Auflage der Zeitung war seit dem Sommer langsam gestiegen, gemessen jedoch an der Zahl unserer Parteimitglieder und der gewerkschaftlich organisierten Arbeiter war sie viel zu niedrig. Ein rechtssozialistischer Versuch, ein Konkurrenz-

18 Karl Liebknecht war am 23. Oktober 1918 aus dem Zuchthaus Luckau entlassen worden, die LVZ feierte ihn in einem Artikel „Wir grüßen Dich, Liebknecht" vom 23.10.1918. Rosa Luxemburg konnte trotz der preußischen Amnestie für politische Gefangene erst am 9. November das Breslauer Gefängnis verlassen; sie hatte sich seit 10. Juli 1916 in „Sicherheitshaft" befunden.

19 Hermann Liebmaun (1882-1935), seit 1912 Redakteur bei der LVZ, USPD-Mitglied, 1918 bis 1923 Stadtverordneter in Leipzig, 1918-1933 MdL, 1923-1924 sächsischer Innenminister. 
organ ins Leben zu rufen, war ein kläglicher Mißerfolg geblieben. ${ }^{20}$ Als nun der Bevölkerung klar wurde, was vor sich ging und bevorstand, wuchs unsere Auflage rasch an. Die Bevölkerung, die sich von den großen bürgerlichen Zeitungen Leipzigs in die Irre geführt fühlte, wandte sich uns zu. Ich schlug nun vor, und zwar jeden Tag aufs neue, nicht auf weitere offizielle Lockerung oder Aufhebung der Vorzensur zu warten, sondern aus eigenem revolutionären Recht die Zensur abzuwerfen und ohne Vorzensur frei zu erscheinen. Wenn die Zeitung frei wäre, könnte sie das vornehmste Propagandamittel zur Aufrüttelung der Arbeiterbevölkerung werden. Ich stieß auf den hartnäckigen Widerstand des Chefredakteurs Hans Block, hinter dem nicht so sehr die Parteileitung als die geschäftliche Leitung der Zeitung stand, die Beschlagnahme oder Zerstörung ihrer Maschinen befürchtete. Vergebens wies ich darauf hin, daß wir uns dagegen schützen könnten und daß dies den Übergang zur revolutionären Aktion erleichtern würde. Eines der Gegenargumente gegen meine Vorschläge war übrigens, daß wir schon hinreichend frech geworden seien und daß es erstaunlich sei, was die Vorzensur alles durchlasse. Das bezog sich weniger auf die Leipziger als auf die Berliner militärische Zensurbehörde, die schon Wochen vor der Revolution in ziemlicher Auflösung war. Nun galt der Grundsatz, daß alles, was die Berliner Vorzensur passierte, auch anderswo gedruckt werden konnte, ohne dex örtlichen Zensur unterbreitet zu werden, auch konnte man dafür nicht belangt werden. In diesen Tagen ließ die Berliner Vorzensur ein Gedicht passieren mit dem Refrain: „Kronen werden auf dem Pflaster rollen." Wir druckten es in Fettdruck an der Spitze des Blattes und mußten im Laufe des Nachmittags und Abends diese Nummer in vielen tausenden von Exemplaren für den Straßenverkauf nachdrucken. ${ }^{21}$ Aber das genügte mir nicht. Ich wollte den revolutionären Akt aus eigenem Recht, aber ich konnte ihn nicht durchsetzen, obgleich ich in der Redaktion sehr kräftige Unterstützung fand. Als am 2. November allgemein die Zensur eingeschränkt wurde und wir öffentliche Versammlungen abhalten konnten, war es grotesk, daß die Zeitung, die schon ganz offen revolutionäre Propaganda betrieb, sich formal mit bürokratischer Exaktheit an die Vorschriften der Zensurbehörde hielt. Für mich war diese Vorsicht noch grotesker, wenn ich sie an den Reden maß, die ich in diesen Versammlungen hielt.

Ein weiterer Punkt, der nicht in der Parteileitung, sondern in der Redaktion, das heißt unter den Intellektuellen der Partei diskutiert wurde, war die Frage, welche Form der kommenden Revolution gegeben werden sollte. Mein Vater und ich hatten etwa September oder Anfang Oktober in einem lockeren Gespräch versucht, in die

20 Die „Freie Presse“ erschien vom 1.7.1917 - 30.9.1922 als SPD-Organ in Leipzig. Bis Ende 1917 war sie in Altenburg gedruckt worden, am 1.10.1922 wurde sie wieder mit der LVZ vereinigt.

21 Gemeint ist sicherlich folgendes Gedicht, das in der LVZ vom 12. Oktober 1918 auf Seite 1 veröffentlicht wurde:

Es dämmert

Herunter die Fetzen vom morschen Thron!

Herunter die Götzen von Babylon.

Ob Krone, ob Fetisch es gilt uns gleich!

Es tagt majestätisch ein neues Reich!
Auf tönernem Rande du goldnes Vieh: Großmoloch der Schande, herab aufs Knie! Moloch wie Mammon: im Blut, im Kot! Ihr Kinder Ammon, es dämmert rot!
Es dämmert, es dämmert, bald wird es Licht; es hämmert, es hämmert: das Weltgericht! Horch! horch! das Geläute! Dröhnender Schlag! und morgen und heute ist jüngster Tag!

M. v. Stern 
Zukunft zu sehen und uns schlüssig zu werden, was wir tun würden, wenn wir regierten. Für Sachsen schien uns die Lage ziemlich unproblematisch zu sein und für Groß-Leipzig erst recht. Bei einer demokratischen Neuwahl des sächsischen Landtags, die nach dem Machtübergang kurzfristig verordnet werden konnte, würde sich eine Mehrheit aus Unabhängigen und Rechtssozialisten ergeben und also eine sozialistische Regierung. In Groß-Leipzig würde eine unabhängige Mehrheit selbstverständlich sein, so daß die Form unseres Regimes nach dem Sturz des alten nicht von erstrangiger Bedeutung sein würde. Wir legten diesen Betrachtungen die Ergebnisse der letzten Reichstagswahlen zugrunde. Besonders mein Vater, der die Tradition unaufhörlicher Kämpfe um ein wirklich freies demokratisches Landtagswahlrecht in Sachsen verkörperte, neigte diesen Anschauungen zu. Aber in diesen Tagen wandelten sich Situationen wie Anschauungen blitzschnell, und besonders nach der Haftentlassung von Karl Liebknecht und Rosa Luxemburg ging von den Berliner Obleuten eine starke Propaganda für die Bildung von Arbeiter- und Soldatenräten nach sowjetischem Vorbild und zugleich für ein Bündnis zwischen der kommenden deutschen und der russischen Revolution, praktisch für enge Zusammenarbeit der USPD und der revolutionären deutschen Arbeiter mit den Bolschewiki aus. Liebknechts Propaganda brachte das Problem auf die Formel: „Die russische Revolution ist in Gefahr, wenn ihr die deutsche nicht zu Hilfe kommt - Weltrevolution oder Untergang, auf zur Tat!" Diese Frage wurde sehr schnell in der USPD umstritten, besonders nachdem unmittelbar vor dem 9. November die russische Botschaft aus Berlin ausgewiesen worden war und die Regierung Max von Baden die diplomatischen Beziehungen zu Sowjetrußland abbrach. ${ }^{22}$ Von vornherein wurde das Problem "Westorientierung oder Ostorientierung" aufgeworfen.

Einige Tage nach der Haftentlassung Rosa Luxemburgs bat mich der Chefredakteur Hans Block um eine vertrauliche Unterredung. Er sagte, es sei anzunehmen, daß Rosa Luxemburg und ihr Mitarbeiterkreis auf die Bildung von Arbeiterräten statt demokratischer Lösungen drängen würden und daß solche Anschauungen auch im Parteivorstand der USPD Anhänger besäßen, während andere, besonders der Führer der Partei, Hugo Haase, Bedenken dagegen hätten. Für ihn gehe es um den Kurs der Zeitung, wir müßten damit rechnen, daß die Gruppe Luxemburg, die früher die Seele der Zeitung gewesen war, Einfluß auf die Zeitung in diesem Sinne zu gewinnen suchen werde. Er wußte natürlich, daß ich das Haupt der radikalen Richtung in der Leipziger USPD war, und da mein Einfluß auf den Kurs der Zeitung ohnehin schon groß war, wollte er wissen, wie ich zu der Frage stand. Ich sagte ihm wahrheitsgemä $\beta$, ich selbst hätte mich nicht festgelegt, auch die Parteileitung habe sich nicht festgelegt, bei der Entscheidung dieser Frage werde vieles davon abhängen, welchen Gang die Ereignisse nehmen würden und besonders wie die Dinge in Berlin behandelt werden würden. Aber ich sagte ihm: „Nicht Rosa Luxemburg wird die Zeitung führen, sondern wir" - was in der Praxis der nächsten anderthalb Jahre be-

22 Die sowjetrussische Botschaft in Berlin war bald nach ihrer Errichtung im April 1918 ein Dorn im Auge der deutschen Behörden geworden, da sie als revolutionäre Propagandazentrale fungierte, in der reger Verkehr mit USPD-Abgeordneten herrschte. Nachdem am 13. 10. 1918 auf deutscher Seite der Entschluß zum Abbruch der Beziehungen gefaßt war, wurde am 4. November ein Zwischenfall herbeigeführt (Zerbrechen einer Kurierkiste mit Flugschriften des Spartakusbundes, die von der deutschen Polizei hineinpraktiziert worden waren), der den unmittelbaren Anlaß zur Ausweisung des Botschafters Joffe bot. Am 6.11.1918 mußte das Botschaftspersonal abreisen. S. Baumgart, Deutsche Ostpolitik 1918, S. 334 ff. 
deutete, daß ich sie führte. Zehn Tage später hätte ich ihm mit Entschiedenheit gesagt: „Ich werde für die Diktatur der Arbeiterräte eintreten“ - aber da war ihm das ohnehin klar, und er trat selbst dafür ein.

\section{Revolution - Der Leipziger Arbeiter- und Soldatenrat}

Aber zehn Tage später war ich bereits der Führer der revolutionären Bewegung in Leipzig, nicht nur in den Augen meiner persönlichen Anhänger und der Leipziger Arbeiter, sondern auch in den Augen des Leipziger Bürgertums - dank der Serie von öffentlichen Riesenversammlungen, die ich in allen Leipziger Vororten in den größten Sälen abhielt. Es waren echt revolutionäre, aufgewühlte Versammlungen. Ich wußte, daß ich als Redner Versammlungen faszinieren konnte, selbst kleine Versammlungen, am besten aber Massenversammlungen. Ich warf meine ganze Kraft in diese revolutionären Versammlungen und alle meine politisch-historischen Kenntnisse. Ich sprach völlig frei, etwa anderthalb Stunden lang, aber ich hatte jede meiner Reden vorher sorgfältig durchdacht und disponiert. Ich legte sie dabei nicht im Wortlaut fest, auch die Stellen nicht, die besonders wirken sollten. Ich konnte mich darauf verlassen, daß ich die wirksamste Formulierung finden würde durch die Eingebung des Augenblicks, in dem erhöhten Selbstgefühl, das die rednerische Beherrschung einer Massenversammlung verleiht. Diese Versammlungen leiteten tatsächlich die Revolution in Leipzig ein, sie waren der Auftakt zu weiteren Massenversammlungen, die ich nach der Revolution abhielt und zu riesigen Massendemonstrationen auf der Straße an kritischen Zeitpunkten.

Die größte dieser Versammlungen fand in einem der westlichen Arbeitervororte Leipzigs statt. Die Polizeiüberwachung funktionierte noch - in einer gewissen Art. Der überwachende Beamte saß wie zuvor auf der Bühne an einem Ende des Vorstandstisches, vor dem ich frei stand und redete. Ich wurde nie gestört. Diese große Versammlung im Westen wurde von dem Leipziger Polizeidirektor persönlich überwacht, demselben, der einst die Versammlung des Reichstagskandidaten Cohen überwacht hatte. Meine Rede enthielt eine Paraphrase über das Thema „Kronen werden aufs Pflaster rollen", und da ich den Polizeidirektor gespannt zuhören sah, lenkte ich zielbewußt allmählich in die Worte ein, die Max Cohen damals gebraucht hatte: „Diese Könige und Großherzöge, diese Herzöge und Fürsten und wie diese . . ." Ich machte dieselbe Kunstpause wie Cohen damals. Ich sah, mit welcher Spannung der Polizeidirektor die nächsten Worte erwartete. Und dann fuhr ich fort: „und wie diese Herren alle genannt werden." Während ich weiter redete, sah ich zu dem Polizeidirektor hinüber, um seine Reaktion zu sehen. Er hielt die Hand vors Gesicht, um sein Lächeln zu verbergen. Ebensogut wie ich erinnerte er sich an die Szene von damals. Aber eigentlich wollte ich ihn nicht amüsieren, ich hatte vielmehr vor, ihn zur Zielscheibe einer Demonstration zu machen. Ich griff die Politik und die Person Wilhelms II. mit den härtesten Verurteilungen und mit den schärfsten Ausdrücken an. Ich sah wohl, daß er am Ende nicht mehr alles schweigend hinnehmen werde trotz guter Vorsätze und Instruktionen. Als er schließlich aufstand und sagte: „Aber, Herr Doktor, ich muß Sie doch bitten, sich etwas zu mäßigen" hatte ich ihn, wo ich wollte. Ich richtete mich auf, deutete mit ausgestrecktem Arm und Zeigefinger auf ihn und rief: „O nein, Herr Polizeidirektor, das ist vorbei. Was in dieser Versammlung gesagt wird, bestimme ich und nicht die Polizei, und wann sie beendet wird, 
bestimme ich, nicht Sie!“ Die Versammlung stand auf und rief wie ein Mann : „Jawohl." Und brachte mir eine Ovation. Er setzte sich resigniert nieder - es war das Ende der polizeilichen Überwachung unserer Versammlungen in den vorrevolutionären Tagen.

Die Macht lag wirklich auf der Straße, und die Leipziger Parteileitung beschloß, nicht mehr zu warten, sondern die Macht selber zu übernehmen und sich zunächst in einer Überraschungsaktion der wichtigsten Einrichtungen zu bemächtigen. Der Vorsitzende des Bezirksverbands Leipzig, Richard Lipinski, ${ }^{23}$ sollte Garnisontruppen, die in Leipzig-Connewitz in einem Versammlungslokal untergebracht waren, auffordern, sich hinter uns zu stellen. Die Mehrheit dieser Truppen bestand aus unseren Parteimitgliedern. Mein Vater sollte den Oberbürgermeister und die Stadtverwaltung unter Kontrolle stellen. Hermann Liebmann mit fünfundzwanzig Mann, bewaffnet mit Pistolen, das Generalkommando überfallen und absetzen, und ich sollte mit ebenfalls fünfundzwanzig Mann und gleicher Bewaffnung das Hauptpostgebäude, Telegraph und Telephon besetzen, alle Verbindungen sperren und nur kontrollierte Mitteilungen durchlassen. Wir kamen nicht mehr zur Durchführung dieses vorgefaßten Planes, wir wurden selber von den Dingen überrascht; denn inzwischen hatte die Gründung von Arbeiter- und Soldatenräten durch Abteilungen revolutionärer Matrosen von Kiel in den Großstädten begonnen. So kam auch für uns selbst überraschend der Tag des Machtüberganges in Leipzig.

Am Morgen des 8. November kam Chefredakteur Hans Block in die Räume der politischen Redaktion der Zeitung, laut lachend schwenkte er ein Telegramm in der Hand und sagte: „Das ist doch kaum glaublich, das ist doch mehr eine Operette.“ Neugierig fragten wir, was im Telegramm stehe. Er sagtc: „Stellt Euch vor, Revolution in Bayern, der König geflohen und Kurt Eisner ${ }^{24}$ Ministerpräsident." Er schüttelte sich abermals vor Lachen und fuhr fort: „Eine Schlawinerregierung in München, denkt Euch, Schwabing regiert!" Wir waren genauso überrascht; denn wir kannten alle die solide Stärke der rechtssozialistischen Partei in München und die zahlenmäßige und politische Schwäche der kleinen Gruppe um Kurt Eisner aber es war kein Zweifel, in München hatte die Revolution gesiegt und Kurt Eisner regierte in Bayern.

Monate später gab mir Wilhelm Herzog ${ }^{25}$ eine Schilderung der Münchner Vorgänge ohne diese amüsante Note, mit der wir die Nachricht aufgenommen hatten. Wilhelm Herzog, der in allen Ereignissen und Situationen in erster Linie die feierlichen und großartigen Züge sah, erzählte eindrucksvoll, wie sich die provisorische Regierung Bayerns in der Nacht in einem halbdunklen Saal des Landtagsgebäudes versammelte, wie jeder einzelne von ihnen im Bann der großen historischen Stunde stand und wie tief bewegt Eisner war, als er als Führer der Regierung die erste Ansprache an den provisorischen Arbeiter- und Soldatenrat hielt und die Republik ausrief. Ich konnte

23 Richard Lipinski (1867-1936), Buchhändler, 1891-1901 Redakteur der LVZ, 1903-1906 und 1920-1933 MdR, 1918/19 sächs. Ministerpräsident, 1920-1923 Innenminister.

24 Kurt Eisner (1867-1919), 1899-1905 Redakteux des „Vorwärts“, 1907-1910 der „Fränkischen Tagespost" Nürnberg, 1917 Führer der Münchner USPD, 1918/19 bayerischer Ministerpräsident, am 21. 2.1919 ermordet.

25 Wilhelm Herzog (1884-1960), Schriftsteller, 1914/1915 und 1918-1929 Hrsg. der pazifistischen Zeitschrift „Das Forum“, 1918-1919 Redakteur der Tageszeitung „Die Republik“, 1920 Redakteur der Hamburger Volkszeitung, 1929 Emigration (Schweiz, Frankreich, Trinidad, USA), 1952 Rückkehr nach Deutschland. Vgl. W. Herzog, Menschen, denen ich begegnete, Bern 1959, S. 55 ff. 
nicht mit einer gleich pathetischen und würdevollen Erzählung über die Revolution in Leipzig aufwarten; denn da ging es weit nüchterner zu.

An diesem Tage hatten wir in der Zeitung die Revolution in Bayern natürlich zu unserer Hauptnachricht gemacht. Die Zeitung war abgeschlossen und im Druck und die Redakteure nachhause gegangen. Es war gegen zwei Uhr mittags, ich war noch allein in der Redaktion und las. Plötzlich kam aufgeregt der Redaktionssekretär zu mir und sagte: „Genosse Geyer, kommen Sie doch bitte ans Telephon, Sie werden offenbar verlangt, aber da ist etwas, was ich nicht verstehen kann." Zur Kennzeichnung der damaligen Zustände in unseren Redaktionen muß ich erzählen, daß die Redaktion einen einzigen Telephonanschlu $\beta$ und einen einzigen Apparat besa $\beta$, und der hing an der Wand in einer Ecke des Redaktionssekretariats.

Ich ging ans Telephon und hörte, wie eine aufgeregte weibliche Stimme flüsternd sagte: "Genosse Geyer, Genosse Geyer, sind Sie am Apparat?" Ich erkannte die Stimme, es war eine unserer Funktionärinnen, die einen meiner Kurse besucht hatte. Sie war Telephonistin im Haupttelephonamt. Ich sagte ebenfalls flüsternd: „Ja, Martha, ich bin hier.“ Sie flüsterte weiter: „Seien Sie ganz still, hören Sie gut zu“, und dann hörte ich, wie sie den Leipziger Oberbürgermeister, Dr. Rothe ${ }^{26}$ mit dem kommandierenden General verband. Ich hörte folgendes Gespräch : „Herr General, eben zieht eine Abteilung revolutionärer Matrosen mit roter Fahne vom Hauptbahnhof durch die innere Stadt, offenbar um das Rathaus zu besetzen. Was soll ich tun?" - „Herr Oberbürgermeister, Sie haben doch Ihre Schutzmannschaft." - „Herr General, Sie wissen so gut wie ich, daß ich mich darauf nicht verlassen kann. Ich ersuche Sie deshalb, mir militärische Hilfe zu schicken." - „Herr Oberbürgermeister, das kann ich leider nicht, denn Sie wissen, daß ich nach den neuesten Anweisungen nur auf direkte Anweisung der Landesregierung handeln kann. Im übrigen kann ich mich auf die Garnisontruppen ebensowenig verlassen wie Sie sich auf Ihre Schutzleute, Sie kennen doch die Situation." - „Aber was soll ich denn tun, Herr General?" - „Ich kann Ihnen nicht raten, was Sie tun sollen, Herr Oberbürgermeister, Sie müssen Thre eigenen Entschlüsse fassen und sehen, wie Sie sich durch die Situation hindurchfinden." - Die Macht lag tatsächlich auf der Straße.

Ich will nicht über meine Erregung und über meine Gefühle reden. Ich hängte den Hörer ein, informierte den Redaktionssekretär und nahm dann sofort den Hörer wieder auf, um in einer Reihe von Gesprächen Lipinski, meinen Vater und andere Mitglieder der Parteileitung zu alarmieren. In kurzen Worten verabredeten wir, welche Aufgaben ein jeder übernehmen sollte. In der Praxis genügten wenige Worte, um die Garnisontruppen im Süden und Norden der Stadt hinter die Parteileitung der USPD zu stellen. Der Bezirksverbandsvorsitzende Richard Lipinski fuhr zum Generalkommando, und der Kommandierende General legte höchst bereitwillig und offenbar erleichtert die Macht und das Kommando über die Truppen in die Hände der USPD-Parteileitung. Wir zogen kleine Abteilungen der Garnisontruppen nach der inneren Stadt zur Besetzung der wichtigsten Ämter und Gebäude und wiesen die Truppen an, Soldatenräte zu wählen. Keiner der Offiziere protestierte oder hob auch nur eine Hand zum Widerstand, sie hatten es alle erwartet. Der Oberbürgermeister

${ }_{26}$ Karl Rothe (1865-1953), Jurist, 1896-1917 Direktor der Leipziger Hypothekenbank, 1899 bis 1917 Stadtverordneter (ab 1909 Vorsteher), 1918-1930 Oberbürgermeister von Leipzig, 1945 bis 1948 Stadtverordneter (LDP) und Stadtrechtsrat. Vgl. Karl Rothe, 50 Jahre im Dienste einer Großstadt 1899-1948, nach hinterlassenen Aufzeichnungen bearb. v. Edith Rothe (Ms., Archiv IfZ). 
Dr. Rothe war der einzige, der protestierte, als ihm mein Vater im Amtszimmer des Oberbürgermeisters erklärte, daß er sich fortan den Weisungen des Arbeiter- und Soldatenrates zu fügen habe. Es blieb dem Oberbürgermeister nichts anderes übrig, als sich grollend zu fügen. Seine eigenen Schutzleute hätten ihn verhaftet, wenn er es nicht getan hätte. Die Frage, welche provisorischen Organe die Macht übernehmen sollten, wurde in der Parteileitung gar nicht mehr diskutiert. Es war uns allen selbstverständlich, daß wir einen Arbeiter- und Soldatenrat bilden würden. Zu diesem Zweck beriefen wir die kleine "Capora", die engere Funktionärsversammlung sofort nach dem Volkshaus ein.

Ich ging von der Zeitung zum Hauptbahnhof, um von dort zum Volkshaus zu fahren. Die Straßen begannen sich mit ungeheuren Menschenmengen zu füllen. Wie überall riß die Menge Offizieren, die sich auf die Straße wagten, die Epauletten und Rangabzeichen ab. Ich übernahm die Hauptpost. Über dem Hauptbahnhof und der Kreishauptmannschaft wehten bereits rote Fahnen, ebenso auf dem Turm des Rathauses. Ich hörte später, es hätte massiver Drohungen bedurft, um den Oberbürgermeister zu zwingen, dem Hausmeister die Hissung der roten Fahne zu befehlen. Als ich im Volkshaus ankam, wehte auf dem Turm eine riesige rote Fahne.

Die Funktionärsversammlung unserer Partei trat in einem der kleineren, schlecht beleuchteten Versammlungsräume des Volkshauses zusammen. Alles ging genau nach der steifen Geschäftsordnung solcher Funktionärsversammlungen. Die Versammlung erklärte sich durch einstimmige Abstimmung zum provisorischen Leipziger Arbeiterrat, jeder unserer engen Funktionäre war damit Arbeiterratsmitglied. Dann wurden nach den Vorschlägen der Parteileitung, die sich rasch unter sich verständigte, die Kommissare für die Überwachung und Kontrolle aller städtischen und aller Landesbehörden in Leipzig sowie aller städtischen Einrichtungen gewählt, angefangen von der Polizeidirektion bis Feuerwehr, Gas, Wasser und Elektrizität und Müllabfuhr. Nahezu alle unsere Stadträte und Stadtverordneten hatten solche Funktionen zu übernehmen. Da inzwischen der Soldatenrat einen Vorsitzenden gewählt hatte, wurde dieser Vorsitzende aufgefordert, zur Sitzung des Arbeiterrats zu kommen.

Bei allen diesen Anordnungen, die nach unseren vorgefaßten Plänen selbstverständlich waren, hörte ich mit gespanntesten Sinnen und größter Aufmerksamkeit zu. Ich sah mir dabei unsere Funktionäre und ihre Gesichter an. Es war die nüchternste und kühl geschäftsmäßigste Funktionärssitzung, die man sich vorstellen kann. Als aber der Vorsitzende des Soldatenrats [Erich Geschwandtner] erschien, konnte man sehen, daß wir mitten in der Revolution waren. Der Vorsitzende war ein Mann von etwa dreißig Jahren, mit kühnem Bart und wirrem, dunklem Schopf. Er hatte über die Uniform an der Hüfte eine fünfzehn Zentimeter breite rote Schärpe geschlungen, und an der Seite trug er am langen Gehenk einen riesigen Kavallerieschleppsäbel, der ihm an die Beine schlug und hinter ihm herklirrte. In längerer tönender Rede versicherte er den Arbeiterrat der unbedingten Loyalität des Soldatenrats und der Leipziger Garnisontruppen. Die Frage des Oberbefehls über die Garnisontruppen wurde nicht erwähnt. Uns war ganz klar, daß praktisch der Oberbefehl bei der USPD-Parteileitung lag, und die Soldatenräte hatten darüber nicht nachgedacht. Später übernahm ich mit dem Arbeiterrat auch den Oberbefehl. Den Mann mit der roten Schärpe und dem Kavallerieschleppsäbel ersetzten wir übrigens sehr bald durch einen bewährten, angesehenen Genossen aus der Parteihierarchie.

Die gewählten Kommissare begaben sich sofort an die ihnen zugewiesenen Posten. 
Die Polizeidirektion übernahm unser Vorsitzender der Stadtverordnetenversammlung. Eine seiner ersten Handlungen war, daß er die Auslieferung der geheimen Personalakten der politischen Polizei verlangte. Mein Vater und ich studierten unsere Akten mit großem Vergnügen, es stand in ihnen nur, was eigentlich jeder wußte. Über mich stand in dem Aktenstück, daß ich sehr großen Anhang hätte. An persönlichen Dingen stand darin nur: „Wird sich voraussichtlich mit Fräulein X. Y. verloben." Diesem Eintrag folgten keine weiteren persönlichen Notizen, es handelte sich um eine verflossene Liebschaft, die Polizeiaufpasser waren also beträchtlich hinter der Zeit zurück.

Nachdem die Kommissare ernannt waren, tagte der provisorische Arbeiterrat in Permanenz weiter, und da die eigentlichen Geschäfte erledigt waren, durften die Mitglieder über die Situation reden. Ich habe selten so viele und so bunt gemischte Kannegießerei gehört. Ich saß dabei und hörte zu. Ich hatte ein unbestimmtes Gefühl, daß dies nicht gerade eine autoritative Körperschaft sei. Auch hatte ich mir persönlich unter einem Arbeiterrat etwas anderes vorgestellt. Wir hatten einfach ein Parteiorgan zum Arbeiterrat ernannt. Ich hatte auch das Gefühl, es müßte mehr geschehen, als das, was wir getan hatten.

Während dieser uferlosen Reden erschien ein Mann und sagte, vor dem Tore des Volkshauses halte ein Lastwagen mit mehreren Soldaten und einem Major, und der Major wolle den Dr. Geyer sprechen. Ich ging hinaus, der Major nahm mich beiseite und sagte: „Herr Geyer, was machen Sie. Ich habe mir das Volkshaus angesehen, Ihre Tore sind offen, Sie sitzen da drin ohne den geringsten Schutz, nicht einmal Wachen haben Sie ausgestellt. Ich hätte in den Hof einfahren und Sie mit Hilfe meiner vier Mann alle hochnehmen können. Sie brauchen bewaffnete Wachen und für die brauchen Sie Gewehre. Ich habe hundertfünfzig Gewehre und Munition auf dem Wagen, für fünfzehnhundert Mark gehören Ihnen die Gewehre und der Lastwagen." - Ich sagte ihm sofort: „Ich mache das Geschäft, warten Sie, ich hole das Geld." Ich sprach mit dem Parteikassierer, wir borgten das nötige Geld in den Gewerkschaftsbüros des Hauses und beim Verwalter des Restaurants, zahlten die fünfzehnhundert Mark, der Major verschwand, die Soldaten auch, allerdings mit dem Lastwagen, und die Gewehre waren unser. Ich schämte mich vor mir selber über die Lektion, die mir erteilt worden war. Ich nahm nunmehr, ohne auf einen Auftrag zu warten, die Sicherung in die Hand, ich ließ die Tore schließen, stellte bewaffnete Wachen aus und forderte vom Soldatenrat ein Kommando zum Schutze des Arbeiterrats an. Bei dieser Gelegenheit wurde mir übrigens klar - und in den nächsten Tagen bei anderen Gelegenheiten noch klarer -, daß ich bei Freund und Feind als der Führer der Revolution angesehen wurde.

Einige Tage später hielt die Partei eine große Versammlung im Alten Theater, auf der mein Vater redete. Während seiner Rede wurde ich hinausgerufen. Ein höherer Bankbeamter - ich kannte ihn als einen der nationalliberalen Führer - erzählte mir, am anderen Morgen wäre Freitag, das heißt Zahltag, und die Leipziger Banken hätten nicht genügend Barmittel, um die Industriefirmen mit den Lohngeldern zu versehen. Er fragte, was wir zu tun gedächten, wenn die Arbeiter kein Geld bekämen, und ob ich nicht mit den Banken und den Leitungen der Industrieunternehmungen darüber verhandeln wollte. Ich erkannte sofort, daß ein Druck auf uns ausgeübt werden sollte und daß man uns zu Verhandlungen bringen wollte, die zur Einschaltung des Bürgertums führen sollten. Ich sagte lächelnd, wenn sich am Morgen herausstellen würde, daß nicht genügend Barmittel vorhanden seien, würde ich primitives 
Stadtgeld drucken lassen, wir würden nicht die erste Stadt sein, die Stadtnotgeld drucke. Er wisse auch, daß ich in Leipzig für diesen Zweck genügend Druckereibetriebe requirieren könnte. Er war etwas verlegen und meinte, das könnten wir natürlich tun, und verschwand wieder. Am anderen Morgen waren durchaus genügend Barmittel bei den Banken vorhanden.

Aber ich hatte eine Warnung erhalten, und ich kannte das Leipziger Bürgertum, vor allem das Großbürgertum viel zu gut, als daß ich geglaubt hätte, sie würden auf die Dauer unsere provisorische Ordnung hinnehmen. Sie hatten in dem Leipziger Oberbürgermeister, Dr. Rothe, einem sehr selbstbewußten und sehr klassenbewußten energischen Mann, ihren natürlichen Führer. Der Widerstand ließ nicht sehr lange auf sich warten, und es fiel mir zu, ihn mit diktatorischen Mitteln zu brechen.

Ich nahm meine umfassende Versammlungstätigkeit sofort wieder auf. In Massenversammlungen sprach ich über das Thema, daß dem Machtübergang nunmehr die Vorbereitung einer sozialistischen Wirtschaftsordnung folgen müsse, gestützt auf die bestimmende Teilnahme der Arbeiter in den Betrieben an der Leitung der Unternehmungen. Ich war aber auch nach wie vor Redakteur der „Leipziger Volkszeitung", und zugleich war ich Mitglied des Arbeiter- und Soldatenrats. Mein Tag war vollständig ausgefüllt bis in die tiefe Nacht.

Die Parteileitung der USPD erkannte sehr rasch, daß wir den Leipziger Arbeiterrat nicht so formlos lassen konnten, wie er ins Leben getreten war. Von ihm ging die Kontrolle aller Verwaltungen aus, und er mußte deshalb in eine entsprechende Form gebracht werden, er mußte einen Exekutivausschuß haben, den wir das Präsidium nannten, und dieser Exekutivausschuß wieder einen Vorsitzenden. Im Präsidium war der Soldatenrat vertreten, den Vorsitzenden nannten wir: Präsident des Arbejter- und Soldatenrates Leipzig. Wir übertrugen den Vorsitz zunächst einem unserer Parteifunktionäre, aber es war bald klar, daß der „Präsident" Autorität haben mußte, und so wurde ich zum Präsidenten des Arbeiter- und Soldatenrates gewählt. ${ }^{27}$ In dieser Funktion war ich die übergeordnete Instanz aller Verwaltungsorgane, ich war tatsächlich der Chef der Exekutive, der gemeinsam mit dem Ausschuß zugleich Verordnungsgewalt besaß. Obgleich der Arbeiterrat unmittelbar aus der Parteiorganisation hervorgegangen war, bekam er nun eigenes Leben als Träger der Macht. Die Parteileitung trat in den Hintergrund. Ich war Mitglied der Parteileitung, aber bei aller Loyalität erkannte ich bald, daß ich die Führung ergreifen mußte

27 Am Abend des 9. November hatten sich 600 Arbeiter- und Soldatenräte als „Großer Rat der Arbeiter- und Soldatenräte" konstituiert. Als Vollzugsorgan war der "Engere Ausschuß" gebildet worden, dem je $10 \mathrm{~A}$ - und S-Räte, außerdem Friedrich und Curt Geyer, der Reichstagsabgeordnete Karl Ryssel, Hermann Liebmann sowie drei Gewerkschaftsvertreter und zwei Schriftführer angehörten (LVZ v. 11.11.1918). Als gleichberechtigte Vorsitzende des Großen Rats fungierten zunächst Richard Lipinski für die Arbeiter- und Erich Geschwandtner für die Soldatenräte. Lipinski wurde, nachdem er am 15. November die Ministerien des Außern und Inneren in Dresden übernommen hatte, durch Friedrich Seger ersetzt. An die Stelle Geschwandtners, der wegen der Weitergabe vertraulicher Beschlïsse des A- und S-Rats am 21. November vorübergehend verhaftet und abgesetzt worden war, trat Johannes Schöning. Der Vorsitz im Engeren Ausschuß und im Großen Rat war identisch. (Die von Geyer verwendeten Bezeichnungen Präsidium und Präsident gab es mindestens offiziell nie.) Curt Geyer wurde erst am 21. Februar 1919 als Nachfolger Segers zum Vorsitzenden des Leipziger A- und S-Rates gewählt, die Bekanntgabe der Wahl erfolgte erst am 4.3.1919 in der LVZ. Vgl. Gerhard Puchta, Der Arbeiter- und Soldatenrat in Leipzig vom November 1918 bis vor dem 2. Rätekongreß Anfang April 1919, in: Wiss. Zeitschr. d. Karl-Marx-Universität Leipzig 7 (1957/58), S. 363-384. 
und nicht jeden Entschluß von vorheriger Zustimmung der Parteileitung abhängig machen konnte. Damit begann der zunächst geheime, später offene Konflikt und Machtkampf zwischen mir und der Parteileitung.

Es war auch selbstverständlich, daß alle richtungsweisenden Reden in größeren Versammlungen und Demonstrationen von mir gehalten wurden. Das waren zum Teil sehr turbulente Versammlungen. Am Tage der Bekanntgabe der Waffenstillstandsbedingungen riefen wir für den Abend zu einer Massendemonstration auf dem Augustusplatz, dem größten Platz Leipzigs zwischen dem Neuen Theater und der Gemäldegalerie, auf. Auf diesem Platz standen vor dem Opernhaus, damals Neues Theater genannt, drei riesige Flaggenmasten, jeder mit einem etwa zwei Meter hohen Sockel. Ich sprach, wie üblich, von dem Sockel des mittleren Flaggenmastes, von allen drei Masten wehten riesige rote Fahnen. ${ }^{28}$ Am Morgen dieses Tages wurde mir mitgeteilt, daß ein von den Alliierten gesuchter Militär, den sie als Kriegsverbrecher ansahen, in einem Leipziger Vorort wohne. Die Belgier beschuldigten ihn schwer. Ich ließ ihn verhaften und zu dieser Massenversammlung bringen. Er stand neben mir, als ich im Fackellichte sprach. Ich deutete auf ihn und sagte: „Das ist einer jener Männer, denen wir diese Waffenstillstandsbedingungen zu verdanken haben." Ich stellte ihn so öffentlich an den Pranger, dann sagte ich ihm vor der Massenversammlung, er sei aus Leipzig ausgewiesen, und ich gab Befehl, ihn zum Bahnhof und zum Zug nach Halle zu bringen, was geschah. Es war ein grausamer Akt.

Inzwischen war eine sächsische Landesregierung gebildet worden, in der mein Vater Finanzminister war. ${ }^{29}$ Er übernahm die Dienstwohnung des Finanzministers in Dresden. Meine Schwester begleitete ihn als Hausdame. Für sie wurde ein besonderes Zimmer eingerichtet, neben der Dienstwohnung meines Vaters, die Einrichtung dafür, Toilettentisch, Bett, Bettbezüge und Daunendecken, Tische und Stühle, wurden aus den Beständen des ehemals königlichen Schlosses geholt. In den Augen dex leitenden Beamten galt ich als sachverständiger Berater meines Vaters, wenn ich nach Dresden kam, pflegte der Staatssekretär die laufenden Probleme mit mir zu besprechen.

Die Stellung dieser ersten Regierung wurde untermauert durch die Bildung eines Landesarbeiterrats, und damit entstand für den Leipziger Arbeiter- und Soldatenrat die Frage, ob er diesen Landesarbeiterrat als übergeordnete Instanz anerkennen sollte oder nicht. In Leipzig war das parteipolitische Verhältnis sehr einfach, die USPD hatte hier eine gewaltige Mehrheit gegenüber den Rechtssozialisten. In Sachsen war sie gegenüber den Mehrheitssozialisten, die besonders in Dresden und Ost-

28 Die Waffenstillstandsverhandlungen wurden vom 8.-11. November geführt. Die Versammlungen am Sonntag den 10. November, die in die Demonstration auf dem Augustusplatz einmündeten, waren mit der Tagesordnung „Weltrevolution und Arbeiterschaft" bereits Tage vorher geplant gewesen; anstelle der 12 vorgesehenen Veranstaltungen wurden 17 abgehalten, bei denen ebenso viele Vertreter der Leipziger Parteiprominenz (unter ihnen Curt und Anna Geyer) als Redner auftraten. Vgl. LVZ v. 11.11.1918 „Eine Siegesfeier der Revolution“ (als Redner auf dem Augustusplatz werden nur Friedrich Geyer, Lipinski und Ryssel erwähnt).

29 Die am 15. November 1918 gebildete sächsische Regierung setzte sich aus folgenden „Volksbeauftragten“ zusammen: Lipinski (USPD), Vorsitz, Inneres und Außeres; F. Geyer (USPD), Finanzen; Fleißner (USPD), Militärwesen; Schwarz (SPD), Arbeit und Wohlfahrt; Gradnauer (SPD), Justiz; Buck (SPD), Kultus und Unterricht. Nach dem Rücktritt der USPD-Minister wurde diese Regierung am 21.1.1919 durch ein Kabinett aus Mehrheitssozialdemokraten unter Gradnauer ersetzt. 
sachsen stark waren, in der Minderheit. ${ }^{30}$ Während der Tagung des Landesarbeiterrats in Dresden erhielt ich eine Lektion über die Verhältnisse außerhalb Leipzigs. Der Dresdner Arbeiterrat veranstaltete eine Massenversammlung, ich ging hin, um nach dem Referat in der Diskussion zu sprechen. Ich hatte kaum wenige Minuten geredet, als ich glatt niedergeschrieen wurde. Aus den Beratungen des Landesarbeiterrats erwuchs ein Konflikt. Ich war durchaus bereit, eine Neuwahl des Leipziger Arbeiterrats auf Grund eines für ganz Sachsen geltenden Wahlrechts vornehmen zu lassen, was später auch geschah, aber ich war nicht bereit, den Landesarbeiterrat als übergeordnete Instanz anzuerkennen, was das Machtproblem offen aufwarf. Als angedeutet wurde, daß die sächsische Regierung ihre Autorität und die des Landesarbeiterrats durchsetzen könnte, antwortete ich mit einem Ultimatum und der Drohung, Leipziger Garnisontruppen gegen Dresden in Bewegung zu setzen. Es kam zu schwierigen Verhandlungen. Ich saß in meinem Hotelzimmer und beharrte auf meiner Autonomie-Forderung. Richard Lipinski ging zwischen mir und den rechtssozialistischen Ministern hin und her und verhandelte. Es endete mit einem gentlemen's agreement, das dem Leipziger Arbeiter- und Soldatenrat die Autonomie zubilligte, und außerdem versprach die sächsische Landesregierung, auf die Reichsregierung einzuwirken, keine direkten Schritte gegen Leipzig zu unternehmen. Das Abkommen ist an einem sehr kritischen Punkte, über den ich später berichten werde, durchaus eingehalten worden. Es stellte angesichts der Entwicklung im Reiche bereits beim Abschluß eine Anomalie dar. Ich wußte das sehr wohl, aber da ich an eine zweite revolutionäre Welle glaubte, wollte ich die Leipziger Position so lange wie möglich behaupten. Ich war dabei im Einklang mit der Parteidoktrin der USPD, die sich theoretisch gegen die Nationalversammlung und demokratisch gewählte Parlamente und für das Rätesystem erklärte. Der parteipolitische Gegensatz dieser Tage zwischen West- und Ostsachsen ist übrigens nie voll ausgeglichen worden. Als später viele sächsische Sozialdemokraten nach Prag in die Emigration gingen, sagten die erstaunten Prager, die Sachsen wären in die feindlichen Stämme der Westsachsen und Ostsachsen getrennt in Prag aufgetreten.

[...]

Die Grenzen der Revolution wurden rasch sichtbar, aber auch die Spannung zwischen den beiden Fraktionen in der Regierung der Volksbeauftragten. ${ }^{31}$ Wir stellten

so Bei der Bildung des Landes-Arbeiter- und Soldatenrats am 19. November 1918 kam es wegen des Beteiligungsschlüssels der einzelnen Kreishauptmannschaften zum Konflikt zwischen SPD und USPD. Die Leipziger Delegation plädierte für je 10 Vertreter der Bezirke Leipzig, Chemnitz und Dresden. Bautzen und Zwickau sollten ohne Vertretung bleiben. Auf den Antrag der SPD, Bautzen und Zwickau in gleicher Stärke zu beteiligen, reagierten die USPD-Vertreter mit dem Antrag, Dresden und Leipzig mit je 10, Chemnitz mit 8, Zwickau mit 6 und Bautzen mit 4. Vertretern zu beteiligen. Außer für Leipzig sollten die Vertretungen paritätisch aus USPD und SPD zusammengesetzt werden. Aufgrund des Verlangens, auch die Leipziger Delegation paritätisch zu besetzen, erklärten die USPD-Vertreter eine weitere Zusammenarbeit für unmöglich. Vgl. auch LVZ v. 22.11.1918, „Der Zentralrat der A. und S. für Sachsen“.

31 Das politische Kabinett, der „Rat der Volksbeauftragten“, setzte sich aus 6 Mitgliedern zusammen. Aufgrund der Koalitionsabsprachen vom 10.11.1918 traten neben die 3 Mehrheitssozialdemokraten Ebert, Scheidemann und Landsberg drei Vertreter der USPD: Hugo Haase als Vorsitzender und Vertreter des koalitionsbereiten Flugels der USPD, Wilhelm Dittmann, ebenfalls ein Vertreter des Koalitionsflügels, und Emil Barth für die Revolutionären Obleute. Dittmann und Barth waren aufgrund der Weigerung Liebknechts und Ledebours delegiert worden. Mit Liebknecht sollten der Spartakusbund, mit Ledebour die radikale Linke der USPD bzw. die Revolutionären Obleute an der sozialistischen Koalition betejligt werden. Vgl. Regierung der Volksbeauftragten, I, S. XXXI f.; vgl. Anm. 41. 
in Leipzig mit Sorgen fest, daß nicht nur Liebknecht sich von der Beteiligung aus geschlossen hatte, sondern daß von vornherein auch wesentliche Spannungen zwischen dem Parteivorstand der USPD und dem Großberliner Arbeiter- und Soldatenrat bestanden, der in den ersten Tagen als der Träger der Souveränität des neuen Regimes anerkannt wurde. ${ }^{32}$ In der Frage „Nationalversammlung oder Rätesystem“ nahm ich selbst gemeinsam mit der Leipziger Parteileitung keine extreme Stellung ein - noch nicht. Wir wollten die Räteherrschaft so lange aufrechterhalten, bis die Regierung der Volksbeauftragten mit Hilfe der Arbeiter- und Soldatenräte die ersten entscheidenden Schritte zur Durchführung des Sozialismus und zu ihrer Sicherung ergriffen haben würde. Als Ende November die Regierung der Volksbeauftragten beschloß, die Nationalversammlung am 16. Februar wählen zu lassen, war dies für uns weniger eine Frage des Prinzips als der Zweckmäßigkeit, die Frist bis zur Wahl erschien uns als zu kurz. Nach dem ersten Rätekongreß und den nachfolgenden Wochen wurde mir klar, wie die inneren Machtverhältnisse in der am 9. November gegründeten Republik wirklich waren. ${ }^{38}$ Ich glaubte nun, daß zum Schutze gegen einen Rückschlag des Pendels die Räteherrschaft aufrechterhalten werden müßte, bis wirklich entscheidende Schritte in der Richtung des Sozialismus durchgeführt und gesichert worden waren und nicht nur die Änderung der politischen Verfassung. Die Frage „Nationalversammlung oder Rätediktatur“ und später die allgemeinere Form: „Parlamentarische Demokratie oder Rätesystem“ wurde für mich zu einer Prinzipienfrage. Dabei erkannte ich sehr früh, daß ich in Leipzig wohl die formlose Bewegung in der Arbeiterschaft hinter mir hatte, die Welle, die mich in den ersten Stunden und Tagen in die führende Position getragen hatte, aber daß dabei die Parteileitung mir nicht geschlossen folgte. Je stärker ich in den Mitgliederversammlungen der Partei die Doktrin der Rätediktatur vertrat und herausarbeitete, um so deutlicher war zu erkennen, daß eine Opposition aus führenden Kreisen nicht aus den Kreisen der Mitglieder - gegen das prinzipielle Bekenntnis zur Rätediktatur auftrat. Es war besonders ein früherer Landtagsabgeordneter, der mir nach meinen Reden entgegentrat. Ich war überrascht und crblickte darin so etwas wie eine Ketzerei; denn im Arbeiter- und Soldatenrat wie in allen Mitgliederversammlungen fand ich für diese Weiterentwicklung der Rätedoktrin ungeteilte Zustim-

32 Am 10.11. 1918 hatten 3000 gewählte Vertreter der Berliner Arbeiter und Soldaten in einer Versammlung im Zirkus Busch den „Rat der Volksbeauftragten“ als provisorische Reichsregierung bestätigt. Obwohl nur aus lokalen Vertretern zusammengesetzt, spielte der Arbeiterund Soldatenrat Großberlin vorübergehend unangefochten die Rolle des Inhabers der Souveränitätsrechte für ganz Deutschland. Der in der gleichen Versammlung am 10.11.1918 als "Aktionsausschuß" gewählte "Vollzugsrat des Arbeiter- und Soldatenrats Groß-Berlin" (14 Soldaten, 7 Revolutionäre Obleute als Vertreter der USPD, 7 Vertreter der SPD) verstand sich als oberstes Kontrollorgan und beanspruchte alle legislativen und exekutiven Rechte gegeniiber Reichs-, Landes- und Kommunalbehörden. Nach dem I. Rätekongreß waren die Kontrollbefugnisse auf Berlin beschränkt, die überregionalen Funktionen gingen auf den Zentralrat (vgl. Anm. 38) über. Vgl. Zentralrat, S. XIV ff. und Regierung der Volksbeauftragten I, S. XX ff.

33 Der Rat der Volksbeauftragten hatte in der Kabinettsitzung am 29. November 1918 beschlossen, die Wahlen zur verfassunggebenden deutschen Nationalversammlung ,vorbehaltlich der Zustimmung der am 16. Dezember 1918 zusammentretenden Reichsversammlung der Arbeiter- und Soldatenräte Deutschlands, am 16. Februar 1919" abzuhalten. Dieser Beschluß wurde am 30. November veröffentlicht (vgl. Regierung der Volksbeauftragten I, S. 224 f.). Auf Antrag des Delegierten Cohen (SPD) beschloß der Rätekongreß am 19.12.1918 die Festsetzung des Wahltermins auf den 19. Januar. Vgl. Allg. Kongreß der Arbeiter- und Soldatenräte De atschlands, Sten. Ber. Sp. 282. 
mung. Diese Frage wurde von vornherein zum Ausgangspunkt des inneren Machtkampfes in der Führung der Leipziger USPD-Organisation und später der Auseinandersetzung der beiden großen Richtungen in der USPD. Damals sah ich diesen Tatbestand keineswegs mit meiner heutigen Objektivität an. Die übergeordnete Idee war für mich die sozialistische Revolution, die Durchführung eines integralen Sozialismus, was die politische Macht der Arbeiterklasse voraussetzte, also ihre Diktatur. Der völlig formlose und auslegbare Begriff der marxistischen Dolktrin „Diktatur der Arbeiterklasse oder des Proletariats" nahm bei mir die konkrete Form an "Diktatur der Arbeiterräte", und ich glaubte mit demselben Eifer daran wie ein gläubiger Katholik an seine Dogmen.

[...]

\section{Im Führungskreis des linken USPD-Flügels}

Der Rätekongreß im Dezember 1918

Von unserem Leipziger Standpunkt der unbestrittenen Vormachtstellung der USPD aus blickten wir auf die weit turbulenteren und zum Teil für uns undurchsichtigen Vorgänge in Berlin mit Sorgen und Mißbilligung. Als daher der Leipziger Arbeiterund Soldatenrat der Wahlkreisorganisation Leipzig-Stadt Friedrich Seger ${ }^{34}$ und mich als Delegierte in den ersten Rätekongreß entsandte, kamen wir auf der Fahrt nach Berlin überein, nach Möglichkeit zu verhindern, daß die Führung der USPD-Fraktion des Rätekongresses von der Berliner Organisation übernommen würde. Wir fanden bei unserer Ankunft in Berlin ein völliges Durcheinander in der Frage vor, ob und unter welchen Bedingungen Karl Lieblnecht und Rosa Luxemburg zum Rätekongre $\beta$ zugelassen werden sollten. Der einfachste Weg wäre natürlich gewesen, wenn der Berliner Arbeiter- und Soldatenrat sie delegiert hätte, damit sie sich wie andere ihrer Freunde an der Bildung der USPD-Fraktion beteiligen konnten. Dieser Weg hätte gefunden werden können, aber Liebknecht lehnte ihn ab, weil er eine Sonderstellung für sich beanspruchte, so wie er es bereits bei den Vorverhandlungen zur Bildung der Regierung der Volksbeauftragten getan hatte. Rosa Luxemburg war bereit, den einfachen Weg zu gehen, aber ohne Liebknecht wollte sie ihn nicht betreten. Nach der Konstituierung der USPD-Fraktion konnten wir lediglich ihre Zulassung zum Kongreß beantragen. Sie wurde abgelehnt, und nun erlebten wir staunend drohende Aufmärsche vor dem Tagungslokal, plötzliches Auftreten von lärmenden Demonstranten mit Fahnen im Sitzungssaal, von Soldaten auf der Tribüne des Kongresses und Demonstrationen in der USPD-Fraktion. ${ }^{\mathbf{3 5}}$

34 Friedrich Seger (1867-1928), Schneider, Redalteur, 1915-1918 MaL, Sachsen, 1919-1928 MdR (USPD/SPD), einer der drei Vorsitzenden des 1. Rätekongresses.

35 Der (I.) Rätekongreß tagte vom 16.-21.12.1918 im preußischen Abgeordnetenhaus in Berlin als Delegiertenversammlung aller Arbeiter- und Soldatenräte Deutschlands. Die Einladung war vom Berliner Vollzugsrat ausgegangen. Von den 489 Delegierten (jeder Delegierte vertrat 200000 Personen bzw. 100000 Soldaten) waren 403 Arbeiter- und 86 Soldatenvertreter. Die SPD-Fraktion hatte mit 292 Mitgliedern die absolute Mehrheit, der USPD-Fraktion gehörten 94. Delegierte an (mit denen auch die 10 "Vereinigten Revolutionäre" aus Hamburg und Bremen stimmten). Der Demokratischen Fraktion gehörten 31, der Soldatenfraktion 27 Mitglieder an. Bei 35 Delegierten ist die Fraktions- bzw. Parteizugehörigkeit unklar. S. Allgemeiner Kongreß der Arbeiter- und Soldatenräte Deutschlands vom 16. bis 21. Dezember $1918 \mathrm{im}$ Abgeordnetenhause zu Berlin. Sten. Berichte. Hrsg. u. Verleger: Zentralrat der sozialistischen Republik Deutschlands, Berlin 1919; vgl. Zentralrat, S. XXII ff. 
Für den Plan, die Führung nicht der Berliner Organisation zu überlassen, fanden Seger und ich Zustimmung vor allem bei den Delegierten aus dem Ruhrgebiet und aus Mitteldeutschland. So wurde ich, siebenundzwanzig Jahre alt, zum Vorsitzenden der USPD-Fraktion des Kongresses gewählt und vertrat damit die Fraktion im „Ältestenrat“, das heißt dem Ausschuß, der den Gang der Geschäfte vorbereitete. Die Debatten und Beschlüsse des Kongresses gehören der Geschichte an, ich verbreite mich darüber nicht. Die Verhandlungen wurden wie auch die des Zweiten Rätekongresses stenographisch aufgenommen. Ich hatte die beiden Bände auch noch in der Emigration in meiner Bibliothek, bis die gesamte Bibliothek im Jahre 1940 in Paris in die Hände der Gestapo fiel.

In den Fraktionssitzungen der USPD, an denen mit Ausnahme ihrer beiden Führer alle bekannten späteren Kommunisten teilnahmen, bereitete sich die Abspaltung der Kommunisten als selbständiger Partei von der USPD bereits vor. Die Beschlüsse der Fraktion hätten dazu keinen Anlaß geboten, aber von vornherein trat hervor, daß die Mitglieder des Spartakusbundes sich als die berufenen intellektuellen Führer der deutschen Arbeiterschaft und der Revolution ansahen, während wir auf der beträchtlich breiteren und realistischeren Grundlage einer wirklich existierenden Partei mit wirklich existierenden Parteiorganisationen und Zeitungen standen.

Einer der späterhin in der Literatur umstrittenen Entschlüsse der USPD-Fraktion war die Eventualentschließung, daß die USPD-Fraktion sich nicht an der Bildung des Zentralrats, ${ }^{\mathbf{3 6}}$ das heißt der Körperschaft, welche die Regierung der [Volks-] Beauftragten überwachen sollte, beteiligen würde, wenn diese Körperschaft nicht zu gleichen Teilen aus Vertretern der beiden sozialistischen Parteien, sondern proportional der Stärke ihrer Vertretungen auf dem Kongreß zusammengesetzt werden sollte. Ich wurde beauftragt, diese entscheidende Erklärung abzugeben, falls der Kongreß die Frage durch Abstimmung statt durch Vereinbarung gegen uns entscheiden sollte. Praktisch bedeutete diese Eventualentschließung, daß wir in diesem Falle die drei unabhängigen Volksbeauftragten aus der Reichsregierung abberufen würden. Die Eventualentschließung war einstimmig gefaßt worden. Als deshalb der Kongre $\beta$ gegen uns entschied, gab ich auftragsgemä $\beta$ die schwerwiegende Erklärung ab. Sie schloß die Vorstellung ein, daß die USPD als revolutionäre Kraft die Revolution weiterführen und steigern würde im Kampfe gegen die Sozialdemokratische Partei und die Regierung der Volksbeauftragten. Mir war der Charakter dieser Kampfansage klar, anderen auch. Ich kam deshalb nicht gleich dazu, sie abzugeben, denn als ich mich erhob, kam es vor unseren Bänken angesichts des ganzen Kongresses zu einer heftigen persönlichen Auseinandersetzung zwischen mir und Ernst Toller, ${ }^{37}$ der den Münchner Arbeiter- und Soldatenrat vertrat. Wir hatten uns bis dahin ausgezeichnet verstanden, aber nun beschwor er mich mit erhobener Stimme, die Eventualerklärung nicht abzugeben. Man müsse die Lage neu prüfen. Als ich auf den einstimmigen Beschluß der Fraktion verwies und erklärte, ich könne mich auf

36 Der „Zentralrat der deutschen sozialistischen Republik“ war als oberstes Räteorgan und Kontrollinstanz des Rats der Volksbeauftragten und der preußischen Regierung gedacht. De facto betrachtete sich der Zentralrat - dessen 27 vom Rätekongreß am 19.12.1918 gewählte Mitglieder ausnahmslos der SPD angehörten - als Provisorium zur Sicherung des Übergangs zur parlamentarischen Republik. Vgl. Zentralrat, S. XI ff.

37 Ernst Toller (1893-1939), Schriftsteller. Nach der Exmordung Kurt Eisners im Februar 1919 de facto Führer der Münchner USPD, im April 1919 Vorsitzender des Zentralrats der (1.) Münchner Räterepublik, im Juli 1919 zu fünf Jahren Festungshaft verurteilt. 
meine eigene persönliche Verantwortung hin nicht darüber hinwegsetzen, machte er mir laute und heftige Vorwürfe. Die Mitglieder des Fraktionsvorstandes unterstützten mich gegen ihn, und ich $^{\mathbf{3 8}}$ gab schließlich die Erklärung ab. Die Situation der USPD-Volksbeauftragten wurde dadurch unmöglich. Sie zogen etwa vierzehn Tage nach den Schießereien vor dem Marstall in Berlin die Konsequenz des Rücktritts. ${ }^{30}$

Da dies in späteren Auseinandersetzungen zwischen den beiden Parteien eine Art Schuldfrage war, habe ich öfters darüber nachgedacht, ob Toller nicht vielleicht recht hatte. Als ich ihn sehr viel später und viel gereifter wiedersah, kamen wir bei gemeinschaftlicher Prüfung der Frage zu einem Unentschieden. Man konnte argumentieren, daß die Mitglieder und die Anhängermasse der Sozialdemokratischen Partei bei verschiedenen Gelegenheiten keineswegs die Politik Eberts gebilligt hatten, daß also bei den Schießereien am 29. Dezember 1918 eine Ablehnung des Einsatzes militärischer Kräfte durch den Zentralrat möglich gewesen wäre, wenn wir uns beteiligt hätten, und sicherlich, daß für diesen militärischen Einsatz kein Mehrheitsbeschluß der Volksbeauftragten zustandegekommen wäre. Aber das war ein post festum-Argument. Ich war immer überzeugt, daß der Gang der Ereignisse im wesentlichen nicht anders gewesen wäre, wenn wir uns beteiligt hätten. Weder die rechtssozialistische Führung noch wir stolperten über Zwirnsfäden.

[...]

Der Rätekongreß wurde für den weiteren Gang der Ereignisse nicht nur durch seine Beschlüsse bedeutsam. Er wurde zu einem Treffpunkt für eine Reihe der jüngeren Führer der USPD, die sich bis dahin kaum dem Namen nach kannten. Wie ich selbst in Leipzig, so waren sie in ihren Bezirken in der Propaganda der USPD hervorgetreten und waren dann in der Revolution von den ihnen folgenden Volksmassen auf die Schultern gehoben worden. Sie waren fast ausnahmslos Söhne älterer Sozialisten, die junge Generation, die über die Köpfe der Parteihierarchie hinweg nach der Führung griff. In gewissem Sinne war es der entscheidende Zug der USPD-Fraktion des ersten Rätekongresses, daß sie eine Versammlung der Söhne war. Intellektuelle wie Organisatoren gehörten zu dieser Sammlung. Zwischen ihnen wurden nicht nur Abreden darüber getroffen, künftig in engster Verbindung zu bleiben, sondern auch persönliche Freundschaften geschlossen, die selbst dann noch weiter wirkten, als die Wege dieser jungen Politiker auseinandergegangen waren. Auf diese Weise bildete sich auf dem ersten Rätekongreß die radikal und aktivistisch denkende Führungsgruppe, die der Parteirichtung der linken USPD in ihren Aktionen allmählich feste Gestalt gab. [...]

Die junge Führungsgruppe nahm noch während des Rätekongresses und unmittelbar

38 Nach dem Sten. Bericht des I. Rätekongresses, a.a. O., Sp. 300, wurde die Erklärung der USPD-Fraktion, sich an der Wahl zum Zentralrat nicht zu beteiligen, von Otto Braß abgegeben. Vgl. auch Zentralrat, S. XXVII f. u. S. 22 f.

39 Nach Differenzen über die Löhnung und die Räumung von Schloß und Marstall zwischen dem Stadtkommandanten Otto Wels (SPD) und der Volksmarinedivision, bei der nach der Erschießung eines Matrosen am 23. Dez. Wels im Marstall festgesetzt worden war, riefen die SPD-Volksbeauftragten Truppen des Generalkommandos Lequis zu Hilfe, um die Befreiung von Wels und die Räumung von Schloß und Marstall zu erzwingen. Die schweren Kämpfe am 24. Dezember, bei denen es 67 Tote gab, lösten den Rücktritt der drei USPD-Volksbeauftragten Haase, Dittmann und Barth am 29.12.1918 aus (sie wurden durch die Mehrheitssozialdemokraten Noske und Wissell ersetzt). Vgl. Regierung der Volksbeauftragten, I, S. LXXV, und II, S. $18 \mathrm{ff}$. u. $73 \mathrm{ff}$. 
danach engste Beziehungen auf zu den Mitgliedern des Vollzugsrates Großberlin ${ }^{40}$ um Ernst Däumig und Richard Müller, ${ }^{41}$ den beiden vornehmsten Propagandisten des Rätegedankens, wie zu den Führern der Revolutionären Berliner Obleute.

Nach dem Abschluß des Rätekongresses verabschiedeten sich die Mitglieder dieser Führungsgruppe voneinander mit der Frage: "Werden wir uns in der Nationalversammlung wiedersehen?" Sie sahen sich alle in der Nationalversammlung wieder.

Die Bildung dieser Führungsgruppe, unter deren Einfluß die USPD im Laufe eines Jahres zu einer wirklichen Massenpartei heranwuchs, und noch mehr die Tatsache, daß in allen großen Industriegebieten der radikale Teil der Arbeiterschaft in ihr seine natürliche Führung erblickte, bedeutete eine bittere Enttäuschung für die alten Spartakusanhänger. Den Vorstellungen ihrer intellektuellen Führerin, Rosa Luxemburg, folgend, hatten sie geglaubt, daß sich die deutsche Arbeiterschaft, von ihnen inspiriert, zu spontanen revolutionären Aktionen erheben und in diesen Aktionen die Spartakusgruppe als ihre politische und intellektuelle Führung anerkennen würde. Der Zug, so glaubten sie, würde von selber in Bewegung kommen, und dann könnten sie sich mit ihrer Lokomotive vor den fahrenden Zug rangieren. Liebknechts erste Erfolge in Berlin konnten ihn in diesem Glauben bestärken, aber Rosa Luxemburg sah weiter als er, und die Bedeutung des Hervortretens dieser jungen Führungsgruppe in der USPD, die nicht aus dem Spartakusbund hervorging, blieb ihr nicht verborgen. Die Vorgänge während des ersten Rätekongresses und die Fraktionssitzungen der USPD-Fraktion des Kongresses enthielten eine deutliche Lehre, bereits vor dem dramatischen Zusammenbruch der neu gegründeten Kommunistischen Partei und der Ermordung Liebknechts und Luxemburgs. Eine neue junge Führungsgruppe übernahm die Führung des radikalen Teils der deutschen Arbeiter in den entscheidenden Industriegebieten und hielt sie fest. Die Intellektuellen der Spartakusgruppe standen daneben, während diese Gruppe die Massen anzog und führte, wie sich in Aktionen und bei Wahlen zeigte. Alle Versuche, dieser Führungsgruppe in der USPD die Führung wieder zu entreißen und sie auf die Spartakusanhänger und das führende Personal der neu gegründeten Kommunistischen Partei ${ }^{42}$ zu übertragen, so wie sie systematisch von Moskau aus unternommen wurden, endeten in Mißerfolg. Als die führende Gruppe der linken USPD späterhin den Anschluß an die Kommunistische Internationale vertrat, suchte sie nicht die Bundesgenossenschaft der KPD, die sie für einen zu vernachlässigenden Faktor hielt, sondern die Bundes-

$40 \mathrm{Vgl}$. Anm. 32.

41 Ernst Däumig (1866-1922), 1912-1916 Redakteur am „Vorwärts“, 1917 Mitgründer der USPD (linker Flügel), einer der Führer der Revolutionären Obleute, 1919 Mitvorsitzender der USPD, 1920 Mitvorsitzender der VKPD, 1921 Mitgründer der „Kommunistischen Arbeitsgemeinschaft", die sich im Februar 1922 wieder der (Rest-)USPD anschloß. S. a. S. 159. Richard Müller (1880 - ), Metallarbeiter, 1918/19 Vors. des Vollzugsrats der Berliner A- und S-Räte und der Revolutionären Obleute.

$42 \mathrm{Am}$ 29. Dezember 1918 hatten Delegierte des Spartakusbundes die organisatorische Trennung von der USPD beschlossen. Vom 30.12.1918 bis 1.1.1919 tagte der Gründungsparteitag, aus dem die „Kommunistische Partei Deutschlands (Spartakusbund)“ hervorging. Die neue Partei umfaßte außer dem Spartakusbund auch die Bremer Linksradikalen (Internationale Kommunisten Deutschlands). Schon im Januar bzw. März 1919 wurde die IKPD durch die Ermordung von Rosa Luxemburg, Karl Liebknecht und Leo Jopiches ihrer Führer beraubt und geriet in die Illegalität. Vgl. Hermann Weber (Hrsg.), Der Gründungsparteitag der K.PD. Protokoll und Materialien, Frankfurt/Wien 1969. 
genossenschaft mit der Sowjetregierung. Sie war keineswegs bereit, die Führung freiwillig abzugeben.

\section{Die USPD zwischen West- und Ostorientierung}

Unmittelbar nach dem Kongreß trat der weitere Differenzpunkt in der USPD hervor, der am Ende parteispaltende Kraft annahm. Es ging um das Verhältnis zur Sowjetregierung und um das Verhältnis der USPD zur russischen bolschewistischen Partei. Die diplomatischen Beziehungen der deutschen Regierung zur Sowjetregierung waren abgebrochen, weil die Regierung Max von Baden mit sozialdemokratischer Zustimmung sich gegen die von den Bolschewiki und der Sowjetregierung ausgehende revolutionäre Propaganda in Deutschland zur Wehr gesetzt hatte. Zwischen damals und dem Dezember 1918 lag die deutsche Revolution, und trotzdem blieben die Beziehungen abgebrochen. Die Sowjetregierung hatte sich sofort nach der Revolution um Wiederanknüpfung bemüht. Zunächst hatte Lenin der Regierung der Volksbeauftragten einen Transport russischen Getreides angeboten zur Milderung der durch die Ententeblockade hervorgerufenen Not und als Zeichen der Solidarität mit der deutschen Revolution. Hugo Haase hatte abgelehnt mit der Begründung, daß das russische Volk selbst schwer Not leide, in Wahrheit aber aus politischen Gründen. Er vertrat die Ansicht, die später am stärksten und längsten von Rudolf Breitscheid ${ }^{43}$ vertreten wurde, daß eine Interessensolidarität zwischen der deutschen Revolution und den siegreichen Ententemächten gegen den deutschen Militarismus bestehe. Diese vermeintliche Interessensolidarität nicht aufs Spiel zu setzen durch Beziehungen zur Sowjetregierung - das war das eigentliche Motiv in der Haltung Haases und des Parteivorstandes der USPD.

Aber Lenin ließ nicht locker. Er ließ nun Haase sondieren, ob die deutsche Revolutionsregierung sich für die Fortsetzung des Kampfes im Westen entschließen könnte, und bot für diesen Fall die Hilfe der Sowjetregierung an. Ob bei dieser Sondierung das formelle Angebot eines Kriegsbündnisses gemacht wurde, steht dahin - Rudolf Hilferding hat es in späteren Jahren in Gesprächen mit mir stets behauptet und hat schließlich auch diese Version im "Neuen Vorwärts“ in Paris im Jahre 1939 nach dem Abschluß des Hitler-Stalin-Paktes unmittelbar vor Kriegsausbruch veröffentlicht. ${ }^{44}$ Man kann innere Gründe dafür anführen, daß seine Version richtig war. In den letzten vorrevolutionären Tagen hatte in Deutschland eine von Karl Radek ${ }^{45}$ betriebene Propaganda für die Verwandlung des Krieges in einen revolutionären Krieg und seine Fortsetzung an der Elbe eingesetzt. Die späteren Versuche der So-

43 Rudolf Breitscheid (1874-1944), 1903 Mitglied der Freisinnigen Vereinigung, 1908 Mitgründer der Demokratischen Vereinigung, 1912 SPD, 1917 USPD, 1915-1922 Hrsg. d. Wochenschrift „Sozialistische Auslandspolitik - Der Sozialist“, Nov. 1918 - Jan. 1919 preuß. Innenminister, 1920-1933 MdR (USPD/SPD), 1933 Emigration nach Frankreich, 1941 an die Gestapo ausgeliefert, 1944 im KZ Buchenwald umgelrommen.

44 Dr. Richard Kern [d. i. Rudolf Hilferding], Der Kurs der russischen Außenpolitik. Pg. Stalin und Towaritsch Hitler, Neuer Vorwärts, Nr. 324 v. 2. 9. 1939.

45 Karl Radek (1883-1939), ursprüngl. polnischer Sozialdemokrat, seit 1907 in Deutschland, SPD-Mitglied, Mitarbeiter u. a. der LVZ, im Krieg in der Schweiz (Anhänger der Zimmerwalder Linken), 1917 im Auslandsbüro der russ. Bolschewiki in Stockholm, ZK-Mitglied der russ. KP, Ende 1918 in Berlin, russ. Delegierter beim Gründungsparteitag der KPD, Mitglied des EKKI, 1927 Ausschluß, 1929 Wiederaufnahme in die KPdSU, 1936 verhaftet. 
wjets, den wiederaufsteigenden deutschen Nationalismus ihren eigenen Interessen und revolutionären Zielsetzungen im Westen dienstbar zu machen, und die $\mathrm{Zu}$ sammenarbeit der Reichswehr unter General von Seeckt ${ }^{46}$ mit der Sowjetregierung für die geheime Rüstung deuten in die gleiche Richtung. Jedenfalls war die Frage Westorientierung oder Ostorientierung aufgeworfen. Das wiederum stand in $\mathrm{Zu}$ sammenhang mit der Frage, wie die USPD als Partei sich zu den westeuropäischen sozialistischen Parteien verhalten sollte, deren Haltung zur Unterstützung ihrer kriegführenden Regierungen noch entschiedener gewesen war als die der Mehrheitssozialisten bei der Unterstützung der Reichsregierung.

Die Frage wurde im Dezember 1918 auf einer Sitzung im Abgeordnetenhaus besprochen. Die linke Führungsgruppe, die sich auf dem Rätekongreß gebildet hatte, empfand Haases völlig ablehnende Haltung als gänzlich unnatürlich. Wir wußten alle, daß mindestens in Berlin beträchtliche sowjetische Geldmittel für die Bewaffnung der Revolutionären Obleute verwendet worden waren. Auch wir in Leipzig hatten den Besuch eines Beauftragten der Berliner Sowjetbotschaft erhalten, mit dem wir uns freundschaftlich über die Interessensolidarität zwischen uns und der russischen Revolution und über die Aufnahme von Parteibeziehungen unterhalten hatten. In dieser Sitzung drängte ich als Wortführer der linken Führungsgruppe also darauf, den Bolschewiki nicht die kalte Schulter zu zeigen, und betonte, daß sie uns näher stünden als die sozialistischen Parteien der Ententeländer. Ich geriet in eine wütende Auseinandersetzung mit Rudolf Hilferding, der sich vor Haase stellte und dessen vorsichtig abwägende Argumentation beträchtlich verschärfte. Freundliche Beziehungen zu Sowjetrußland aufzunehmen hätte natürlich geheißen, den antibolschewistischen Ententeregierungen ins Gesicht zu springen. Ich vertrat die Anschauung, daß durch freundschaftliche Beziehungen zur Sowjetregierung und Parteibeziehungen zu den Bolschewiki der Weltrevolution, an welche die Linke fest glaubte, neuer Elan gegeben werden könnte. Die Gesamtheit der Anschauungen, die dahinter standen, hat später Ernst Däumig, der sie von vornherein mit noch größerer Entschiedenheit als ich vertrat, in dem Schlagwort zusammengefaßt: „Ex oriente lux." Hilferding dagegen sagte den baldigen Zusammenbruch der Sowjetregierung voraus und prägte schließlich den Satz : „Wir dürfen das solide Schiff unserer Partei nicht an den sinkenden Kahn der Bolschewiki binden."

Später habe ich begriffen, daß es nicht nur ein Unterschied der Einschätzung der Dauerhaftigkeit des Sowjetregimes war, was mich in dieser Frage von Hilferding trennte. Bei ihm wirkte nicht so stark wie bei Breitscheid die Rücksichtnahme auf die westeuropäischen sozialistischen Parteien, als die Rücksichtnahme auf die Menschewiki, die von den Bolschewiki unterdrückte sozialdemokratische Partei Rußlands. Der Austromarxismus - und Hilferding war stets einer seiner vornehmsten und typischsten Vertreter - hielt enge Beziehungen zu ihnen und ihre dogmatischen Anschauungen begegneten sich. Beide verkörperten jene Richtung der marxistischen Schulen, die sich von anderen aktivistischeren durch ihr Abwarten einer geschichtlichen Entwicklung unterschieden, als deren Träger "die Arbeiterklasse“ angesehen wurde, ohne diese Entwicklung durch Handlungen unterstützen zu wollen. Auf Grund dieser Mentalität erschien das parlamentarisch-demokratische System als die

46 Hans von Seeckt (1866-1936), Generaloberst, März 1920 - Okt. 1926 Chef der Heeresleitung, Organisator der Reichswehr, 1930-1932 MdR (DVP), 1934-1935 militär. Berater Tschiang Kai-scheks. 
geeignetere Staatsform als eine Rätediktatur, die wie jede Diktatur notwendig aktivistisch sein mußte.

Die Unterstützung der Idee der Rätediktatur in Deutschland und damit die dogmatische Absage an die Demokratie durch Hilferding und seine Freunde und erst recht ein Parteibündnis mit den Bolschewiki wäre natürlich ein schwerer Schlag gegen die Menschewiki gewesen, die damals auf den Sturz der Sowjetregierung durch eine demokratische Revolution in Rußland hofften und deren Söhne und Enkelsöhne in der Emigration auch heute noch darauf hoffen.

Die weitere Entwicklung der Richtungsgegensätze in der USPD ließ diese Dinge noch schärfer hervortreten, besonders nachdem sich der Richtungsstreit auf die Frage konzentriert hatte, ob die Partei in die kommunistische Internationale eintreten sollte oder nicht. Diese meine erste Auseinandersetzung mit Rudolf Hilferding war eine Ouvertüre zu dem, was später kam; denn er und ich waren die intellektuellen Wortführer unserer Richtungen. Er hatte die „Freiheit" ${ }^{47}$ zur Verfügung, ich zunächst die „Leipziger Volkszeitung“ und eine Reihe kleinerer Parteizeitungen der USPD, später die „Hamburger Volkszeitung“.

In dieser Besprechung wurde nichts beschlossen - aber es blieb bei der Haltung Haases.

Als mich beim Schlu $\beta$ des Rätekongresses meine neuen Freunde gefragt hatten: „Werden wir dich in der Nationalversammlung wiedersehen?" hatte ich bezweifelt, daß ich in Leipzig als Kandidat an aussichtsreicher Stelle aufgestellt werden würde. Wir konnten sicher sein, drei Sitze zu erhalten, und die natürliche Reihenfolge für die Kandidaten für diese drei sicheren Plätze auf der Liste sah so aus: Friedrich Seger, der Vorsitzende der Wahlkreisorganisation Leipzig-Stadt; dann mein Vater, der bisherige Reichstagsabgeordnete für Leipzig-Land, und an dritter Stelle Richard Lipinski, der tatkräftige und umsichtige Vorsitzende und Organisator des Bezirksverbandes, der bereits bei einer Ersatzwahl während des Krieges im Reichstagswahlkreis Oschatz-Wurzen kandidiert hatte.

Über die Kandidatenliste für die Nationalversammlung wie für die [sächsische] Volkskammer (Landtag) entschied die große Funktionärsversammlung der Partei. Meine Freunde stellten meine Kandidatur für beide Parlamente auf. Ich erwartete ein sicheres Landtagsmandat. Die Übertragung eines Landtagsmandats an den Präsidenten des Leipziger Arbeiter- und Soldatenrates erschien aus sachlichen Gründen geboten. Zu meiner eigenen großen Überraschung liefen die Dinge anders. Die Abstimmungen für den ersten und zweiten Platz auf der Nationalversammlungsliste verliefen so, wie die Parteileitung vorgeschlagen hatte und wie zu erwarten war. Aber bei der Abstimmung über den dritten Platz erhielt ich ganz erheblich mehr Stimmen als Lipinski. Der Bekanntgabe des Ergebnisses, das von der Mehrheit der Versammlung mit großem Beifall aufgenommen wurde, folgten Augenblicke der Konsternation am Tische der Parteileitung, an dem ich saß. Ich sah die ungeheure Enttäuschung Lipinskis, der mir am Tische gegenüber saß. Die Versuchung war riesengroß. Ich mußte mich blitzschnell entscheiden, ob ich die Kandidatur annehmen wollte. Bei all der führenden Position, die mir inzwischen zugefallen war, brachte ich den Beschlüssen der Parteileitung ein Maß der Loyalität entgegen, das

47 Die „Freiheit. Berliner Organ der Unabhängigen Sozialdemokratie Deutschlands" erschien als zentrales Parteiblatt der USPD vom 15.11.1918 bis 30.9.1922 (bis 28.2.1919: "Die Freiheit"). 
mir selbst später nicht erwiesen wurde. Ich schlug vor, die Abstimmung zu wiederholen, um den wirklichen Willen der Funktionärsversammlung festzustellen und eine Zufallsabstimmung auszuschließen. Die Wiederholung der Abstimmung ergab eine noch größere Mehrheit für mich. Nun nahm ich die Kandidatur an. Aber ich bot Lipinski eine persönliche Vereinbarung an. Wenn als Ergebnis der Wahl zur Nationalversammlung nux drei unserer Kandidaten gewählt werden sollten, wollte ich auf das Mandat verzichten zu seinen Gunsten gegen ein sicheres Landtagsmandat. Er lehnte ab mit der Erklärung, die Funktionäre hätten ihren Willen mit so entschiedener Mehrheit gezeigt, daß er respektiert werden müsse. Zuvor hatten die Funktionäre beschlossen, Doppelmandate müßten vermieden werden. Mit der Annahme der Kandidatur für die Nationalversammlung an sicherer Stelle fiel ich also für die Landtagswahlliste aus, an deren Spitze die Funktionäre num Lipinski stellten. An ebenso sicherer Stelle der Landtagswahlliste wurde als Vertreterin der Frauen Anna aufgestellt. Mein Vater und ich Nationalversammlungsabgeordnete, Anna Landtagsabgeordnete (Volkskammermitglied) - das war das überraschende Ergebnis dieser Kandidatenaufstellung. Sofort wurde aus den Reihen der Minderheit das Wort „Dynastie Geyer" geprägt, das dann bei inneren Parteiauseinandersetzungen wie in der breiten Öffentlichkeit eine Rolle gespielt hat.

Für mich persönlich bedeutete diese überraschende Aufstellung eine Stärkung meines Selbstgefühls und meines Führerehrgeizes. Die Schilderhebung wurde durch den offiziellen Beschluß der Parteifunktionäre bestätigt. Meine Stellung in der Parteileitung und der Parteileitung gegenüber wurde befestigt durch die Tatsache, daß ich eine große Mehrheit der Parteifunktionäre hinter mir wußte. Diese Kandidatenaufstellung bewirkte, daß ich fortan in der öffentlichen Meinung in Leipzig, bei den Zeitungen und den bürgerlichen Parteien als der erklärte Führer der USPD in Leipzig angesehen wurde. Ich war auch Redakteur an der „Leipziger Volkszeitung“, Präsident des Arbeiter- und Soldatenrates und nach der Wahl Mitglied der Nationalversammlung. Natürlich wirkte die Kandidatenaufstellung auf meine Autorität in der Redaktion zurück, noch stärker als zuvor bestimmte ich den Kurs der Zeitung. Die Häufung von Funktionen - die übrigens weder in der USPD noch in der Sozialdemokratischen Partei ungewöhnlich war - erforderte in den nächsten Monaten ein Höchstmaß von Arbeitsleistung, von Hin- und Herfahren zwischen Weimar und Leipzig. Es war ein gehetztes Leben, das ich in diesen Monaten führte.

Der Weg in die Nationalversammlung bedeutete für mich nicht nur die direkte Fühlung mit meinen neuen Freunden, sondern überhaupt den Weg in die Reichspolitik, zur zentralen Beeinflussung der Politik der Partei. Nach der Wahl der Nationalversammlung trat die Unabhängige Fraktion neben den Parteivorstand mit mindestens derselben Autorität als zentrales Organ der Partei. [. . .]

\section{Die Januarkämpfe in Berlin - Ermordung Rosa Luxemburgs und Karl Liebknechts}

Aber noch vor dem Wahltermin sandte mich der Arbeiter- und Soldatenrat auf eine wichtige Mission nach Berlin. Am 1. Januar 1919 besiegelten die Kommunisten durch die Gründung der Kommunistischen Partei ihre endgültige Loslösung von uns. Der Parteigründung folgte wenige Tage später der Spartakusaufstand in Berlin nach. Es handelte sich nicht um eine kaltblütig beschlossene Aktion der neuen Partei. 
Die Vorgänge sind hinreichend bekannt. Die Absetzung des der USPD angehörenden Polizeipräsidenten von Berlin, Emil Eichhorn, ${ }^{48}$ durch die Regierung der rechtssozialistischen Volksbeauftragten nach dem Ausscheiden der USPD aus der Reichsregierung, wurde von den radikalen Berliner Arbeitern als eine Provokation und eine Machtprobe empfunden. Die Berliner Organisation der USPD, die Revolutionären Obleute und die Kommunisten beschlossen Straßendemonstrationen. Dann aber gründeten Karl Liebknecht und der frühere Reichstagsabgeordnete der USPD Ledebour mit einem Dritten [Paul Scholze] einen revolutionären Aktionsausschuß, erklärten kurzerhand die Reichsregierung für abgesetzt und leiteten die Straßendemonstrationen in einen bewaffneten Aufstand über, bei dem die Masse der Kämpfenden nicht etwa von der Kommunistischen Partei gestellt wurde, die dazu zahlenmäßig viel zu schwach war, sondern von den Revolutionären Obleuten.99

Ich will hier ein Wort über die beiden Führer des Aufstandes sagen. Karl Liebknecht befand sich seit seiner Haftentlassung Ende Oktober [23.10.1918] in einem fortwährenden Exzitationsstadium. Das war nicht erstaunlich, da ihm in der Haft die weiteren Entwicklungen im Reiche und in Berlin natürlich nicht völlig bekannt geworden waren. Er fühlte sich als eigentlicher Führer der Revolution in Deutschland und von Anfang an wollte er stets anders als die anderen und wirkte so von Anfang an verhängnisvoll auf die Ereignisse ein. Daß die Massen der Berliner Arbeiter ihn jubelnd begrüßten, als das Regime ihn in Freiheit setzte, gab ihm falsche Vorstellungen ein. Er wollte nicht nur anders als die Unabhängigen und der Berliner Vollzugsrat, sondern er wollte auch ständig anders als seine nächste politische Freundin Rosa Luxemburg, die intellektuelle Führerin des Spartakusbundes, die ihn nur mit Mühe auf einem noch einigermaßen vernünftigen Kurs festhielt. Sie allein hätte niemals den Spartakusbund von der USPD losgelöst. Er unternahm den Aufstand gegen den ausgesprochenen Willen Rosa Luxemburgs und der kommunistischen Parteileitung.

Georg Ledebour wiederum war das, was man in England einen crank nennt, ein von brennendem Ehrgeiz erfülltter, eingebildeter Mann, der seine Schwäche, sein Hinken aufgrund einer Hüftgelenksluxation, durch äußerste Streitsucht überkompensierte. Selbst seine nächsten Freunde konnten ihn bisweilen kaum ertragen. Ich weiß das recht gut, denn er war ein Freund meines Vaters. Er hatte einige Zeit in England gelebt, war ein Anglomane und hatte einige abstruse Ideen über England mitgebracht. So schwärmte er beständig von der Selbstverwaltung der englischen Gemeinden als Grundlage der Freiheit, obgleich es bekanntlich bis heute keine wirkliche Selbstverwaltung der Gemeinden in England gibt. Von der deutschen Geschichte und

48 Emil Eichhorn (1863-1925), 1881 Beitritt zur SPD, Redakteur in Dresden und Mannheim, 1901-1909 MdL in Baden, 1903-1912 und 1919-1925 MdR, 1917 USPD, 9. 11. 1918-12.1. 1919 Polizeipräsident von Berlin, nach der USPD-Spaltung Mitglied des ZK der linken USPD, Dezember 1920 KPD, 1921 KAG-Gruppe im Reichstag, dann wieder KPD (rechter Flügel).

40 Nach dem Ausscheiden der USPD-Mitglieder aus dem Rat der Volksbeauftragten traten am 3. 1. 1919 die Unabhängigen auch aus dex preußischen Regierung aus. Mit Ausnahme Eichhorns gaben alle Unabhängigen wichtige Ämter im Reich und in den Länderregierungen auf. Eichhorn weigerte sich am 4. Januar, seine Entlassung durch den preußischen Ministerpräsidenten hinzunehmen. Nach der Besetzung des Vorwärtsgebäudes und anderer großer Berliner Zeitungsbetriebe in der Nacht vom 5. zum 6.1.1919 durch die Aufständischen wurde Noske als Befehlshaber der Truppen in Berlin und Umgebung vom Rat der Volksbeauftragten und dem Zentralrat mit weitgehenden Vollmachten ausgestattet. Vermittlungsversuche der gemäßigten USPD-Führung zwischen Regierung und Aufständischen waren fehlgeschlagen, am 13. Januar waren die Noske-Truppen nach beträchtlichem Blutvergießen Herren der Lage. 
der Rolle des Freiherrn vom Stein schien er weniger zu wissen. Er war von den Liberalen zur Sozialdemokratie gekommen, in gewissem Sinne war er ein Epigone des Kronprinzenliberalismus von $1888 .^{50} \mathrm{Er}$ hielt sich für den eigentlichen Gründer der USPD, war tief gekränkt und empört, daß er nicht zum Volksbeauftragten ernannt wurde $\mathrm{e}^{51}$ und fand, daß alle alles verkehrt machten und daß nur er wüßte, was zu geschehen habe. Über den Aufstandsversuch habe ich später, und zwar weit über das hinaus, was ich selber gesehen hatte, eingehende und intime Berichte über die Vorgänge hinter den Kulissen erhalten. Das Merkwürdige an diesem Aufstand war, daß die Reichsregierung für abgesetzt erklärt, aber keinerlei militärische Aktion zu ihrer praktischen Absetzung unternommen wurde. Ernst Däumig, der von diesem Aufstandsversuch abgeraten hatte, erbot sich, mit einer Truppe der Revolutionären $\mathrm{Ob}$ leute die Reichskanzlei vom Tiergarten aus anzugreifen und die Volksbeauftragten zu verhaften, was eine ziemlich aussichtsreiche Aktion gewesen wäre. Aber Ledebour lehnte diesen Vorschlag Däumigs ab mit den Worten: „Ach, was wollen Sie denn, Sie verstehen davon gar nichts." Er fühlte sich bereits als Herr der Reichsregierung und fürchtete im geheimen, daß ihm seine Führerrolle von dem Führer einer siegreichen militärischen Aktion bestritten werden könnte. Ähnlich erging es anderen, die sich dann mit schlimmen Vorahnungen von der Aktion zurückzogen. Die Parteileitung der USPD und Rosa Luxemburg mit ihren Freunden standen händeringend daneben.

Es ist begreiflich, daß wir im Leipziger Arbeiter- und Soldatenrat nicht erkannten, was eigentlich in Berlin vor sich ging. Obgleich wir erbittert über Lieblnecht und die Abspaltung der Kommunisten waren, fühlten wir uns mit den Berliner Revolutionären Obleuten solidarisch, wir wußten aber nicht, wie unsere Parteizentrale und wie unsere Freunde in der Führung der revolutionären Obleute dazu standen.

So wurde beschlossen, mich mit einem Mitglied des Soldatenrats als militärischen Adjutanten im Flugzeug nach Berlin zu schicken und je nach Lage und der Stellung unserer Parteileitung den Aufständischen eventuell die Unterstützung durch Leipziger Garnisontruppen anzubieten. Ich will gleich bemerken, daß dies das einzige Mal war, daß der Leipziger Arbeiter- und Soldatenrat eine militärische Intervention über Leipzig hinaus ins Auge faßte und glaubte, größere Truppentransporte unternehmen zu können. Wir requirierten ein Flugzeug und flogen verhältnismäßig spät am Nachmittag von Leipzig ab. Die Maschine war ein offener Dreisitzer, der Pilot verflog sich und machte eine Bruchlandung auf einem Sturzacker im Havelland in der Nähe von Brandenburg. In den Stößen der Maschine beim Landen schlug mich eine Kante des Flugzeugs von unten gegen das Kinn, daß ich fast die Besinnung ver-

50 Der Kronprinz, der nach dem Tode Wilhelms I. den Thron bestieg, hatte den Zusammenschluß der Linksliberalen zur Deutschen Freisinnigen Partei (1884) begrüßt; ein Kurswechsel in der deutschen Politik im liberalen Sinne kam aber schon infolge der schweren Krankheit und kurzen Regierungszeit Friedrichs III. nicht zustande. - Ledebour hatte sich 1891 der SPD angeschlossen, nachdem er sich ab 1884 für die „Demokratische Partei“, die zwischen Freisinn und SPD stand, als Redakteur und Herausgeber der „Demokratischen Blätter“ engagiert hatte.

51 Ledebour hatte den Eintritt in den Rat der Volksbeauftragten abgelehnt, weil er ,mit politisch kompromittierten Persönlichkeiten, die sich durch Begünstigung der bisherigen Kriegspolitik im Inlande und Auslande als Politiker vollkommen diskreditiert haben, nicht auf einer Ministerbank sitzen" wollte (Sten. Ber. I. Rätekongreß, Sp. 95). Außerdem hatte Ledebour eine Koalitionsregierung, in der sich SPD und USPD die Waage hielten, grundsätzlich abgelehnt. Vgl. Ursula Ratz, Georg Ledebour 1850-1947, Berlin 1947, S. 180. 
lor und daß mir noch lange danach der Kopf dröhnte. Die Maschine war gründlich entzwei. Sie hatte sich über den Propeller überschlagen, der vollkommen zerbrochen war. Wir pilgerten ins nächste Dorf. Der Pilot verlor sich in der Richtung der Bahnstation, er war froh, uns los zu sein, mein Begleiter und ich übernachteten im Dorfgasthaus. Der Gastwirt witterte in meinem Begleiter den Offizier und war sehr devot. Am anderen Morgen fuhren wir mit der Bahn nach Berlin. Unser erster Besuch galt dem USPD-Parteivorstand am Schiffbauerdamm. Anwesend war nur das Parteivorstandsmitglied Frau Zietz. ${ }^{52}$ Sie weinte. Ich fragte nach der Haltung des Parteivorstands. Sie erklärte, die Partei versuche zu verhandeln, um so einen $\mathrm{Ab}$ bruch der Kämpfe herbeizuführen. Ich fragte nach Crispien ${ }^{53}$ und Dittmann ${ }^{54}$ sie wußte nicht, wo wir sie erreichen konnten. Der Besuch hinterließ bei mir den Eindruck, daß die Parteileitung nicht wüßte, was sie wollte. Deshalb fragte ich Frau Zietz schließlich: „Fassen Sie eventuell Unterstützung des Aufstands von außerhalb ins Auge? Wir sind die Nächsten." Sie lehnte mit Entschiedenheit ab: „Nein, nein, wir wollen keine Kämpfe, wir wollen den Abbruch der Kämpfe herbeiführen."

Von da ging ich zur Redaktion der „Freiheit“. Hier wurde mir gesagt: „Eine dilettantische Aktion, die niemals hätte unternommen werden sollen und die wahrscheinlich in den nächsten Stunden zusammenbrechen und zu Ende sein wird mit all dem politischen Schaden, den sie angerichtet hat." Ich fragte nach melr Einzelheiten, aber auch hier wußte man nicht, wo sich die Führung der Aufständischen befand. Ich fragte nach Eichhorn und erhielt die Antwort: „Er hält noch das Polizeipräsidium besetzt." Dann fragte ich nach Liebknecht, Antwort, das wisse man nicht, schließlich nach Ledebour, worauf mir mit offen verächtlicher Miene gesagt wurde: „Sie kennen doch Ledebour, er ist doch nicht ernst zu nehmen." Danach machte ich mich mit meinem Begleiter auf den Weg nach dem Polizeipräsidium am Alexanderplatz. Wir hatten eine Vorstellung von Bürgerkrieg, und wir glaubten, wir müßten zu Fuß durch eine kämpfende Stadt wandern, aber nein, wir fuhren unbehelligt in einem Taxi zum Portal des Polizeipräsidiums. Man war versucht zu fragen: „Wo findet hier der Bürgerkrieg statt?" Wir legitimierten uns bei den Wachen am Portal des Präsidiums und wurden dann zu Eichhorn geführt. Er gehörte zu meinen Berliner Freunden und Bekannten, so da $\beta$ ich offen mit ihm reden konnte. Wir sprachen in seinem großen Amtszimmer. Die Fensterflügel der drei großen Fenster waren herausgenommen, an jedem Fenster stand auf einem hohen Holzblock ein schußbereites Maschinengewehr, die Bedienungsmannschaft darum herum. Alle drei Gewehre zielten auf den Alexanderplatz. Ich sagte ihm offen: „Wir haben daran gedacht, Euch militärische Unterstützung zu schicken, aber nach allem was ich bisher

52 Luise Zietz (1865-1922), seit 1908 Mitglied des SPD-Parteivorstands, seit 1917 Mitglied des Vorstands und Sekretärin der USPD, MdR 1919-1922.

53 Arthur Crispien (1875-1946), 1902 Redakteur der Königsberger „Volkszeitung“, 1912 der „Schwäbischen Tagwacht" in Stuttgart, Nov. 1918 württ. Innenminister, 1919 MdL Württemberg, 1919 Mitvorsitzender der USPD, 1922 Mitvorsitzender der SPD, 1920-1933 MdR, 1933 Emigration in die Schweiz (vgl. S. 153).

54 Wilhelm Dittmann (1874-1954), 1899-1904 Redakteur der "Norddeutschen Volksstimme" (Bremerhaven) und der „Bergischen Volksstimme“ (Solingen), 1904-1908 Sekretär der SPD in Frankfurt/M., 1917 Mitgründer der USPD, Nov. - Dez. 1918 Mitglied des Rats der Volksbeauftragten, 1920 USPD-Delegierter auf dem II. Weltkongreß der Komintern in Moskau, 1922 Vorsitzender der Rest-USPD, 1922-1923 Vorstandsmitglied der SPD, 1912-1918 und 1920-1933 MdR, 1933 Emigration in die Schweiz, 1951 Rüicklehr nach Deutschland, Mitarbeiter des SPD-Archivs. 
gehört und gesehen habe, wäre das wohl sinnlos. Der Parteivorstand verhandelt zwecks Feuereinstellung.“ Er meinte: „Sie möchten gerne verhandeln, aber man wird sie nicht anhören. Wir müssen entweder den Kampf und das Polizeipräsidium aufgeben oder kämpfen.“ - „Mit welchen Aussichten?" - „Das hängt davon ab, wie Liebknecht sich benimmt", - und dann erzählte er mir, daß er seit dem letzten Abend und den ganzen Vormittag über versucht habe, mit Liebknecht in Verbindung zu kommen, er habe einen Kurier nach dem anderen gesandt, aber niemals eine Antwort erhalten. Er habe gefragt, was Liebknechts militärische Absichten seien, er habe ihn dringend gebeten, ihm einige von seinen vielen Maschinengewehren abzulassen, und meinte, wenn er sie mit der nötigen Bemannung erhielte, könnte er sich im Polizeipräsidium mit Leichtigkeit noch drei bis vier Tage behaupten. Ich fragte erstaunt: "Warum antwortet er nicht?" Eichhorn zuckte mit den Achseln. Ich meinte, vielleicht sei die Verbindung unterbrochen. "Aber nein“, sagte Eichhorn, „Sie können mit der Straßenbahn zu ihm fahren." - „Wo ist er denn?" - „Er sitzt mit seinen Leuten in der Bötzow-Brauerei." - „Gut", sagte ich, „ich werde ihn besuchen." - „Sagen Sie ihm, ich brauche Maschinengewehre, dann kann ich mich behaupten, und ich muß wissen, was seine Absichten sind." Danach fragte mein militärischer Berater ohne Festlegung nach Auslademöglichkeiten für eventuelle Verstärkungen, und Eichhorn empfahl ihm Ausladung in Südende.

Danach machten wir beide uns auf den Weg zu Liebknecht, wirklich mit der StraBenbahn. Es war inzwischen Abend geworden. Vor der Bötzow-Brauerei, also praktisch an der Peripherie der Stadt, hielten uns Liebknechts Wachen an. Wir wiesen uns aus, und ich verlangte Liebknecht zu sprechen. Ein Bote wurde geschickt, er kam zurück und sagte: „Er ist im großen Saal.“ Ich fragte: „Will er uns sehen?" Der Bote zuckte mit den Achseln, ich begriff bald, warum. Wir wurden dann durch mehrere Räume in den großen Saal geführt. In den Gasträumen und kleineren Sälen saßen Liebknechts Truppen auf Stühlen und Sofas, aber die meisten von ihnen lagen auf dem Fußboden und schliefen. Wir hatten den Eindruck einer völlig erschöpften Truppe.

Im großen Saal bot sich uns ein makabres Bild. Eine einzige nackte elektrische Birne hing vom Gebälk des Daches herunter und ließ den großen Saal im Dunkel. Auf dem Boden des Saales lagen Maschinengewehre so, daß ein schmaler Gang zwischen ihnen blieb, links etwa ein Dutzend Maschinengewehre, rechts etwa ein Dutzend Maschinengewehre. In dem Gang zwrischen den Maschinengewehren ging Liebknecht auf und $a b$, die Hände auf den Rücken gelegt, ohne Hut, in einem schwarzen Anzug. Wir blieben zunächst erstaunt stehen und sahen zu, wie er auf und ab ging. Er beachtete uns überhaupt nicht. Schließlich ging ich vor und trat ihm in den Weg. Ich will hier einfügen, daß wir persönlich sehr gut miteinander bekannt waren, schon von sozialdemokratischen Parteitagen des Vorkrieges her. Ich hatte im Anfang des Krieges vor seiner Verhaftung mehrfach mit ihm über Propaganda geredet und war auch sonst mit ihm zusammengekommen. Er erkannte mich offenbar nicht. Mit einem nervösen Zucken des Gesichts, das bei ihm häufig war, sah er mich zunächst starr an. Dann herrschte er mich an: „Wer sind Sie? Was wollen Sie? Wer hat Sie hier hereingelassen?" - Ich konnte bei dieser Gelegenheit noch besser verstehen, daß er so wenige wirkliche Freunde unter seinen nächsten politischen Freunden hatte, aber ich steckte meinen Stolz in meine linke Hosentasche und sagte sehr ruhig zu ihm: „Ich sehe, Sie erkennen mich nicht. Ich bin Curt Geyer." - Wieder herrschte er mich an: „Was wollen Sie von mir?" - Ich zwang mich, meine Ruhe zu behalten; 
denn der ganze Jammer dieser Szene versetzte mich in größte innere Erregung. Ich sagte ihm: „Ich bin der Präsident des Leipziger Arbeiter- und Soldatenrats, und ich habe Auftrag, mich zu erkundigen, ob Sie Unterstützung wünschen." - Von allem was ich sagte, hatte er wahrscheinlich überhaupt nur Leipziger Arbeiter- und Soldatenrat gehört, und es schien ihm zu dämmern, wer ich war. Statt auf die Frage der Unterstützung einzugehen, fragte er in etwas ruhigerem Ton: „Wie steht es bei Ihnen, wie geht es bei Ihnen?" Ich antwortete: „O bei uns, bei uns steht soweit alles gut.“ Da brach er los, nahezu schreiend: „Steht alles gut? Was steht alles gut? Nichts steht gut. Kann nicht gut stehen, darf nicht gut stehen." - Nun versuchte ich, ihm Eichhorns Botschaft auszurichten. Aber er hörte schon nicht mehr zu. Er hatte wieder die Hände auf den Rücken gelegt und begann wieder zwischen den Maschinengewehren auf und ab zu gehen. Ich blieb einen Augenblick unschlüssig stehen, dann ging ich leise zu meinem Begleiter, winkte ihm, und wir verließen den Saal und die Brauerei. Im Herausgehen aus der Brauerei fragte mich mein Begleiter: „Sie werden sich doch um Gotteswillen hier nicht engagieren wollen?" Ich antwortete ihm: „Ich denke nicht daran, ich habe völlig genug gesehen." Ich war tief erschüttert. Für mich war diese Szene der Kulminationspunkt des erratischen Benehmens Karl Liebknechts seit dem Beginn der Revolution, und ich zweifelte an seinem Verstand; denn das war mehr als reine Verzweiflung angesichts der kommenden Niederlage.

Wir gingen zur Stadtbahn und fuhren schließlich auf weiten Umwegen nach Jeeipzig zurück. Auf der langen Fahrt hatte ich genügend Zeit zum Nachdenken. Ich konfrontierte meine eigenen putschistischen Neigungen mit dem, was ich gesehen hatte. Macht? Zwei Dutzend Maschinengewehre? War das revolutionäre Macht, war Liebknecht revolutionäre Macht? Wie hätte ich mich verhalten? Meine Gedanken gingen um das Problem herum, ohne daß ich damals zu einer gültigen Schlußfolgerung gekommen wäre. Ich habe später wiederholt mit Ernst Däumig über diesen Aufstandsversuch gesprochen. Er hatte in erster Linie die Unzulänglichkeit oder vielmehr Abwesenheit militärischer Vorbereitung und die irrsinnige militärische und politische Führung Liebknechts und Ledebours gesehen, aber er war trotzdem bereit gewesen mitzumachen, um wenigstens etwas Sinn in die Geschichte $z u$ bringen. Ich war dagegen überzeugt, daß es durchaus richtig war, was man mir in der „Freiheit" gesagt hatte: "Dieser Putsch durfte nie angefangen werden." Ich wußte, Liebknechts Niederlage ging uns alle an. Mir schärfte sie den Blick noch mehr für die wirklichen Machtverhältnisse und half mir weiter, die rosenroten Illusionen der ersten Stunden beiseitezuschieben. Heute im Rückblick nehme ich an, daß ich ohne das aufwühlende Ereignis der Ermordung von Karl Liebknecht und Rosa Luxemburg noch rascher an Einsicht in die wirklichen Machtverhältnisse gewonnen hätte und zu einer besseren Abschätzung dessen gekommen wäre, was in Deutschland möglich war und was nicht.

Nachdem ich nach Leipzig zưückgekehrt war, erstattete ich dem Arbeiter- und Soldatenrat wie der Parteileitung Bericht über meine Berliner Beobachtungen. I.ch äußerte mein Urteil über Liebknecht sehr deutlich und machte besonders auf die fundamentalen Differenzen aufmerksam, die sich bei der Gründung und seit der Gründung der Kommunistischen Partei zwischen Liebknecht und Luxemburg gezeigt hatten und die in der Verurteilung des Putsches durch Rosa Luxemburg ihren Höhepunkt erreichten.

Aber dann traf uns die Nachricht von der brutalen Ermordung der beiden [15. 1 . 1919] wie ein Donnerschlag. Diesmal brauchte ich nicht erst zu einer Demonstration 
aufzurufen. Sobald die Nachricht bekannt wurde, versammelte sich eine erregte Menschenmenge in den Straßen, und die Arbeiter strömten aus den Betrieben zum Augustusplatz. ${ }^{55}$ Diese spontane Kundgebung von weit über hunderttausend Menschen war die größte von allen, die ich auf dem Augustusplatz erlebt habe. Die Menge rief nach Vergeltung, nach Waffen, nach dem Sturz der Reichsregierung, der die Schuld an den Morden zugeschrieben wurde, nach Vergeltung an Bürgertum und Rechtssozialisten in Leipzig.

Nach den Berliner Erfahrungen war ich fest entschlossen, keine wilden Experimente zu machen. Ich verständigte mich mit der Parteileitung, gemeinsam fürchteten wir, da $\beta$ wir nur sinnlose Terrorakte und Blutvergießen hervorrufen würden, wenn wir dem Verlangen nach breiter Volksbewaffnung nachgeben würden. Was unser Regime an bewaffneten Kräften zu seinem Schutze brauchte, das besaßen wir.

Ich fuhr in dem kleinen roten Auto des Branddirektors der Leipziger Feuerwehr, der von unserem Kommissar bei der Feuerwehr gesteuert wurde, durch die ungeheure Menge auf dem Augustusplatz und in den Straßen. In Abständen hielten wir an, und ich sprach vom Wagen aus zu der erregten Menge. Ich fühlte, was sie fühlten, und die Empörung schüttelte mich. Auch in mir war ein instinktiver Trieb nach Vergeltung - aber an wem und gegen wen? Ich wußte, die Spontaneität dieser empörten Masse würde mir Macht geben zu allem, was ich unternehmen würde. Ich wußte, daß ich sie bewaffnen könnte - aber das stärkste meiner Gefühle war ein Gefühl der Ohnmacht. Vor mir selber begriff ich die Grenzen der Macht und die Grenzen meiner lokalen Macht in Leipzig. Es war eine böse Stunde. Meine Freunde und die Menge drängten sich um mich und erwarteten, daß ich in irgendeiner Weise ihre Gefühle in die Tat umsetzen würde, und ich wußte, daß ich ihnen nichts anderes geben konnte als Worte, tönende, zornige, drohende Worte, und da $\beta$ ich ihrem Schrei nach rächenden, unbestimmten, sinnlosen Taten nicht nachgeben durfte. Ich wußte intellektuell, daß sowohl ich als auch unsere Parteileitung jede Führung und jede Kontrolle der Masse aus der Hand verlieren würden, wenn wir nachgaben. Es gab auch in Leipzig genügend Elemente von links und von noch weiter links, die von der Entfesselung des Acheron Gebrauch für ihre Zwecke gemacht hätten. Aber ich will nicht aus der Erinnerung behaupten, $d a ß$ es weise politische Zurückhaltung gewesen ist, was mich damals bestimmte - ich weiß heute noch mit aller Bestimmtheit, daß es viel mehr ein Gefühl der Ohnmacht war.

So sagte ich der Menge, der Leipziger Arbeiter- und Soldatenrat würde seine Machtposition gegenüber jedem behaupten, der sie angreifen würde, und er würde sie weiter ausbauen und alle Versuche des Widerstands gegen ihn, die sich bereits gezeigt hätten, zu Boden schlagen. Das war tatsächlich meine Absicht. Die Neuwahl des Arbeiterrates, die Neuformierung der politischen Parteien für die Wahl zur Nationalversammlung und die Wahl zur Nationalversammlung hätten automatisch die revolutionäre Spannung, die wir aufrecht zu erhalten suchten, geringer werden lassen. Aber nunmehr war ich entschlossen, alles mit harter Hand zu behaupten, was der Arbeiter- und Soldatenrat an Macht besaß, und die Rätediktatur in Leipzig aufrechtzuerhalten in der Hoffnung, daß abermals in der nächsten Entwicklung die

55 Unter der Uberschrift „Thr Blut komme über Euch“ hatte die LVZ am 17.1.1919 ausführlich über die Ermordung berichtet und für Samstag, 18. Januar, zu einem „Demonstrationsstreik der Leipziger Arbeiter" aufgerufen. Es hatte aber auch schon am 17. Januar Volksversammlungen gegeben, in denen „die Festnahme von Geiseln aus den Kreisen der Leipziger Kapitalisten verlangt" worden war. Vgl. LVZ v. 19.1.1919. 
Macht in Deutschland auf der Straße liegen würde. Meine Handlungen als Vorsitzender des Leipziger Arbeiter- und Soldatenrates in den nächsten vier Monaten, die in steigendem Maße die Empörung des Leipziger Bürgertums hervorriefen und mir seinen $\mathrm{Haß}$ zuzogen, waren bestimmt von der Empörung über diese beiden Morde.

Ich habe an einem späteren Zeitpunkt - drei Jahre später - sehr intensiv darüber nachgedacht, wie die allgemeine Entwicklung und wie meine eigene Entwicklung ohne diese Morde weitergegangen wäre. Im Persönlichen habe ich mir klar gemacht, daß die Führungsfrage in der Kommunistischen Partei sehr bald zu einer entscheidenden Auseinandersetzung zwischen Liebknecht und Luxemburg geführt haben würde, wobei ich aber nicht glaubte, daß die Führung in die Hand Rosa Luxemburgs gefallen wäre. Sie war das geistige Haupt, die Seele und die Lehrerin der intellektuellen Sekte, die der Spartakusbund darstellte. Aber schon zur Zeit ihrer Ermordung paßte sie nicht mehr hinein in die äußerste Linke, bei der wie überall die Brutalisierung der Politik durch das Kriegsgeschehen entscheidend hervortrat. Ich habe mich später oft gefragt: "Was wäre aus Rosa Luxemburg geworden?" Ich hatte die Entwicklung ihres Freundes und intellektuellen Erbens Paul Levi ${ }^{56}$ vor Augen, und meiner Ansicht nach wäre sie den Weg, den er gegangen ist, mit noch größerer Klarheit und Entschiedenheit gegangen, über den Punkt hinaus, an dem er innehielt. Dies war für mich später eine wesentliche Frage, weil ich denselben Weg ging - aber noch nicht an diesem Zeitpunkt.

$[\ldots]^{57}$

\section{Der mitteldeutsche Generalstreik}

Die Wahl zur Nationalversammlung [19.1. 1919] hatte in Leipzig das von uns erwartete Ergebnis, nämlich drei Mandate. 1150 Stimmen fehlten uns zur Eroberung des vierten Mandats durch Richard Lipinski, 1150 von 60000 . Das Ergebnis der Wahl für die USPD im ganzen war nichts weniger als eindrucksvoll: 2317000 Stimmen und 22 Mandate bei 30400000 Gesamtstimmen. ${ }^{58}$ Aber wir waren weder überrascht, noch entmutigt. Die kurzfristige Ansetzung des Wahltermins hatte nicht. gestattet, die Organisationen der USPD auszudehnen und auf alle Wahlkreise zu erstrecken, und tatsächlich sah anderthalb Jahre später das Bild ganz anders aus. Aber eines war klar: Wer erwartet hatte, daß eine große Masse der Wähler sich spontan auch ohne Organisation der USPD zuwenden würde, der mußte enttäuscht sein. Im übrigen entfielen von den 2300000 Stimmen der Partei 1800000 auf folgende große Industriegebiete: Großberlin, Mitteldeutschland, Leipzig, Thüringen

56 Paul Levi (1883-1930), Rechtsanwalt, Mitglied der Zentrale des Spartakusbundes, ab März 1919 de facto Leiter der KPD, Dez. 1920/Anfang 1921 Parteivorsitzender der KPD (zusammen mit Däumig), 1921 Ausschluß, Gründer der KAG, 1922 Übertritt zur USPD und mit ihr wieder zur SPD, 1920-1930 MdR. Vgl. S. $147 \mathrm{f}$.

57 Auf den Ms.-Seiten 148-14.9 wird die Sprengung einer Wahlversammlung der DDP durch Geyer, der in Begleitung von 10 Bewaffneten erschien en war, beschrieben.

58 Von den 421 Mandaten entfielen auf die SPD 163, die Christliche Volkspartei (Zentrum und BVP) 91, die DDP 75, die DNVP 44, die DVP 19, sonstige 7. Die USPD war im Verhältnis zu ihrem Stimmenanteil von 7,6\% durch das Mandatsverteilungssystem benachteiligt worden. Bei einer Verteilung nach dem reinen Proporzsystem aufgrund der Gesamtzahl der abgegebenen Stimmen hätte sie 32 Mandate anstatt 22 erhalten. Vgl. Alfred Milatz, Wähler und Wahlen in der Weimarer Republik, Bonn 1965, S. $34 \mathrm{f}$. 
und Ruhrgebiet. In allen diesen Gebieten, ganz Sachsen eingeschlossen, hatten Unabhängige und Sozialdemokraten zusammen erhebliche, zum Teil Zweidrittelmehrheiten. Der Ruf nach dem Sozialismus war deshalb an diesem Zeitpunkt keineswegs eine verstiegene revolutionäre Illusion. Wohl hatten Sozialdemokraten und Unabhängige zusammen keine Mehrheit der abgegebenen Stimmen, aber immerhin 45,60 Prozent. Von den übrigen sechs Parteien folgte die nächststärkste, das Zentrum, mit rund sechs Millionen Stimmen nach. Im Jahre 1948 verglich ich in einer Schrift das Ergebnis der Hitlerwahl vom März 1933 mit der Nationalversammlungswahl. Ich sagte, Hitler habe damals mit 4.4. Prozent der abgegebenen Stimmen zwar nicht die arithmetische Mehrheit erhalten und seine Partei sei noch eine Minderheit im Volke gewesen, aber praktisch politisch die dynamische Mehrheit. Ich sagte dann, daß bei der Nationalversammlung die Sozialdemokratie unstreitig die dynamische Mehrheit war, aber „sie hat nicht daraus den Schluß gezogen, ihren Willen, sich selbst treu bleibend, durchzusetzen". 59

In den genannten großen Bezirken mit den sozialdemokratisch-unabhängigen Mehrheiten spielte sich in den kommenden Monaten der Kampf um die Verwirklichung des Sozialismus ab - nicht ohne Erfolge, bis der Wahnsinn der Friedensbedingungen dieser Entwicklung ein Ende machte. Schon zuvor begann die Reichsregierung mit der Niederwerfung der revolutionären Arbeiterräte in den führenden radikalen Städten dieser Bezirke, um einheitlich ihre Autorität und später die provisorische Reichsverfassung ${ }^{\mathbf{B}}$ durchzusetzen. Aber das Ringen um den Sozialismus ging auch nach der Niederwerfung in diesen Bezirken weiter, zum Teil in offenen blutigen Bürgerkriegskämpfen.

Auf diesem Hintergrund wird man verstehen, daß wir durchaus nicht entmutigt waren. Wir glaubten daran, daß mit der Nationalversammlungswahl die Revolution im sozialistischen Sinne keineswegs geschlossen sei und daß die revolutionäre Situation nach wie vor bestehe. Wir glaubten, folgende objektive Falktoren dafür zu erblicken: die völlige Ungewißheit des Friedensschlusses; das ungewisse Schicksal der feierlich versprochenen Sozialisierung; das Drängen des radikalen Teiles der Arbeiterschaft, auch des größten Teiles der Sozialdemokratie, auf die Erfüllung des Versprechens; die wirtschaftliche Not des Volkes, Lebensmittelknappheit, Geldentwertung und Lohnfragen - und dabei stand immer im Hintergrunde das Beispiel der Bolschewiki, die schließlich als die Friedenspartei die Macht ergriffen hatten - so glaubten wir wenigstens damals. Wenn die kritische Stunde der Friedensverhandlungen kommen sollte, so meinten wir, könnte wieder eine Situation entstehen, in der die Macht auf der Straße liege und in der die USPD als Ausdruck des Friedenswillens des Volkes sie ergreifen könnte.

$[\ldots]$

Die Konzentrierung unserer Wahlstimmen in Mitteldeutschland - Thüringen, Halle-Merseburg und Leipzig -, wo zusammengenommen die USPD allein 800000

59 Curt Geyer: Macht und Masse. Von Bismarck zu Hitler, Hannover 1948, S. 254 f.

${ }_{60}$ Gesetz über die vorläufige Reichsgewalt vom 10. Februar 1919 (RGBl. 1919, S. 169 f.). Diese „Notverfassung" war auf Initiative der süddeutschen Staaten Bayern, Württemberg und Baden, unterstützt von Hessen und Sachsen, als Ergebnis einer Konferenz der deutschen Länder am 25. Januar 1919 über den Verfassungsentwurf von Hugo Preuß3 zustande gekommen. Das Gesetz sicherte u. a. die föderalistische Struktur des Deutschen Reiches gegenüber der Reichsregierung. Vgl. Wolfgang Benz, Süddeutschland in der Weimarer Republik, Berlin 1.970, S. $94 \mathrm{ff}$. 
Stimmen erhalten hatte, legte mir und meinen nächsten politischen Freunden nahe, diese Position weiter zu befestigen und aus diesen Gebieten ein neues Land zu gründen, das wir unter uns und in der Propaganda „das rote Herz Deutschlands" nannten. Diese Pläne, die von der linken Führungsgruppe, die auf dem Rätekongre $\beta$ entstanden war, intern besprochen wurden, ließen wir an die Öffentlichkeit gelangen, als gegen Ende Januar sich ein Kongreß der Arbeiterräte in Braunschweig versammelte. ${ }^{61}$ Gegen solche Projekte wurde von der Preußenregierung sofort heftigster Protest erhoben, sie wurden als Landesverrat gegen das Land Preußen bezeichnet, was zu dieser Zeit, wo es noch keine provisorische Reichsverfassung gab, merkwürdig in unseren Ohren klang. Ich versuchte später, dem sächsischen Ministerpräsidenten, dem Sozialdemokraten Gradnauer, ${ }^{62}$ diese Pläne unter Einbeziehung ganz Sachsens schmackhaft zu machen mit dem Argument, daß damit die Annexion der Provinz Sachsen durch Preußen im Jahre 1815 rückgängig gemacht werden könnte, aber er wußte so gut wie ich, daß in dieser Konzentration die Unabhängigen die beherrschende stärkste Partei, eine dynamische Mehrheit sein würden. Übrig blieb von allen diesen Plänen nur die Verschmelzung der thüringischen Länderfetzen zu einem einheitlichen Land [1.5.1920], was in jeder Hinsicht eine vernünftige Aktion und einen Fortschritt darstellte.

Am 6. Februar [1919] trat die Nationalversammlung zusammen. Der Eröffnung gingen Verhandlungen zwischen der sozialdemokratischen und der unabhängigen Fraktion über die Regierungsbildung voraus mit dem Ergebnis, daß die unabhängige Fraktion eine Koalition mit den Sozialdemokraten ablehnte. Hätten die Sozialdemokraten die Unabhängige Fraktion sondiert mit dem Ziele, eine rein sozialistische Regierung zu bilden, so wäre die radikale Linke in der Fraktion wahrscheinlich mit ihrer Ablehnung jeder Koalition in der Minderheit geblieben. Da aber von vornherein klar war, daß die Führer der sozialdemokratischen Fraktion und vor allem Friedrich Ebert eine Mehrheitsregierung auf breiter Grundlage anstrebten, gab es in der Unabhängigen Fraktion keine ernstlichen Differenzen über die Frage.

Auch die Abgeordneten, die später unter der Führung Hugo Haases und unter dem geistigen Einfluß Rudolf Hilferdings den rechten Flügel bildeten, glaubten, daß die Revolution nicht abgeschlossen sei, auch sie glaubten vielmehr, daß die USPD in nächster Zukunft vor die Frage der Machtergreifung gestellt werden könnte. Wir alle wußten, wie in den wenigen Tagen seit der Wahl unsere Organisationen anschwollen und die Partei sich im Reiche ausbreitete. Als die Fraktion deshalb daran ging, ihre Vertreter für die Ausschüsse der Nationalversammlung zu bestimmen, stellte sie darüber hinaus etwa ein Dutzend eigener Ausschüsse auf, zu denen nicht nur Abgeordnete, sondern auch Nicht-Abgeordnete berufen wurden. Der Gedanke war, daß die Partei auf die Machtübernahme vorbereitet sein müßte, wenn die

61 Am 13. Januar 1919 hatte die braunschweigische Regierung vorgeschlagen, durch den Zusammenschluß von Braunschweig, Anhalt und Hamburg und den dazwischenliegenden preußischen Gebietsteilen eine „mittelnorddeutsche Bundesrepublik" mit kantonaler Verfassung zu gründen. Am 25. Januar war daraufhin in Braunschweig ein „Kongreß dex Arbeiter- und Soldatenräte Westdeutschlands“ zusammengetreten, auf dem die Gründung einer „Bundesrepublik Nordwestdeutschland“ exörtert wurde. Vgl. Deutscher Geschichtskalender, Ergänzungsband: Die deutsche Revolution, S. 470, $473 \mathrm{f}$.

62 Georg Gradnauer (1866-1946), seit 1890 SPD-Mitglied, 1896 Redalkteur am „Vorwärts“, 1907-1918 Redakteur der „Dresdner Volkszeitung““, 1898-1907, 1912-1918, 1919, 1920-1924 MdR, 1919-1921 sächs. Minısterpräsident, Mai - Okt. 1921 Reichsinnenminister. 
Stunde käme. Diese Ausschüsse stellten gewissermaßen die Schattenregierung der USPD dar.

Die Mitglieder der linken Führungsgruppe der USPD-Fraktion des Rätekongresses, die alle in die Nationalversammlung gewählt worden waren, beherrschten die wichtigsten dieser Ausschüsse, und sie drängten darauf, daß die Forderung der Verwirklichung des Sozialismus in den Mittelpunkt der Aktivität der Partei wie der Fraktion gestellt werden sollte, namentlich angesichts der Tatsache, daß die für diesen Zweck eingesetzte Sozialisierungskommission ${ }^{63}$ nicht weiterzukommen schien.

Zusammen mit meinen Freunden konzentrierte ich mich auf diese Aufgabe und schenkte deshalb der Verfassungsfrage wenig Aufmerksamkeit, besonders da wir alle der Ansicht waren, daß eine demokratisch-parlamentarische Verfassung keine lange Lebensdauer haben würde. Wir opponierten in der Nationalversammlung wohl gegen alles, was uns gefährlich erschien, und schließlich gegen die Verfassung überhaupt, aber die wahren Gefahren, die in den plebiszitären Zügen dieser Verfassung und in der Behandlung der Frage der Kommandogewalt über das Heer lagen, vermochten wir damals noch nicht genau zu durchschauen und abzuschätzen, ebensowenig wie die große Mehrheit der sozialdemokratischen Fraktion, die der Führung Eberts folgte, ohne über dessen Vorstellungen von der Verteilung der Gewichte zwischen dem Reichstag und dem Präsidenten eine klare Vorstellung zu haben. Was es für uns bedeutete, daß die Nationalversammlung sofort eine provisorische Reichsgewalt einsetzte und Ebert die [Reichs-]Präsidentschaft übertrug [11.2. 1919], bekamen wir in den radikalen Vororten in den nächsten Monaten deutlich genug zu spüren. Aber daß die Weimarer Verfassung - die freieste Verfassung der Welt - gewissermaßen von Anfang an die Keime zu ihrer Vergewaltigung durch eine Diktatur von rechts in sich trug, wurde damals von uns noch nicht verstanden, trotz der Warnungen, die Hugo Preu ${ }^{64}$ der Autor des Verfassungsentwurfs, gegen die plebiszitären Elemente erhob, die in seinen Entwurf hineingeschrieben wurden. Zum Unterschiede von uns verstanden dies andere. Max Weber ${ }^{65}$ bejahte den plebiszitären Charakter, weil er ihn für die Verwirklichung sozialistischer Maßnahmen für nötig hielt. Er verstand den Zusammenhang zwischen Diktatur und Planwirtschaft sehr wohl, aber an diesem Zeitpunkt war es auch ihm noch nicht klar, daß Ebert als Prä-

63 Am 18.11.1918 war ein Kabinettsbeschluß zur Berufung einer „wissenschaftlichen Kommission" zur Beratung der Sozialisierungsbestrebungen ergangen. Unter dem Vorsitz von Karl Kautsky konstituierte sich das Gremium am 5.12.1918. Am 11. Dezember veröffentlichte die Kommission einen Arbeitsplan und am 16. Dezember bat sie den Rat der Volksbeauftragten um ,genaue Bestallung, Umschreibung ihrer Rechte und Pflichten“. Ein Antrag der Kommission auf Sozialisierung des Bergbaus wurde Mitte Januar 1919 vom Rat der Volksbeauftragten und vom Zentralrat einstimmig abgelehnt. Da organisatorische Voraussetzungen wie Kompetenzen fehlten (die Berufungsurkunde wurde erst am 4.2.1919 ausgefertigt), demissionierte die Kommission am 3. Februar, nahm die Rücktrittserklärung am 15.3.1919 zwar wieder zurück, blieb aber auch in der Folgezeit infolge mangelnder Unterstützung durch Behörden und Reichsregierung wirkungslos. Vgl. Zentralrat, S. 67 u. $521 \mathrm{f}$. und Gerhard A. Ritter/Susanne Miller (Hrsg.), Die deutsche Revolution 1918-1919, Frankfurt 1968, S. 235 f.

64 Hugo Preuß (1860-1925), seit 1906 Prof. für Staatsrecht an der Handelshochschule Berlin, Nov. 1918 Staatssekretär des Innern, 1919 Reichsinnenminister (DDP).

65 Max Weber (1864-1920), Professor für Nationalökonomie und Soziologie in Berlin, Freiburg, Heidelberg, München, 1918/19 Mitarbeiter der Sachverständigenkommission für den Reichsverfassungsentwurf, Mitgründer der DDP. Vgl. Wolfgang J. Mommsen, Max Weber und die deutsche Politik 1880-1920, Tübingen 1959. 
sident seine Vollmachten eher als Mittel zur Verhinderung radikaler sozialistischer Maßnahmen ansah.

[...]

Meine ganze Aufmerksamkeit und die meiner nächsten Freunde konzentrierte sich auf die sozialen Vorgänge und die Sozialisierung. Größte Unruhe erfüllte die Arbeiterbevölkerung in unseren Wahlkreisen, vor allem im mitteldeutschen Industriegebiet und im Ruhrgebiet. Nicht nur die Gewerkschaftsmitglieder und die Anhänger der Sozialdemokratie und der Unabhängigen waren in Bewegung, wie Serien von Lohnstreiks zeigten, sondern auch die bisher unorganisierten und ausgesprochen rechtsstehenden Arbeiter. Diese Erscheinung war am markantesten im Industriegebiet um Halle und im Bergwerksgebiet von Mansfeld. Diese Arbeiter wandten sich unserer Partei zu. Sie verlangten aktivistisches Vorgehen zur Verwirklichung des Sozialismus, weil sie nun glaubten, daß nur der Sozialismus ihrer Not und der Krise in der Wirtschaft ein Ende machen könnte.

Die soziale Unruhe rief Unzufriedenheit mit der Haltung ihrer Regierung in der sozialdemokratischen Fraktion der Nationalversammlung hervor. Wir lebten in Weimar so eng gedrängt nebeneinander, daß keiner der beiden Fraktionen verborgen blieb, was bei der anderen vorging. Wir wußten, daß nicht nur das Temporisieren der Regierung in der Sozialisierungsfrage, sondern auch die Formierung dex neuen militärischen Einheiten der Regierungstruppen unter Führung von reaktionären Offizieren der alten kaiserlichen Armee große Unruhe in der sozialdemokratischen Fraktion hervorrief. Im übrigen gab es genügend intellektuelle sozialdemokratische Kritiker, die ihre Ansichten in Zeitungen und Zeitschriften zum Ausdruck brachten. Die mit gewaltiger Mehrheit gefaßten Beschlüsse des Ersten Rätekongresses über die neue Militärmacht ${ }^{66}$ waren schon von den rechtssozialistischen Volksbeauftragten unter dem Einfluß der Obersten Heeresleitung Hindenburg-Groener ${ }^{67}$ einfach beiseite geschoben worden. Sie mochten dilettantisch und kaum durchführbar sein - in einer Revolution ist übrigens alles dilettantisch -, aber die neuen Militärformationen waren weder von sozialistischem, noch demokratisch-republikanischem noch revolutionärem Geiste beleckt. Unsere gesamte Propaganda und unsere Zeitungen griffen unaufhörlich die Reichsregierung wegen dieser beiden Fragen an, und die parteipolitischen Erfolge, die wir erzielten, riefen allmählich in der sozialdemokratischen Fraktion die Anschauung hervor, daß es so nicht weitergehen könne und daß die Reichsregierung eine positive sozialistische Politik führen müsse.

o6 Der Beschluß des Rätekongresses vom 18.12.1918 („Sieben Hamburger Punkte“) sah die Kommandogewalt über Heer, Marine und Schutztruppen durch die Volksbeauftragten vor, ferner die beschleunigte Abschaffung des stehenden Heeres und Errichtung einer Volkswehr, die Entfernung aller Rangabzeichen, Wahl der Führer durch die Soldaten u. a. (Rätekongreß, Sp. 140 u. S. 181). Gegen diesen Beschluß protestierten OHL, Waffenstillstandskommission u. a. militärische Stellen energisch und erfolgreich. Auf einer gemeinsamen Sitzung des Zentralrats und des Rats der Volksbeauftragten wurde am 20.12. 1918 beschlossen, da $\beta$ es bis zur gesetzlichen Regelung der Ausführungsbestimmungen zum Kongreßbeschluß „bei den bisherigen Zuständen" bleiben solle. Regierung der Volksbeauftragten, II, S. 3 ff., u. Zentralrat, S. $24 \mathrm{ff}$.

67 Paul von Beneckendorff und von Hindenburg (1847-1934), 1916 Chef des Generalstabs und Chef der OHL, 1925-1934. Reichspräsident. - Wilhelm Groener (1867-1939), General, 1914 Chef des Feldeisenbahnwesens, Oktober 1918 Nachfolger Ludendorffs in der OHL, Organisator von Rückmarsch und Demobilmachung des Heeres, zwischen 1920 und 1923 mehrfach Reichsverkehrsminister, 1928-1932 Reichswehrminister, 1931-1932 auch Reichsinnenminister. 
Dies war der Hintergrund zu den Beschlüssen, die meine nächsten Freunde und ich für die Ausrufung des mitteldeutschen Generalstreiks ${ }^{68}$ faßten. Es war ein ausgesprochen politischer Streik. Er galt nicht nur dem Protest gegen die neue Militärgewalt, sondern das eigentliche Ziel war es, die Regierung zur Einlösung ihres Sozialisierungsversprechens zu zwingen. Gleichzeitig stellten sich die Streikenden hinter die Arbeiterräte im mitteldeutschen Industriegebiet, in Thüringen und in Leipzig. Es war ein Riesenstreik, viel zu eindrucksvoll für die Regierung. In diesen radikalen Industriegebieten war jedenfalls die revolutionäre Welle noch nicht abgeflaut. Die Regierung wußte nichts Besseres zu tun, als die neue Militärmacht gegen den Streik einzusetzen, so daß aus dem Streik offener Bürgerkrieg wurde, in dem die Regierung dann schließlich der Sozialisierungsforderung gegenüber kapitulierte - für eine gewisse Zeit.

Nachdem der Streik zwei Tage lang in Gang war, wies die Reichsregierung General Maercker $^{69}$ an, mit seiner Division die Stadt Halle zu besetzen, die Führer des Streiks zu verhaften und so dem Streik im Bezirk Halle-Merseburg das Rückgrat zu brechen. Ich erfuhr von dieser Aktion, als plötzlich alle unsere telephonischen Verbindungen mit Halle unterbrochen wurden, was dem Leipziger Arbeiterrat die Möglichkeit nahm, sich mit den Arbeiterräten im sächsisch-preußischen Industriegebiet zu verständigen. Gerüchtweise verlautete, daß in Halle schwerste Straßenkämpfe im Gang seien. Schließlich gelang es mir, vom Hauptbahnhof aus über das Eisenbahntelephon eine Verbindung mit dem Bahnhof Halle zu erhalten. Ich wurde informiert, daß die bekannten Abgeordneten der Linken und die Streikführer, die verhaftet werden sollten, nicht auffindbar seien und daß jedenfalls das Personal des Bahnhofs Halle keine Verbindung mit ihnen herstellen könne. Kämpfe wären im Gange, aber mehr vermochten meine Gesprächspartner nicht zu sagen.

Wir berieten im Leipziger Arbeiter- und Soldatenrat über die Lage und schließlich schlug ich vor, ich wollte mit einer starken Militärpatrouille nach Halle gehen, nicht um in eventuelle Kämpfe einzugreifen, sondern um die Lage zu erkunden und nach Möglichkeit die Verbindung zwischen den Streikleitungen wiederherzustellen. Der Leipziger Arbeiterrat beschlo $\beta$ demgemä $\beta$, und gegen Abend fuhr ich mit zwei Kraftwagen und zwölf Mann, die mir der Soldatenrat zur Verfügung stellte und die mit Gewehr und Pistole bewaffnet waren, nach Halle, nicht ohne daß ich zuvor Bereitschaftsmaßnahmen angeordnet hatte für den Fall, daß Leipzig angegriffen würde. In mancher Hinsicht wiederholten sich bei dieser Erkundung meine Berliner Erfahrungen während des Spartakusaufstands.

Am Bahnhof Halle wurde uns lediglich mitgeteilt, daß die Maercker-Truppen beim Einmarsch in die Stadt einen Rückschlag erlitten hätten und nun in der Hauptsache im Gebäude der Hauptpost konzentriert seien und sich dort mit bewaffneten Arbeitern herumschössen. Alle uns bekannten Büros, die wir aufsuchen wollten, waren leer, von der Bevölkerung war wenig zu erfahren. Schließlich begegneten wir einer

${ }^{68}$ Im Zeitzer Revier hatte der Generalstreik bereits am 22.2.1919 begonnen, in Halle wurde der Streikbeschluß auf einer mitteldeutschen Bergarbeiterkonferenz am 23. Februar gefaßt. Ab 24. Februar ruhte die Arbeit im Gebiet Halle-Merseburg und im benachbarten Sachsen sowie in Thüringen und Anhalt. Nach Verhandlungen zwischen Regierung, Gewerkschaften, Arbeitgebern und Arbeitnehmern wurde die Arbeit zwischen dem 6. und 8. März überall wieder aufgenommen. In Leipzig dauerte der Generalstreik vom 27. 2. - 10.3. 1919.

69 Georg Maercker (1865-1924), preuß. General, Gründer und Kommandeur d. Freiw. Landesjägerkorps 1918, nach dem Kapp-Putsch verabschiedet. - Vgl. Maercker, Vom Kaiserheer zur Reichswehr. Geschichte des freiwilligen Landesjägerkorps, Leipzig $1922^{3}$. 
Patrouille von zwei bewaffneten Arbeitern mit roter Armbinde. Sie gaben uns einen ungefähren Bericht über den Gang der Geschehnisse. Die Division Maercker war vom Bahnhof aus mit klingendem Spiel und unter Zurschaustellung ihrer Maschinengewehre auf ihren Wagen durch die Straßen der Stadt nach dem Marktplatz gezogen, um so die Autorität der Reichsregierung zu demonstrieren. Auf dem Marktplatz hatte sich eine gewaltige, gegen den Einmarsch protestierende Menschenmenge versammelt, in der vor allem Frauen die große Mehrheit hatten. Plötzlich stürzte sich diese Menge unbewaffnet auf die Kolonne, entriß ihnen Gewehre und zerschlug sie auf dem Pflaster, riß achtzehn Maschinengewehre der Kolonne von den Wagen und warf sie in die Saale. In dem tollen Durcheinander blieb Maercker nichts übrig, als den Rückzug zu befehlen. Er verschanzte sich in der Hauptpost, sandte nur wenige Patrouillen in die Stadt und forderte von der Reichsregierung Verstärkungen an. Während sich seine Patrouillen gelegentlich mit Arbeiterpatrouillen herumschossen, konzentrierte sich eine Kampfgruppe der bewaffneten Arbeiter im Theatergebäude, das über einem nicht allzu weiten Platz dem Hauptpostgebäude gegenüber liegt. Hier hielten sie sich gegenseitig in Schach. Die Stadt war also leer von Polizeikräften der einen wie der anderen Seite. In dieser Situation stürzte sich die ausgehungerte Bevölkerung von Halle in die Hauptgeschäftsstraßen der inneren Stadt und begann die Geschäfte regelrecht auszuplündern. Ich fragte nach der Streikleitung und wurde informiert, daß sie Halle verlassen habe, um sich in einer Stadt des Industriegebietes, in Eisleben, in der Nähe des Mansfeldischen Bergwerkreviers zu etablieren. Dann fragte ich nach der Kampfleitung in Halle und begegnete nur einem Achselzucken der beiden Männer. Sie meinten, vielleicht sei eine Kampfleitung im Theater, sie wüßten es aber nicht.

Ich dachte einen Augenblick daran, nach Eisleben zu fahren, um dort die Verbindung mit der Streikleitung aufzunehmen, oder über Merseburg zurückzufahren, um zu erkunden, was dort vor sich ging. Da es aber bereits spät war, rieten meine Begleiter mir davon ab, sie meinten, wir wüßten nicht, in was wir in Merseburg hineinlaufen würden, und es war klar, daß sie noch in der Nacht wieder nachhause zurück wollten. Ich will hier erwähnen, daß sowohl sie als auch ich selber bei dieser Erkundung niemals das Gefühl dafür verloren, daß wir auf preußischem Gebiet waren. Wir beschlossen dann, uns die Sache im Theater anzusehen. Wir fuhren nach dem rückwärtigen Bühneneingang - von der Feuerzone entfernt - und drangen beim Lichte unserer Taschenlampen in das dunkle Theater ein. Ab und zu fielen einige Gewehrschüsse, Maschinengewehrfeuer war nicht zu hören.

Diese Szene in dem dunklen Theater ist mir fest im Gedächtnis geblieben. Über die Bühne fanden wir schließlich den Weg ins Parterre und arbeiteten uns im Dunklen, über die Sitze stolpernd, nach der Vorderfront des Theaters durch. Es war eine merkwürdige Impression vom Bürgerkrieg - im Dunklen auf der Suche nach Freund und Feind, immer exwartend, daß wir plötzlich angerufen oder beschossen werden würden. Niemand war da, der uns am Eindringen in das Gebäude gehindert hätte, weder Wachen noch Patrouillen, die Straßen waren völlig verlassen. Schließlich gelangten wir auf den Balkon über dem Eingang. Hier standen zwei Maschinengewehre mit zwei Dutzend Leuten ohne eigentlichen Führer. Gegenüber lag die Front des Postamtes. Es fiel kein Schuß von dort, nichts war zu hören. Es war totenstill, nur ab und $\mathrm{zu}$ von anderen Punkten der Theaterfront ein gelegentlicher Gewehrschuß.

Ich fragte, was von anderen Kampfeinheiten bekannt sei, und der Sprecher der zwei Dutzend Leute meinte, wahrscheinlich gebe es hier und da in der Stadt noch 
kleinere Einheiten, aber er wisse darüber nichts, er wisse auch nichts von einer Kampfleitung, sie hätten nach den Vorgängen auf dem Marktplatz das Theater besetzt und wollten es halten. Er deutete auf die Hauptpost: „Da drüben sitzen sie und haben Angst und warten auf Verstärkung, es sind alles sehr junge Leute." - „Nun, und morgen?" Er zuckte mit den Achseln. "Und wenn sie zum Angriff übergehen?" - „Wir werden das Theater halten." Und er wies auf die Maschinengewehre. Dann fragte ich nach der Haltung der Bevölkerung. Mit einiger Bitterkeit sagte er: „Die haben jetzt Besseres zu tun als uns zu helfen, die plündern. Wir können sie daran nicht hindern, es ist auch ganz egal. Fahren Sie nach der Hohen Straße, da werden Sie etwas sehen." Wir schüttelten uns die Hände, diesmal hütete ich mich zu fragen, ob sie Unterstützung von uns erwarteten. Wiederum tasteten wir uns durch den dunklen Theatersaal und fanden unsere Wagen unbelästigt vor. Wir wenigstens hatten Wachen bei ihnen hinterlassen. Wir fuhren nach der inneren Stadt. Schon auf der Fahrt sahen wir Spuren von Plünderung. Aber das war gar nichts gegenüber dem Schauspiel, das die Hauptgeschäftsstraße von Halle bot. Hell erleuchtet lag sie vor uns, in allen den geplünderten Geschäften war das elektrische Licht angeschaltet. Alle Schaufensterscheiben, zum Teil große Spiegelglasscheiben, waren eingeschlagen und herausgeschlagen. Auf dem Bürgersteig wie auf der Fahrbahn lagen die Glassplitter zentimeterhoch, unter ihnen weggeworfene Wäschestücke, Kleidungsstücke, Konservendosen, Lebensmittel, Schmuckwaren, Küchengeräte. Wir konnten hören, daß in einigen der Läden die Plünderung weiterging.

Empörung überkam mich. Zur revolutionären Legende in meiner ganzen Jugend hatte gehört, daß Revolutionäre nicht plündern, sondern aufs Strengste gegen Plünderer vorgehen, daß im Interesse der Revolution harte Lebensbedingungen ohne Murren ertragen werden müßten und daß kein klassenbewußter Arbeiter und Sozialist sich jemals zum „Lumpenproletariat" gesellen würde, wenn es plündert oder stiehlt. In diesem Punkte dachte ich mit geradezu robespierreschem Fanatismus. Als ich von einigen belanglosen Korruptionsfällen im Leipziger Arbeiterrat gehört hatte, waren die Betreffenden sofort hinausgeworfen worden.

Angesichts der weitergehenden Plünderung handelte ich ohme Überlegung ganz instinktiv und automatisch. Wir sperrten unser Ende der Straße ab, feuerten Schreckschüsse in die Straße und riefen: „Wer plündert, wird exschossen." Ich befahl einigen meiner Begleiter, nach dem anderen Ende der Straße zu gehen, es zu besetzen und jeden zu verhaften, der ihnen mit geplünderter Ware in die Hände fallen würde. Wir sahen einige Dutzend dunkle Gestalten sofort verschwinden. Ich ging dann mit zwei Mann durch die Straße. Vor einem geplünderten Wäschegeschäft, das hell erleuchtet war, hörte ich Geräusche. Ich zog die Pistole und ging in das Geschäft, meine Begleiter nach mir. Im Hinterzimmer des Geschäftes fand ich eine alte Frau mit einem etwa achtjährigen Mädchen. Sie hatten einen großen Henkelkorb und waren dabei, ihn sorgfältig mit Wäsche zu packen. Ich herrschte die alte Frau an: "Was machen Sie da?" Sie war bleich vor Schreck, das Mädchen klammerte sich an sie. Mit der Pistole in der Hand herrschte ich sie weiter an: „Sofort den Korb ausleeren und verschwinden!" Die alte Frau sah mich bittend an, dann weinte sie, und das Kind weinte ebenfalls, aber sie gehorchte. Sie drehte den Korb um, es waren einige Handtücher, ein Tischtuch, einige Stücke Leibwäsche für sie, einige Wäschestücke für das Kind - die einfachen Dinge des Lebens, welche die Hallesche ärmere Bevölkerung seit Jahren überhaupt nicht gesehen hatte, wegen der Warenknappheit und der Rationierung und wegen ihrer Armut. Ich ließ ihnen den Korb. Schon als ich sie an- 
herrschte und erst recht als sie davonschlichen, begann eine Stimme in meinem Innern zu rebellieren. Sie hat nie aufgehört zu rebellieren, und je älter ich wurde, desto mehr habe ich begriffen, daß sie recht hatte. Ich kann heute ganz einfach formulieren, was miteinander stritt, nämlich der Kampf einer autoritären revolutionären Haltung und ein einfaches Gefühl der Menschlichkeit. Wegen dieses Vorfalls habe ich jetzt noch ein schlechtes Gewissen. Ich weiß, Mitgefühl mit den beiden, die keine Diebe waren, wäre die menschlichere Haltung und zugleich die bessere, wirklich sozialistische Haltung gewesen. In ihrer Armut war ihnen plötzlich unerwartete Hilfe erschienen, die ihnen dann brutal wieder weggerissen wurde.

[...]

Wir kamen spät in Leipzig an, und ich fand kaum drei Stunden Schlaf, ehe ich dem Arbeiterrat meine Vorschläge zur Behandlung der Situation unterbreitete. Zunächst beschlossen wir, den Generalstreik in verschärfter Form weiterzuführen. Dann erteilte ich dem Soldatenrat Befehl, auf dem Bienitz, einer sandigen Anhöhe an der sächsisch-preußischen Grenze, welche die Straßen von Halle und Merseburg beherrscht, Stellungen ausheben zu lassen und zunächst mit schwachen Kräften zu besetzen. Dann teilte ich der sächsischen Landesregierung mit, daß ich Befehle zur Verteidigung des sächsischen Staatsgebietes gegen einen Vormarsch Maerckers gegeben habe und erinnerte sie an das Dresdner Abkommen. Die Staatsregierung sandte sofort den mehrheitssozialistischen Minister Schwarz ${ }^{70}$ nach Leipzig, der mit unserer Forderung der Einlösung des Sozialisierungsversprechens der Reichsregierung sympathisierte. Das Ergebnis der Verhandlungen und der sofortigen Vorstellungen der sächsischen Landesregierung bei der Reichsregierung war, daß der Landesregierung zugesichert wurde, daß keine Reichstruppen nach Leipzig gesandt werden würden, solange wir nicht preußisches Gebiet verletzten. Dieses Ergebnis verlängerte das Leben des Leipziger Arbeiterrates um zweieinhalb Monate. Ich war erleichtert, daß unsere Fähigkeit, militärischen Widerstand zu leisten, nicht auf die Probe gestellt wurde; denn in diesem Punkte machte ich mir bereits keine Illusionen mehr. Aber wir besaßen immerhin noch so viel militärische Macht, daß ich damit drohen konnte.

Der Einmarsch General Maerckers in Halle ermutigte das Leipziger Bürgertum zu stärkerem Widerstand gegen das Regime des Arbeiter- und Soldatenrates, was mich zu einer Reihe diktatorischer Maßnahmen zwang. Eine der ersten dieser Maßnahmen richtete sich gegen die bürgerlichen Zeitungen Leipzigs. Vom Beginn der Revolution an waren die "Leipziger Neuesten Nachrichten", die einen rechtsnationalliberalen und alldeutschen Kurs verfolgten, eine Zielscheibe der Erbitterung der Bevölkerung gewesen, dieser Zeitung wurden besonders die Kriegslügen angerechnet, als die Bevölkerung aufschrie, sie wäre belogen und betrogen worden. Unsere Anhänger sahen sie mit besonderer Erbitterung, da sie eine unaufhörliche und zum Teil sehr giftige Propaganda gegen uns geführt hatte, auf die wir während des Krieges in unserer Zeitung nicht antworten konnten. Unmittelbar vor dem mitteldeutschen Generalstreik hatte sie Verdächtigungen und Verleumdungen wiedergegeben, die in anderen Zeitungen Deutschlands, so in der Frankfurter Zeitung, gegen den Leipziger Arbeiterrat und gegen mich persönlich ausgestreut wurden. ${ }^{71}$ Ich weiß nicht mehr, welcher Tropfen das $\mathrm{Faß}$ zum Überlaufen brachte, jedenfalls führte die Erbit-

70 Albert Schwarz (1876-1929), Minister für Arbeit und Wohlfahrt, Nov. 1918 - Jan. 1919, Jan. 1919 - April 1921 Wirtschaftsminister in Sachsen.

71 Frankfurter Zeitung vom 5. 3. 1919 (zitiert in LVZ v. 10. 3. 1919). 
terung darüber zu einer spontanen Demonstration vor dieser Zeitung, die immer weiter anwuchs und gefährliche Formen annahm. Ich wurde davon vollständig überrascht. An diesem Tage besuchte der Vorsitzende des Chemnitzer Arbeiter- und Soldatenrates, der Kommunist Heinrich Brandler, ${ }^{\mathbf{7 2}}$ den Leipziger Arbeiter- und Soldatenrat, um mit uns gemeinsame Probleme zu besprechen. Mitten in den Besprechungen wurde ich alarmiert. Die wütende Menge beabsichtigte, in die Druckerei der „Leipziger Neuesten Nachrichten“ einzudringen und die Rotationsmaschinen zu zerschlagen. Diese Demonstration ging drei Minuten zu Fuß von unserem Amtssitz vor sich. Ich ging hin, und Brandler begleitete mich. Ich sah mich einer wütenden, offenbar führerlosen Menge gegenüber, auf die ich zunächst keinerlei Einfluß ausüben konnte. Brandler versuchte, die Kommunisten in der Menge zur Aufgabe der Demonstration zu bewegen, aber ebenso vergeblich. Ich rief Mitglieder des Arbeiterrats zur Unterstützung herbei, und zusammen konnten wir schließlich die Menge von dem Sturm auf die Druckerei abhalten mit dem Versprechen, daß der Arbeiterund Soldatenrat drastische Maßnahmen gegen die bürgerliche Presse ergreifen werde.

Am anderen Tage beschloß der Arbeiterrat ein unbefristetes Verbot der bürgerlichen Zeitungen Leipzigs. Die Erbitterung darüber beim Leipziger Bürgertum war begreiflicherweise groß. Die Verleger der Zeitungen erschienen einige Tage später im Arbeiterrat, um mich in einer Unterredung zur Aufhebung des Verbotes zu veranlassen. Ich stellte ihnen eine Reihe von Bedingungen, die sie nicht annehmen wollten, so daß ich ihnen erklärte, es bleibe bei dem Verbot. Ich sagte ihnen auch deutlich, daß auch für sie das Verbot immer noch besser sei als die Zerschlagung ihrer Maschinen. Als sie die Besprechung verließen, kam der Verleger des „Leipziger Tageblatt", der spätere demokratische Finanzminister in Sachsen, Dr. Reinhold, ${ }^{73}$ ein linksstehender Demokrat, zu mir zurück und sagte: „Herr Geyer, ich will Ihnen nur persönlich sagen, wenn ich an Ihrer Stelle wäre, würde ich uns genauso behandeln."

Als sich die Führer des Leipziger Bürgertums, die mit der Fortsetzung der Aktion Maercker in Leipzig gerechnet hatten, in diesem Punkt enttäuscht fühlten, gingen sie zu einem gefährlichen Gegenstreik ${ }^{74}$ gegen unseren Generalstreik für die Sozialisierung über. Zunächst wurde mir mitgeteilt, daß die Stadtverwaltung nicht mehr in der Lage sein werde, die Unterstützungen an Kriegerwitwen und - waisen sowie

72 Heinrich Brandler (1881-1967), 1901 Mitglied der SPD, 1915 als Anhängex Lieblnechts ausgeschlossen, 1919 Mitglied der KPD-Zentrale, 1921 Mitvorsitzender der KPD, 1922 Vors. der KPD, Okt. 1923 Leiter der sächs. Staatskanzlei, 1924-1928 Aufenthalt in Moskau, 1929 Mitgründer und Führer der rechtsoppositionellen KPO, 1933 Emigration nach Frankreich und Kuba, 1949 Rückkehr nach Deutschland.

73 Peter Reinhold (1887-1955), 1919-1924 MdL Sachsen, 1920 u. 1924-1926 sächs. Finanzminister, 1926-1927 Reichsfinanzminister, 1928-1932 MdR (DDP).

74 Am 28. 2. 1919 rief der „Leipziger Bürgerausschuß" - eine Organisation, die sich im November 1918 unter dem Vorsitz des Historikers Walter Götz als bürgerliche Bewegung gegen den Arbeiter- und Soldatenrat gebildet hatte - ,die gesamte Leipziger Kaufmannschaft, die Handwerkerschaft, das Beamtentum in Stadt und Land, die Ärzte, Apotheker, Rechtsanwälte und Lehrer auf ... in den allgemeinen Ausstand zu treten". Vgl. Horst Beutel, Die Novemberrevolution von 1918 in Leipzig und die Politik der Leipziger USPD-Führung bis zum Einmarsch der konterrevolutionären Truppen des Generals Maercker am 12. Mai 1919, in: Wiss. Zeitschr. d. Karl-Marx-Universität Leipzig, 7 (1957/58), S. 404, und Gerhard Puchta, Der Arbeiter- und Soldatenrat in Leipzig vom November 1918 bis vor dem 2. Rätekongreß Anfang April 1919, ebenda S. 378. 
andere Unterstützungen, von denen ein erheblicher Teil der Bevölkerung lebte, auszuzahlen, da die Reichsbankfiliale Leipzig den Banken eröffnet habe, daß sie ihnen keine weiteren Barmittel zur Verfügung stellen könne. Nach dieser Mitteilung bestellte ich den Direktor der Reichsbankfiliale auf mein Büro und befragte ihn darüber. Als er erklärte, daß er Anweisung von Berlin habe, die in den Tresors vorhandenen Geldmittel nicht herauszugeben, und daß er auf weiteren Zufluß nicht rechnen könne, eröffnete ich ihm, daß ich ihn so lange in Schutzhaft nehmen würde, wie er auf seiner Haltung beharrte. Er schien daran nicht recht zu glauben und war entsetzt, als ich ihn für verhaftet erklärte und selber mit Bewachung nach der nahegelegenen Polizeidirektion brachte. Der Polizeidirektor protestierte, als ich ihn aufforderte, den Direktor der Reichsbank in einer Zelle der Polizeidirektion festzusetzen. Er erhob eine Reihe von Vorstellungen, mußte sich aber schließlich fügen. Am nächsten Tage erschien die Tochter des Verhafteten, die ihm den Haushalt führte, auf dem Arbeiterrat und bat mich dringend, ihren Vater freizulassen, er sei ein gänzlich unpolitischer Mensch und habe nur höhere $W^{\top}$ eisungen befolgt. Da sich die Lage inzwischen zugespitzt hatte, schlug ich das rundweg ab. ${ }^{75}$

Der Gegenschlag gegen uns, der auf Anweisung des Leipziger Oberbürgermeisters Dr. Rothe geführt wurde, bestand in einer Anweisung an die Beamtenschaft, alle städtischen Zahlstellen, die Unterstützungen auszahlten, zu schließen, was zum größeren Teil von den Beamten befolgt wurde. Meine erste Antwort darauf bestand in der Verschärfung des Generalstreiks, ich dehnte ihn auf die Elektrizitäts- und Gasversorgung aus. Aber ich konnte nicht erwarten, damit rasch einen Rückzug des Oberbürgermeisters zu erzwingen, obwohl diese Ausdehnung das Bürgertum weit schwerer traf als die Arbeiterschaft.

Wir berieten deshalb im Arbeiterrat, wie wir die städtischen Zahlstellen in eigener Regie wieder eröffnen könnten. Wir überlegten, daß wir brauchbare Mitglieder unserer Partei und der Gewerkschaften, vor allem Angestellte, mobilisieren könnten, um die streikenden Beamten zu ersetzen. Aber eine solche Übernahme der Verwaltung in den unteren Verwaltungsorganen hätte zum mindesten mehrere Tage der Vorbereitung erfordert. Dann mußte die Frage der nötigen Geldmittel gelöst werden. Noch im November wäre ich entschlossen gewesen, Notgeld drucken zu lassen, aber jetzt überdachte ich alle damit zusammenhängenden Komplikationen, die Schwierigkeiten der Überwachung in den Druckereien und der späteren Wiedereinlösung, und ich stellte diese Eventualität zurück. Ein anderer Weg war, von den Banken direkt auf unsere Anweisung hin Auszahlung von den städtischen Konten zu fordern, was auch geschah, aber die Banken unterstützten die Aktion des Oberbürgermeisters und erklärten, sie würden an den Arbeiter- und Soldatenrat nicht auszahlen. Wir drohten ihnen wie der Reichsbank, daß wir sie besetzen und ihre Safes mit Gewalt öffnen würden, und wir besprachen die Öffnung der Safes mit Sachverständigen. Aber ich wußte sehr genau, wie weit ich mich engagieren müßte, wenn ich zu solchen Mitteln greifen und versuchen würde, die Verwaltung direkt zu übernehmen. In meinen eigenen Überlegungen sah ich nur einen Weg: Ich mußte den Kampfwillen des Oberbürgermeisters brechen. Und ich brach ihn.

75 Nach Beutel und Puchta, a. a. O., war der Amtshauptmann von Fink, der am 28.2.1919 die Amtshauptmannschaft geschlossen hatte und die Ausgabe von Lebensmittelkarten einstellen ließ, vom Arbeiter- und Soldatenrat verhaftet worden. 
Ich ließ ihm telephonisch mitteilen, da $\beta$ ich zu einer Unterredung aufs Rathaus kommen würde, und zwar sofort. Der Sitz des Arbeiter- und Soldatenrates lag dem Rathaus gegenüber. Ich ging ins Rathaus, begleitet von zwei bewaffneten Wachen. Der Oberbürgermeister war in seinem Zimmer. Ich stellte die Wachen vor der Tür auf und betrat den Raum. Der Oberbürgermeister saß in einer halbrunden Nische des Raumes in der Mitte einer halbrunden Sofabank, vor ihm ein großer runder Tisch, neben ihm rechts und links sowie weiter um den Tisch herum saßen seine Stadträte. Ich setzte mich an den runden Tisch ihm gegenüber. Einer der jüngeren Stadträte überfiel mich sofort mit den heftigsten Vorwürfen wegen der Unmenschlichkeit des Gas- und Elektrizitätsstreiks, er schilderte, was in den Krankenhäusern die Folge davon sein könnte - die bekannten Argumente bei solchen Gelegenheiten. Nach ihm redete ein älterer Stadtrat auf mich ein, wahrscheinlich sei mir nicht klar gewesen, welche Wirkungen dadurch hervorgerufen würden, das sei doch unmenschlich. Ich erwiderte mit der Gegenfrage, ob es menschlich sei, Kriegsopfern, Kriegerwitwen und Kriegerwaisen den Lebensunterhalt zu sperren und sie hungern zu lassen. Auf weitere Vorhaltungen wegen des Gas- und Elektrizitätsstreiks erklärte ich schließlich, wenn der Oberbürgermeister den Beamten Anweisung gäbe, die Zahlstellen sofort wieder zu öffnen, und sie mit den nötigen Zahlungsmitteln ausstattete, würde gleichzeitig ich den verschärften Gas- und Elektrizitätsstreik abbrechen und lediglich den Generalstreik ohne diese Verschärfung weiterführen. Meiner Erklärung folgte Schweigen. Ich sah, daß sie erwartet worden war und $d a ß$ sie untereinander beschlossen hatten, nicht darauf einzugehen. Ich sah deutlich, daß der Oberbürgermeister entschlossen war, seine Gegenaktion durchzuhalten. Dann versuchten sie, mich persönlich zum Rückzug zu überreden mit der Formel: „Wir sind doch alles gebildete Leute und Akademiker und sollten uns verständigen." Dieses nutzlose Hin und Her dauerte etwa zwanzig Minuten. Dann stand ich auf, wandte mich direkt an den Oberbürgermeister und warf ihm mein Ultimatum ins Gesicht. Ich sagte ihm: „Herr Doktor Rothe, ich verlange von Ihnen, daß Sie die Zahlstellen wieder öffnen lassen, ich verlange von Ihnen eine Anweisung über städtische Gelder für einen Betrag, den ich Ihnen noch mitteilen lassen werde. Ich gebe Ihnen eine Bedenkzeit von zwei Stunden. Wenn Sie sich dann weiter weigern, werde ich Sie verhaften lassen. Ich werde Sie nicht in die Polizeidirektion bringen lassen. Ich werde Sie unter Bewachung einer Abteilung der Matrosenkompagnie im Asyl für Obdachlose internieren lassen." Nach diesem Ultimatum verließ ich das Rathaus und ging in die Sitzung des Arbeiterrates zurück. Wir überlegten, daß wir lediglich eine Garantiesumme von dreihunderttausend Mark brauchen würden, wenn der Oberbürgermeister kapitulierte, um sie für dringende Unterstützungsnotfälle und für die Löhne der streikenden Eisenbahner zu verwenden. Nach zwei Stunden sandte ich meinen Vater und den früheren Stadtverordnetenvorsteher Krug mit zehn Mann ins Rathaus, um von Dr. Rothe noch einmal die Öffnung der Zahlstellen und die Unterzeichnung einer Anweisung zu fordern und ihn im Weigerungsfalle zu verhaften und zunächst zum Arbeiterrat zu bringen. Die Matrosenkompagnie erhielt Anweisung, seine Internierung im Obdachlosenasyl vorzubereiten. Der Oberbürgermeister kapitulierte. Er gab die gewünschte Anweisung, die Zahlstellen wurden stillschweigend geöffnet, die Gegenaktion war zu Ende. Wir verwandten die städtischen Gelder in erster Linie für die Entlohnung der Eisenbahner. Von dem dafür vorgesehenen Geld unterschlugen zwei Boten einhunderttausend Mark und flüchteten. Sie wurden am anderen Morgen in Halle verhaftet und der größte Teil des Geldes zu- 
rückgebracht. Über die Verwendung der Gelder wurde mit den städtischen Behörden abgerechnet. ${ }^{\mathbf{7 6}}$

Nach dieser Machtprobe zwischen dem Oberbürgermeister und dem Arbeiter- und Soldatenrat wuchs der $\mathrm{Ha}$ des Leipziger Bürgertums gegen mich ins Riesengroße. Die Wirksamkeit meines Ultimatums lag in den sozialen Vorurteilen der Bürger von damals und vor allem des sehr bürgerstolzen Oberbürgermeisters selbst begründet. Verhaftung wäre nichts gewesen - aber Internierung im Obdachlosenasyl bei den Allerelendsten und Deklassiertesten wurde von ihm als die schlimmste und entehrendste Degradierung angesehen, die ihm geschehen konnte.

Ich will hier eine merkwürdige verspätete Sequenz dieser Geschichte vom 4. März 1919 erwähnen. Der Oberbürgermeister Dr. Rothe zeigte Rückgrat nicht nur dem Arbeiterrat von 1919, sondern auch den Nationalsozialisten von 1933 gegenüber. Als ich in Prag in der Emigration den „Neuen Vorwärts" leitete, erhielt ich eine Nachricht, daß Dr. Rothe sich geweigert habe, die Hakenkreuzflagge auf dem Rathausturm aufziehen zu lassen, und daß er deswegen von den Nationalsozialisten verhaftet und im Leipziger Obdachlosenasyl interniert worden sei. Das gab mir $7 u$ denken. ${ }^{77}$

Da ich in diesen kritischen Tagen in Leipzig bleiben mußte, konnte ich nicht an der März-Parteikonferenz der USPD teilnehmen, die vom 2. bis 6. März in Berlin tagte. Diese Konferenz stand völlig unter dem Eindruck des Generalstreiks und der schweren Straßenkämpfe in Berlin. Sie erklärte sich programmatisch für Mitarbeit in den Parlamenten, aber auch für das Rätesystem und die Diktatur der Arbeiterklasse. ${ }^{78}$ Im Laufe des Jahres wurde es strittig zwischen den beiden Parteirichtungen, ob das Bekenntnis zur Diktatur des Proletariats ein Zukunftsziel oder eine Richtlinie für die Gegenwartspolitik darstellte. In der Sozialisierungsfrage jedoch gab es keine Richtungsunterschiede, die Partei stellte sich hinter den mitteldeutschen wie den Berliner Streik für die Sozialisierung. Die ausgesprochen revolutionäre Haltung dieser Streiks wurde von Rudolf Hilferding in der "Freiheit“ mit folgenden Sätzen unterstützt: „Neue revolutionäre Gärung hat die deutsche Arbeiterklasse erfaßt. Als

${ }^{76}$ In einem 1947 verfaßten „Bericht über die politisch wichtigen Vorgänge in der Stadt Leipzig während der Zeit von 1918 bis 1933" (Archiv des IfZ) schreibt der damalige Oberbürgermeister Rothe: „.. am 5.3.19 hatte der Arb. und Sold.R., dem durch den Streik das Geld ausgegangen war, durch seine von bewaffneten Soldaten mit geladenen Gewehren begleiteten Beauftragten Geyer und Scheib mich gezwungen, ihnen aus städtischen Mitteln $400000 \mathrm{M}$ zu zahlen, was nachträglich von den städtischen Stellen gebilligt wurde." - Jacob Krug und Johann Scheib, die zusammen mit Friedrich Geyer die Forderungen des Arbeiter- und Soldatenrats präsentiert und eine Anweisung über 374.500 RM erhalten hatten, mußten sich wegen „räuberischer Erpressung“" vom 8.-12. Juli 1919 vor Gericht verantworten. Sie wurden wegen gemeinschaftlicher Nötigung zu je 4 Monaten Gefängnis verurteilt. Vater und Sohn Gcyer waren durch Immunität geschützt. Vgl. LVZ v. 14. 7.1919 und Horst Beutel, a. a. O., S. 406.

77 Geyer verwechselt hier den 1930 aus dem Amt geschiedenen Dr. Rothe mit dessen Nachfolger Goerdeler, der sich geweigert hatte, die Hakenkreuzflagge zu hissen, solange sie nicht als Reichsflagge deklariert worden war. Ins Obdachlosenasyl mußte Goerdeler deshalb aber nicht. Vgl. Gerhard Ritter, Carl Goerdeler und die deutsche Widerstandsbewegung, München (dtv) 1964, S. 69.

78 Vgl. Unabhängige Sozialdemokratische Partei Deutschlands, Protokoll über die Verhandlungen des außerordentlichen Parteitages vom 2. bis 6. März 1919 in Berlin (Reprint Glashütten im Taunus 1975). - S. a. Hartfrid Krause, USPD. Zur Geschichte der Unabhängigen Sozialdemokratischen Partei Deutschlands, Frankfurt a. M. 1975, S. 124. 
Vorbereiterin und Trägerin der Revolution hat die Partei ihre geschichtliche Sendung erfüllt, als Fortführerin der Revolution muß sie sie beenden."70

Die Kämpfe in Berlin und damit auch der mitteldeutsche Generalstreik wurden nicht durch eine Niederlage der Bewegung, sondern durch Verhandlungen beendet. Die sozialdemokratische Fraktion der Nationalversammlung rebellierte gegen die negative Verzögerungspolitik ihrer eigenen Regierung, die Sozialdemokratische Partei war in der Berliner Streikleitung vertreten. In der Reichsregierung selber verlangte der sozialdemokratische Wirtschaftsminister Wissell, ${ }^{80}$ daß ein Rahmengesetz für Sozialisierung und Planwirtschaft sofort verabschiedet werde. An allen Mauern Berlins erschienen während der Kämpfe riesige Plakate mit der Inschrift: „Die Sozialisierung marschiert, sie ist schon da." Eine Abordnung der Streikenden verhandelte in Weimar mit der Reichsregierung, die sofortige Vorlage eines Sozialisierungsgesetzes und Verankerung des Rätesystems in der Verfassung versprach. Am 7. und 8. März legte Wirtschaftsminister Wissell ein Kohlewirtschaftsgesetz und ein Rahmengesetz über die Sozialisierung und über die Planwirtschaft vor, das trotz bürgerlicher Proteste am 13. März von der Nationalversammlung angenommen wurde. ${ }^{\mathbf{8 1}}$ Die bürgerliche Mehrheit der Nationalversammlung war von dieser neuen revolutionären Welle und der Wucht des Streiks so erschüttert, daß sie nicht wagte, die Existenzfrage für die Nationalversammlung durch eine Ablehnung dieser Gesetze aufzuwerfen.

Ich selbst erblickte in Wissells Gesetzen lediglich ein Versprechen für die Zukunft, obgleich ich von Wissells gutem Willen und der Ehrlichkeit seines Willens zu Planwirtschaft und Sozialismus überzeugt war. Sein Plan stand auf dem Hintergrunde der Planwirtschaft im Ersten Weltkrieg. Sein Staatssekretär war der Ingenieur Wichard von Moellendorf, ${ }^{82}$ der mit Rathenau ${ }^{83}$ gemeinsam die Anfänge der Kriegsplanwirtschaft organisiert hatte. In den „Kriegsgesellschaften“, die während des Krieges die Träger der Planwirtschaft waren, hatte eine ganze Reihe von sozialdemokratischen und unabhängigen akademisch gebildeten Volkswirtschaftlern gearbeitet. Es bestand für die Sozialisierungsforderung also eine planwirtschaftliche Tradition. Bereits auf ihrem Parteitag in Würzburg im Jahre 1917 hatte die Sozialdemokratische Partei programmatisch den Übergang zum Sozialismus durch den Ausbau der Kriegsgesellschaften ins Auge gefaßt, aber das System, das sie vorschlug, war ein gemischtwirtschaftliches System. In der "Sozialisierungskommission“, die von der Regierung der Volksbeauftragten eingesetzt worden war, kam kein geschlossener Plan zustande. ${ }^{84}$ Keiner der führenden Marxisten in dieser Kommission legte einen

79 „Freiheit" Nr. 110 v. 2.3. 1919: „Der Parteitag“.

80 Rudolf Wissell (1869-1962), Maschinenbauer, 1888 SPD-Mitglied, 1908-1918 Mitglied der Generalkommission der Gewerkschaften, Dez. 1918 im Rat der Volksbeauftragten, 1919-1933 MdR, Febr.-Juli 1919 Reichswirtschaftsminister, 1928-1930 Reichsarbeitsminister.

81 Nationalversammlung, 7. und 8.3.1919, Sten. Ber. S. 541 ff., und 12. und 13.3.1919, Sten. Ber. S. $697 \mathrm{ff}$.

82 Wichard von Moellendorff (1881-1937), ehemals leitender Ingenieur bei der AEG, im Ersten Weltkrieg in der Kriegsrohstoffabteilung tätig, Professor in Hannover, ab 20. Nov. 1918 vorläufiger UStSekretär im Reichswirtschaftsamt, am 9. Dez. 1918 im Amt bestätigt.

83 Walther Rathenau (1867-1922), seit 1899 im Vorstand, seit 1915 Präsident der AEG, 1914 bis 1915 Leiter der Kriegsrohstoff-Abteilung im preuß. Kriegsministerium, 1920 Mitglied der Sozialisierungskommission, Teilnahme an dex Konferenz in Spa, 1921 Reichsminister für Wiederaufbau, 1922 Reichsaußenminister, 1922 ermordet.

84 Vgl. Anm. 63 . 
wirklichen Sozialisierungsplan vor. Das nichtaktivistische, nichtvoluntaristische Wesen des Austromarxismus, der intellektuell die Führung des Zentrums der Arbeiterbewegung beherrschte, kam in diesem Versagen zum Ausdruck. Der einzig wirkliche offizielle Plan, ausgearbeitet von Moellendorff und von Reichsminister Wissell vertreten, folgte im allgemeinen den Zügen von Rathenaus Kriegswirtschaftsplänen, die über das Maß der Kriegswirtschaftsplanung, wie sie nach seinem Rücktritt ins Leben trat, wesentlich hinausgingen. Dieser Plan wurde unter dem Titel „Aufbau der Gemeinwirtschaft" dem Reichskabinett nach den großen Märzstreiks vorgelegt. Ich will hier erwähnen, daß Moellendorff im Jahre 1932 den ins Meer der Vergessenheit versunkenen Plan unter dem Titel "Konservativer Sozialismus" neu veröffentlichte. ${ }^{85}$ Wesentliche Gedankenelemente der Ideologie des „Dritten Reichs“ waren darin bereits enthalten.

Die „Verankerung des Rätesystems in der Verfassung“, welche die Reichsregierung zugestand, deutete auf ein gemischtwirtschaftliches System hin. In der Nationalversammlung schrieb der Arbeitsminister [Bauer] den von uns überall ins Leben gerufenen Betriebsräten die Rolle von arbeitsgemeinschaftlichen Organen zu. Die USPD protestierte dagegen - sie erblickte in den Betriebsräten revolutionäre Organe für die Herbeiführung eines integralen sozialistischen Systems. In der Auseinandersetzung mit der Auffassung der Regierung und in der Propaganda für ein integrales System erblickte ich im weiteren Verlauf des Jahres 1919 eine meiner Hauptaufgaben, und in diesem Sinne baute ich die Ideologie der Führungsgruppe der linken USPD aus.

\section{Der Zweite Rätekongreß im April 1919}

Die Differenz der Auffassungen zwischen einem gemischtwirtschaftlichen und einem integralsozialistischen System bestimmte die Beratungen des Zweiten Rätekongresses, der vom 8. bis 14. April in Berlin tagte. Ich wurde auf diesem Rätekongreß abermals zum Vorsitzenden der USPD-Fraktion und gleichzeitig zum zweiten Vorsitzenden des Kongresses gewählt. ${ }^{86}$ Der Kongreß stand unter dem Eindruck der Versprechungen der Reichsregierung und der Absichten von Wissell und Moellendorff. ${ }^{87}$ Für mich und meine Freunde stellte er wiederum eine Gelegenheit zur Sammlung dar. Die umfassende Bildung und Organisation revolutionärer Betriebsräte als Organe einer integralen Sozialisierung wurde von mir und meinen Freunden in den Mittelpunkt unserer Aktivität gestellt, im Gegensatz zu dem Betriebsrätegesetz, das die Reichsregierung später der Nationalversammlung vorlegte. Die Beschlüsse des

85 Wichard von Moellendorff, Konservativer Sozialismus, hrsg. u. eingeleitet von Hermam Curth, Hamburg 1932. - Der Plan „Aufbau der Gemeinwirtschaft“ war unter dem Datum 7. Mai 1919 als „Denkschrift des Reichswirtschaftsministeriums zur wirtschaftspolitischen Lage" dem Reichskabinett vorgelegt worden. Abgedr. in : Akten Reichskanzlei/Kabinett Scheidemann, S. $272 \mathrm{ff}$, und bei Moellendorff, a. a. O., S. $109 \mathrm{ff}$.

86 II. Kongreß der Arbeiter-, Bauern- und Soldatenräte Deutschlands am 8. bis 14. April 1919 im Herrenhaus zu Berlin. Stenogr. Protokoll. Hrsg. und verlegt vom Zentralrat, Berlin, Herrenhaus. - Den Vorsitz der USPD-Fraktion führten gemeinsam Otto Braß, Gurt Geyer und Kurt Rosenfeld (vgl. LVZ v. 9.4.1919). Vorsitzender des II. Rätekongresses war Richard Hauschildt (SPD), Stellvertreter waren Richard Müller (USPD) und Fritz Schröder (Soldatenfraktion).

87 Zentrale Themen des Rätekongresses waren „Der Aufbau Deutschlands und das Rätesystem“ (Referate von Cohen und Däumig) und „Die Sozialisierung des Wirtschaftslebens“ (Referat Kautskys). 
Kongresses, der eine sozialdemokratische Mehrheit hatte, gingen in der Richtung eines gemischtwirtschaftlichen Systems und der Verankerung der Räte in der Verfassung.

Ich habe diesen Hintergrund so ausführlich geschildert, weil sich davon meine persönliche Rolle abhebt. Stärker als zuvor wurde ich in diesen Tagen der intellektuelle Führer der offen revolutionären Richtung in der USPD. Ich stellte einen Plan für die Verwirklichung eines integralen sozialistischen Systems auf, gestützt auf die Betriebsräte als Organe der Sozialisierung und die Arbeiterräte als Organe der politischen Macht einer revolutionären Regierung mit einem Zentralrat der Arbeiterräte, einem Rätekongreß und einem Obersten Volkswirtschaftsrat. Ich vertrat diesen Plan in vielen Versammlungen vor Betriebsräten und Gewerkschaftsfunktionären in ganz Deutschland. Er wurde unter dem Titel „Sozialismus und Rätesystem“88 veröffentlicht und wurde zur Grundlage für die Sammlung der revolutionären Betriebsräte, die schließlich zur Organisation der „Reichszentrale der revolutionären Betriebsräte Deutschlands" 89 führte. Er bildete aber auch die Grundlage für den parlamentarischen Kampf der USPD-Fraktion der Nationalversammlung gegen das von der Reichsregierung vorgelegte Betriebsrätegesetz. Dieser Kampf wurde im Ausschuß und im Plenum der Nationalversammlung in der Hauptsache von den jüngeren Abgeordneten der Linken geführt, von Bernhard Düwell, ${ }^{90}$ Wilhelm Koenen ${ }^{91}$ und mir, wobei ich der Wortführer in Ausschuß und Plenum war. Abgesehen von Einzelheiten ging es zwischen der Regierung und uns um die Frage, ob die Betriebsräte nur ein Recht der Mitbestimmung oder den entscheidenden Einfluß in der Leitung der Betriebe haben sollten. Der Regierungsentwurf sah ein ziemlich weitgehendes Mitbestimmungsrecht der Betriebsräte vor, aber wir forderten den entscheidenden Einfluß, der eine Einschränkung nur durch übergeordnete Weisungen eines Obersten Volkswirtschaftsrates erfahren sollte. ${ }^{02}$ Das ganze System, so wie ich es skizzierte, stellte neben die Organisation der Arbeiterräte, die in der Regierung als Organ der Macht der Arbeiterklasse gipfelte, eine Organisation der Betriebsräte nach Bezirken, aufsteigend in Industriegruppen bis zu einem zentralen Volkswirtschaftsrat. In diesem zentralen Volkswirtschaftsrat erblickte ich die Krönung des ganzen Systems, bei ihm sollte die gesamte Statistik über die Gesamtheit der Produktion zusammenlaufen. Es war der Traum eines Statistikers für die vollständige und

88 Vgl. Verzeichnis der Schriften Curt Geyers im Anhang.

89 Die „Zentrale der Betriebsräte Deutschlands“, von Delegierten regionaler Betriebsrätezusammenschlüsse am 27. Juli 1919 in Halle gegründet, blieb ein Provisorium. Die Betriebsrätezentrale kämpfte zusammen mit USPD und KPD gegen das Betriebsrätegesetz; sie geriet zunehmend in Gegensatz zu den Gewerkschaften. Vgl. Peter von Oertzen, Betriebsräte in der Novemberrevolution, Düsseldorf 1963, S. 96 und $152 \mathrm{f}$.

"0 Bernhard Düwell (1891- ), Kaufmann, Okt. 1918 - Sept. 1919 Redakteur des „Volksboten“ in Zeitz, dann Redakteur des "Unabhängigen Sozialdemokratischen Zeitungsdienstes" in Berlin, 1919-1924 MdR. Vgl. S. 213.

91 Wilhelm Koenen (1886-1963), 1904 Mitglied dex SPD, 1911-1919 Redakteur am „Volksblatt" in Halle, 1917 USPD, 1919-1932 MdR (USPD/KPD), 1919 ZK-Mitglied der USPD, 1920 und 1923 Mitglied der Zentrale der VKPD, 1929 ZK-Mitglied der KPD, 1933 Emigration über CSR und Frankreich nach England, 1945 Rückkehr nach Deutschland, 1946-1949 1. Landesvorsitzender der SED in Sachsen und Mitglied des ZK der SED.

92 Am 21. Juli 1919 stand die „Verankerung der Räte in der Verfassung“ in der Nationalversammlung zur Debatte (Sten. Ber. S. $1748 \mathrm{ff}$.). Der Entwurf des Betriebsrätegesetzes wurde am 21. 8. 1919 eingebracht und in zweiter Lesung im Januar 1920 behandelt (vgl. 3. Kapitel, S. $163 \mathrm{f}$.). 
rationale Erfassung des gesamten wirtschaftlichen Lebens der Nation. Der Plan schloß übrigens alles das ein, was in späteren Jahren unter dem Namen Typisierung und Rationalisierung der Wirtschaft unter Führung der großen Kartelle und Trusts durchgeführt wurde.

Es war gewissermaßen eine Systematisierung aller Elemente unserer revolutionären Illusion. Es war ein Kampfplan und ein Plan für umfassende Propaganda, um die Arbeiterschaft dafür zu gewinnen. Ich war mir völlig im klaren darüber, daß die unserer Führung folgenden radikalen Arbeitermassen in den großen Industriegebieten weder eine Mehrheit des Volkes noch eine Mehrheit der Arbeiterklasse im weitesten Sinne des Wortes darstellten. Dies führte mich einerseits zu einer noch radikaleren Weiterbildung der marxistischen Klassenkampftheorie, andererseits zu verstärkten propagandistischen Anstrengungen. In diesen Tagen nach dem Zweiten Rätekongreß veröffentlichte ich in der "Leipziger Volkszeitung" einen Artikel „Die Diktatur der Minderheit", der den Gedanken vertrat, daß die Minderheit der Arbeiterklasse die Regierungsgewalt ergreifen und diktatorisch ausüben müßte, um durch ihre Herrschaft die Zustimmung der Mehrheit allmählich zu erhalten.

Dieser Aufsehen erregende Artikel brachte mich in Konflikt mit dem rechten Flügel der Partei und der Leipziger Parteileitung. Der Artikel vertrat Anschauungen, die in den Mittelpunkt des inneren Kampfes zwischen der Linken und der Rechten in der USPD gerieten, der schließlich zum Siege der Ansichten der Linken im Geiste der Diktatur der Minderheit auf dem Dezemberparteitag der Partei führten. Der Artikel erhielt aber auch die Zustimmung Lenins, der ihn in der Zeitschrift „Die kommunistische Internationale" nachdrucken ließ und mit einer zustimmenden Erklärung versah. ${ }^{93}$ Meine näheren Freunde billigten, daß endlich offen ausgesprochen wurde, was wir für nötig hielten. Von meinem Freunde Wilhelm Herzog, der in Berlin seine Zeitung „Die Republik" 94 herausgab, erhielt ich ein Buch Romain Rollands mit der Widmung : „Curt Geyer für seine mutige Tat." Diese Wertung entsprach nicht ganz meiner eigenen Beurteilung meines Vorstoßes, aber es war ein charakteristischer Ausdruck seiner enthusiastischen Auffassung des politischen Geschehens. Er und ich waren allmählich engere Freunde geworden. Wir beide erkannten genau die Gefahr einer Wiedererstarkung des deutschen Militarismus mit reaktionärem Vorzeichen. Das meiste, was er schrieb, galt dem Kampf dagegen. Er hatte einen unheimlich scharfen Blick für die Beschränktheit der Führer der Regierung und ihrer Parteien, aber auch einiger unserer eigenen Führer. Der Intellektuelle und Literat in ihm verglich die Größe der politischen Problematik mit der Kleinheit des Geschlechtes der deutschen Politiker. Der Stil und die Rhetorik führender französischer Politiker lagen ihm viel näher. Eines Tages, als er mich in Weimar besuchte und sich über den Stil und die Haltung der Nationalversammlungspolitiker wütend geärgert hatte,

93 Geyer irrt im Datum: Der Artikel erschien unter dem Titel „Zur Reichskonferenz" am 6. 9. 1919 in der LVZ. Unter der Uberschrift „Die Diktatur der Minderheit" folgte am 8.9.1919 in der LVZ eine scharfe Entgegnung aus der Feder Hermann Liebmanns (vgl. dazu 3. Kapitel, Anm.32). Geyers Artikel wurde unter dem Titel „Die unabhängige Sozialdemokratie Deutschlands und die Diktatur des Proletariats" nachgedruckt in: Die kommunistische Internationale (Moskau/Petrograd) Nr.7/8, Nov./Dez.1919, S. 58-63 (Wiederabdruck auch in: Protokolle der Parteitage der Unabhängigen Sozialdemokratischen Partei Deutschlands, Bd. 1, Glashütten 1975, S. 65-71).

94 „Die Republik", gegründet am 3.12.1918 von W. Herzog, ab Ende Mai 1919 mit dem Untertitel „Tageszeitung der Deutschen Arbeiterräte“ von Herzog und E. Däumig gemeinsam geleitet, am 24.6. 1919 verboten. 
sagte er zu mir: "Sagen Sie, Geyer, kann man denn aus dieser Nation von Boches nicht austreten?"

Aber meine Theorie von der Diktatur der Minderheit erfuhr zur gleichen Zeit indirekten Widerspruch von dem Führer der Kommunistischen Partei, Paul Levi. Anna kannte ihn von der gemeinsamen Opposition gegen die Mehrheitssozialisten in Frankfurt her, er und ich waren im Laufe der letzten Monate mehrfach zusammengekommen. Während des Zweiten Rätekongresses wurde ich von führenden Kommunisten darauf angesprochen, ob das Wiedererscheinen ihrer verbotenen Zeitung, der „Roten Fahne", in Leipzig möglich sein würde. Nach einigen Überlegungen und Fühlungnahmen sagte ich ihnen zu, daß der Leipziger Arbeiterrat das Erscheinen des Blattes unter seinen Schutz stellen würde. Die „Rote Fahne" konnte in Leipzig vom 11. April bis zum 9. Mai erscheinen, obgleich die sächsische Landesregierung im Auftrage der Reichsregierung mehrfach die Unterdrückung des Blattes durch ihre Organe versuchte, die sich jedoch gegen den Leipziger Arbeiterrat nicht durchsetzen konnten. Dieser Schutz des kommunistischen Organs hat übrigens das Ende des Leipziger Arbeiterrats beschleunigt.

In der in Leipzig erscheinenden "Roten Fahne" veröffentlichte Levi mehrere richtungsweisende Artikel für die Politik der Kommunistischen Partei. Ihr Inhalt ist am besten bezeichnet durch die Überschrift des wichtigsten dieser Artikel „Im Gleichschritt mit den Massen“. Streng logisch genommen hätte die politische Konsequenz seiner Ansichten die Aufgabe der selbständigen Existenz seiner Partei wie der USPD und die Wiedervereinigung mit der Sozialdemokratie sein müssen, in einer großen Sammlungspartei, in der die Kommunisten nicht als Partei, sondern auf Grund ihrer Einsichten die Rolle spielen könnten, die das Kommunistische Manifest von Marx und Engels ihnen zuwies. Tatsächlich führte der Weg, den er mit diesen Artikeln einschlug, schließlich zu diesem Ziel, und ich ging ihn mit ihm gemeinsam.

Aber zunächst sprang der Unterschied zwischen meinem Ruf nach der Diktatur der Minderheit und seinen Artikeln über die Notwendigkeit, sich dem Gleichschritt der Massen anzugleichen, in die Augen. Die Leipziger Parteileitung benutzte diese Tatsache in der immer stärker werdenden Propaganda, die sie in der Leipziger Arbeiterschaft gegen meine politischen Ansichten und gegen meine Politik als Vorsitzender des Leipziger Arbeiterrates führte. Sie war dabei übrigens nicht konsequent; denn als ich in dem neu gewählten Arbeiterrat der kleinen mehrheitssozialistischen Minderheit des Arbeiterrates proportional Sitz und Stimme im Ausschuß anbot, um seine Basis zu verbreitern, seine Autorität in der Gesamtarbeiterschaft zu verstärken und sein Leben zu verlängern - rechnete mir die Parteileitung in ihrer Propaganda diesen Schritt als eine "rechte Abweichung" an und benutzte ihn zu der Behauptung, ich hätte gegen die Interessen der Partei gehandelt und wüßte nicht, was ich wollte.

Die wirklichen Konsequenzen von Paul Levis Haltung lagen noch im Schatten der Zukunft. Er besuchte mich mehrfach in meiner Leipziger Wohnung, und die Gespräche, die wir miteinander hatten, führten zu einem persönlichen Bündnis. Es war klar, daß er die Entwicklung zunächst bis vor die Gründung der Kommunistischen Partei zurückführen und die Kommunisten wieder in die USPD bringen wollte. Der Weg dazu schien ihm und mir über den Eintritt der USPD in die Kommunistische Internationale zu liegen, die in der USPD allmählich in den Vordergrund der inneren Auseinandersetzungen geriet.

Der Leipziger Arbeiterrat behauptete nach wie vor seine Position, aber er stellte 
immer stärker eine Anomalie im Reiche wie in Sachsen dar. Es war nicht gerade eine Räterepublik Leipzig, aber der Anspruch auf Kontrolle der städtischen Verwaltung wurde aufrechterhalten, obwohl sie sichtlich immer stärker auf die demokratisch gewählte neue Stadtverordnetenversammlung überging. Unter meinem Einfluß behauptete der Arbeiterrat die Position durch Drohungen, so unter anderem durch die Drohung, die Leipziger Messe durch einen Generalstreik zu stören. Ab und zu sah ich mich veranlaßt, Schritte außerhalb der immer deutlicher hervortretenden Normalität zu ergreifen. Hier ist ein Beispiel: Außerhalb der Stadt lag eine Flugzeugfabrik. Der Gitterzaun des Fabrikgeländes wurde von unseren Wachen bewacht, um dunkle Transaktionen zu verhindern. Diese Wachen wurden eines Nachts vom Hauptgebäude der Fabrik aus beschossen. Diesen Fall überließen wir nicht der Polizei, sondern beschlossen, den im Hauptgebäude der Fabrik wohnenden Direktor zu verhaften. Ich fuhr mit einer Wache nach der Fabrik, aber der Direktor war in die Stadt gefahren. Ich fuhr ihm nach, verhaftete ihn persönlich im Zimmer seines Bankmanagers und setzte ihn im Quartier der Matrosenkompagnie in Schutzhaft. Der Polizeidirektor erhob bei mir Vorstellungen, schließlich erklärte ich mich damit einverstanden, daß der Verhaftete im Polizeigefängnis interniert wurde. Die Untersuchung über die Schießerei versandete.

Auch in einem anderen Falle sah ich mich zum Einschreiten veranlaßt. Auf Anforderung der Staatsanwaltschaft Königsberg verhaftete die Leipziger Polizei einen Russen namens Marmorstein, der von Ostpreußen aus wegen kommunistischer Agitation in Gefangenenlagern - also bei russischen Kriegsgefangenen - steckbrieflich verfolgt wurde. Die Haltung der Staatsanwaltschaft Königsberg entsprach durchaus den ostpreußischen Zuständen, die dann während des Kapp-Putsches so deutlich enthüllt wurden. Der Leipziger Arbeiterrat wäre sich lächerlich vorgekommen, wenn er einen so offenkundigen Akt gegenrevolutionärer Machenschaften gedeckt hätte. Wir beschlossen, den Mann herauszuholen. Ich forderte den Polizeidirektor auf, ihn hexauszugeben. Er kam mit legalistischen Argumenten, die ich ablehnte, und er zog sich schließlich darauf zurück, daß er ohne Anweisung des Oberbürgermeisters nichts tun könnte. Ich drohte ihm mit der Gewalt des Arbeiterrats und er meinte: „Ja, wenn ich mich wirklicher Gewalt gegenüber sähe . . " Ich ging weg und lieferte ihm den Beweis, ich versammelte einige tausend Mann vor der Polizeidirektion. Unter Protest gab er nach, ich holte den Mann persönlich aus der Polizeizelle ab. Er wußte zunächst nicht, wie ihm geschah. Ich brachte ihn in meine Wohnung, wo er übernachten konnte. Am anderen Morgen zeigte ich ihm vom Balkon aus den Weg zu einer Eisenbahnstation der Linie Leipzig - Chemnitz und gab ihm einiges Geld und einen Einführungsbrief an den kommunistischen Vorsitzenden des Arbeiterrats Chemnitz, Heinrich Brandler. Diesen Mann habe ich zwei Jahre später in Moskau als Divisionsgeneral der Roten Armee wiedergesehen.

\section{Der Einmarsch General Maerckers in Leipzig}

Die Auflösung des Arbeiter- und Soldatenrats

Aber im allgemeinen war ich mir über die schwindende Macht des Arbeiterrats völlig im klaren. Die Reichsregierung setzte ihren Feldzug zur Auflösung der Arbeiterräte in den radikalen Städten mit Maerckers Truppen fort. Mitte April besetzte General Maercker Braunschweig. Ich konnte voraussehen, daß zum Schluß wir an 
die Reihe kommen würden; denn ich machte mir keine Illusionen darüber, daß die sächsische Landesregierung uns noch decken würde, dazu hatten wir ihr viel zu große Verlegenheiten bereitet. Damit entstand die Frage: kämpfen oder widerstandsloses Ende. Objektiv und subjektiv wären wir in der Lage gewesen, eine schwere Straßenschlacht in Leipzig zu liefern, ähnlich den Märzkämpfen in Berlin, wobei von beiden Seiten Artillerie eingesetzt werden würde. Aber ich wußte nicht nur, daß dieser Kampf keine Aussicht auf Sieg hatte, sondern ich hatte mir inzwischen auf Grund meiner Erfahrungen Vorstellungen über die wirkliche Machtlage gebildet. Sie gingen dahin, daß unsere Stärke an diesem Zeitpunkt - und sie wuchs von Tag zu Tag weiter - nicht in militärischen Aktionen lag. In einer Reihe von radikalen Städten hatten sich zunächst die Arbeiterräte behauptet und zum Teil Landesregierungen gebildet. Eine nach der anderen wurden diese radikalen Städte von der neuen Militärmacht der Reichsregierung unterworfen, die in jeder dieser Städte mit überlegener Macht auftreten konnte. Wenn ein Bündnis dieser radikalen Städte zur Vereinigung ihrer militärischen Kampfkraft möglich gewesen wäre, hätte die Partie ganz anders gestanden. In jeder dieser Städte und so auch in Leipzig war es möglich, eine Arbeiterbewaffnung in größerem Umfange vorzunehmen und sich dabei auf zurückgekehrte Frontsoldaten zu stïtzen. Aber solche Formationen hatten nur lokale Bedeutung, und sie waren nicht feldfähig. Die Leute wollten nachts zuhause schlafen, und ihre Verpflegung war ein weiteres Problem. Sie in Marsch zu setzen, um in einer anderen Stadt zu kämpfen, war völlig unmöglich.

Die Führung der Leipziger Matrosenkompagnie legte mir eines Tages einen Plan vor, um die Reichsregierung zu stürzen. Bewaffnete Arbeiter aus Leipzig und Mitteldeutschland sollten unter Führung der Matrosenkompagnie den Kordon der Regierungstruppen um Weimar durchbrechen, Weimar besetzen, die Reichsregierung verhaften und die Nationalversammlung auflösen. Ich kannte die Absperrung Weimars und die Stärke oder besser Schwäche dieser Regierungstruppen, die mit relativ geringen Kräften hätten überwältigt werden können. Aber ich wußte, daß nicht alle Voraussetzungen für eine solche Expedition auf unserer Seite gegeben waren. Außerdem fragte ich mich: und was kommt dann? So wie sich inzwischen die Machtverhältnisse im Reiche gestaltet hatten, wäre das eine sinnlose Aktion gewesen.

Ich dachte über die Änderung der Machtverhältnisse nach, als ich eines Abends im Parlamentszug von Weimar nach Leipzig fuhr. Einige Abteile von mir entfernt saßen Reichswehrminister Noske ${ }^{85}$ und sein Adjutant von Gilsa im Zuge. Am Tage vorher hatten mein Freund Otto $\mathrm{Bra}^{36}$ und ich eine kleine Auseinandersetzung mit Noske im Wandelgang der Nationalversammlung gehabt. Noske kam an uns vorüber, als wir an einem Fenster stehend uns unterhielten, er blieb stehen und sagte ganz freundschaftlich zu uns: „Na, Ihr beiden, gebt nur acht, daß Ihr nicht in meine Hände fallt." Ich hielt es für unter meiner Würde zu antworten, aber Braß, der Rheinländer, fiel sofort mit den schärfsten Worten über ihn her, bis der Adjutant

95 Gustav Noske (1868-1946), 1886 Mitglied der SPD, 1902-1918 Redakteur der „Volksstimme“ Chemnitz, 1906-1918 u. 1919-1920 MdR, Nov. 1918 Gouverneur in Kiel zur Niederhaltung der Matrosenrevolte, Dezember 1918 Volksheauftragter, Jan. 1919 Oberbefehlshaber der Regierungstruppen und Freikorps in Berlin, 1919-1920 Reichswehrminister, 1920-1933 Oberpräsident der preuß. Provinz Hannover.

96 Otto Braß (1875-1950), Feilenhauer, 1905-1917 Geschäftsführer der „Remscheider Arbeiterzeitung“, 1917-1920 der „Bergischen Volksstimme" (Solingen), 1919-1924 MdR, 1920 Mitglied der Zentrale der VKPD, 1922 Ausschluß aus der KPD, über KAG Rückkehr zur SPD, 1936 bis 1945 inhaftiert, nach 1945 SED-Mitglied und Vorsitzender des FDGB. 
Noske fortzog. Nun saßen die beiden im Zug, sie würden in Leipzig nach Dresden umsteigen, und ich überlegte: An der Sperre in Leipzig stehen meine Wachen, wenn ich ihnen sagte: „Das ist Noske, verhaften Sie diese beiden!“ so werden sie das mit Wonne tun bei dem Ruf, den Noske bei uns hatte. Aber meine Überlegungen gingen weiter: Was fange ich mit ihnen an? Ich kann sie ins Wachlokal nehmen und höhnisch sagen: „Und jetzt sind Sie in meine Hände gefallen." Und dann? Dann muß ich sie entweder mit dem nächsten Zug nach Dresden weiterfahren lassen oder ich muß mobilisieren und die Stadt in Verteidigungszustand versetzen. Damit war diese Überlegung zu Ende, ich wußte, daß ich dies nicht wollte. Ich ging in Leipzig hinter beiden her, ich hatte keine Lust, Noske zu begrüßen oder anzusprechen. Sie gingen zu dem Dresdner Zug, ich durch die Sperre und nachhause. Am 16. und 17. April besetzte General Maercker Braunschweig, ${ }^{97}$ dann überflogen seine Flugzeuge Leipzig und warfen Flugblätter der Reichsregierung ab, am 11. Mai marschierte er mit zwei Divisionen in Leipzig ein. Er fand keinen Feind und keinen Widerstand und verordnete die Auflösung des Leipziger Arbeiterrates und das Verbot der „Roten Fahne“. Ein Versuch von ihm, auf den Kurs der „Leipziger Volkszeitung" einzuwirken, wurde kaltblütig abgewiesen. Die kampflose Übergabe ließ jedoch Waffen in der Hand Leipziger Arbeiter. Ich war nicht in Leipzig, sondern in Berlin zur Protestversammlung der Nationalversammlung gegen die Friedensbedingungen der Entente, die am 7. Mai veröffentlicht worden waren. Das Schicksal des Leipziger Arbeiterrats trat weit zurück hinter der sich erhebenden Krise der Reichsregierung..$^{88}$

$[\ldots]^{98}$

Sommer 1919: Nationalversammlung, Versailler Frieden, enttäuschte revolutionäre Hoffnungen

Als ich nach Weimar zur Eröffnung der Nationalversammlung fuhr, ging Anna nach Dresden zur Eröffnung der sächsischen Volkskammer. Als Glied der „Dynastie

97 Die Reichsexekution gegen Braunschweig, wo am 9. April ein Generalstreik ausgerufen worden war, wurde durchgeführt, um die Ausrufung einer Räterepublik zu verhindern. Vgl. Akten Reichskanzlei/Kabinett Scheidemann, S. 156 f.

${ }_{98}$ Rechtsgrundlage der Besetzung Leipzigs war der Belagerungszustand, der wegen der Ermordung des sächsischen Kriegsministers Neuring durch demonstrierende Kriegsinvalide am 13. 4. 1919 über ganz Sachsen verhängt worden war und bis 17. 4.1920 dauerte (RGBl. 1919, S. 429, u. 1920, S.1334). Die LVZ konnte zwischen dem 10. Mai (Nr. 105) und dem 16. Mai (Nr. 106) überhaupt nicht erscheinen, vom 16.5.-9.6.1919 stand sie unter Vorzensur. Die Auflösung des Arbeiterrats wurde am 22.5.1919 verfügt, Neuwahlen fanden am 22.6.1919 statt. Zur Einschätzung des Verhaltens von Curt Geyer im Mai 1919 durch die Gegenseite vgl. Gustav Noske, Von Kiel bis Kapp, Berlin 1920, S. 146: „Als in das Nest der Geyer, Vater und Sohn, geschaut wurde, war es leer. Sie waren nach Berlin ausgeflogen. Der jüngere ließ sich erst nach sieben Wochen, wie seine Parteigenossen wütend feststellten, wieder in der Pleißestadt sehen" und Georg Maercker, Vom Kaiserheer zur Reichswehr, Leipzig 19223, S. 235: „Kurt Geyer ist einer jener Volksverführer und Maulhelden, denen jedes Mittel, auch die Lüge in Verfolg ihrer politischen Ziele recht ist, die aber für ihre Meinung persönlich ein-zustehen nicht manns genug sind.“ ...,Herr Kurt Geyer war am 10. Mai nach Berlin gefahren. Als er dort von der Besetzung Leipzigs erfuhr, erklärte er, , sein Prestige erfordere, sofort nach Leipzig zurückzufahren'. Er fuhr aber nicht. Er war, wie manche der Arbeiterverführer, nicht der Mann, für seine Sache und für seine Uberzeugung Opfer zu bringen. Er kam erst nach 7 Wochen nach Leipzig zurück, als er die Gefahr vorüber wähnte" (ebenda, S. 243).

99 In den hier nicht abgedruckten Passagen (Ms. S. 182-184) kommt Geyer noch einmal auf die 
Geyer" und als eine der ersten weiblichen Abgeordneten rief sie einiges Aufsehen hervor. Die Scherlsche "Woche“ veröffentlichte ein großes Bild von ihr: „Frau Geyer spricht in der sächsischen Volkskammer." Die räumliche Trennung ließ eine Entfremdung, die zwischen uns eingetreten war, noch stärker hervortreten. Wenn ich irgendeinen freien Tag hatte, fuhr ich von Weimar aus nicht nach Leipzig oder Dresden, sondern nach Frankfurt. Diese Situation hat mir damals neben den politischen Erregungen viele Kopfschmerzen gemacht. Anna legte schließlich im Sommer ihr Mandat in der sächsischen Volkskammer nieder und ging nach Halle als Redakteurin am „Halleschen Volksblatt“.

[...]

In Weimar nahm ich mit meinem Vater zusammen zwei möblierte Zimmer im Inneren der Stadt. Sie waren höchst altmodisch eingerichtet, an fließendes Wasser war nicht zu denken. Wir hatten Glück, daß wir rechtzeitig gekommen waren, andere unserer Freunde fanden schließlich nur Wohnung in den Außenbezirken mit schlechter Verbindung zum Nationaltheater. Wenn wir von unserer möblierten Wohnung kommend um die Straßenecke bogen, standen wir vor dem Schillerhaus, man lebte eben in dem Museum der deutschen Klassiker. Die Abgeordneten saßen in der kleinen Stadt sehr eng aufeinander, auch in den Kaffees und den Weinhäusern, deren beliebtestes der sogenannte „Fürstenkeller“ war. Da ich die „Leipziger Volkszeitung " von Weimar aus bedienen mußte, verkehrte ich viel in den Presseräumen des Nationaltheaters und in journalistischen Kreisen; wenn nachmittags die Beratungen der Versammlung zu langweilig wurden, spielte ich in einem bestimmten Kaffeehaus Schach mit führenden Sozialdemokraten und verlor fast regelmäßig. Bei so engem Beisammenwohnen war es ganz unvermeidlich, daß die sogenannten Parlamentsehen, die keine waren, und die sich nicht nur in unserer Fraktion, sondern in allen Fraktionen anbahnten, stadtbekannt waren. Es war im ganzen eine merkwürdige Existenz. Während der strengsten Einschränkung des Eisenbahnverkehrs konnte man Weimar nur mit dem Parlamentszug Berlin-Leipzig - Frankfurt erreichen, zu Zeiten fanden strenge Kontrollen für Nichtabgeordnete am Bahnhof statt, da man Weimar nur mit Erlaubnis betreten durfte. Um die Stadt herum in weitem Umkreis standen die Truppen der Regierung, sie hielten alle Zufahrtsstraßen besetzt und unterzogen den Verkehr strengster Kontrolle.

Während dieser Monate ging der stille Machtkampf der Leipziger Parteileitung mit mir um die Führung der Parteimitglieder und die Beherrschung des Funktionärskörpers der Partei vor sich. Ich vertrat eine ausgesprochen revolutionäre Perspektive, während die meisten Mitglieder der Parteileitung, soweit sie in der Volkskammer saßen und sich auf sächsische Landespolitik konzentrierten, mit guten sachlichen Gründen sich stärker und stärker auf eine Zusammenarbeit mit den Mehrheitssozialisten hin orientierten. Aber dabei stand ihnen die programmatische Festlegung auf die Diktatur der Arbeiterklasse und erst recht meine neue Doktrin von der Diktatur der Minderheit im Wege. Um die Begriffe links und rechts zu gebrauchen: ich entwickelte mich in der Beherrschung des Arbeiterrates, in meiner Propaganda und in meinen großen mitteldeutschen Streikbündnissen weiter nach links, sie aber aus Gründen der Landespolitik weiter nach rechts. Zu der sachlichen Spannung kam die persönliche und der Altersunterschied. Der Tatbestand war, daß sie die

Verleumdungen zurück, denen er von bürgerlicher Seite, insbesondere durch einen Bericht der Frankfurter Zeitung, ausgesetzt war. Vgl. Anm. 71. 
eigentliche Führung der Partei in Leipzig immer stärker in meine Hände übergehen sahen. Die Kandidatenaufstellung für die Nationalversammlungswahl hatte gezeigt, daß ich eine entschiedene Mehrheit im Funktionärskörper der Partei besaß, und die Parteileitung befürchtete, daß diese Mehrheit noch weiter wachsen würde. Schließlich bildete sich in der Parteileitung eine Gruppe, die den Kampf gegen meinen Einfluß zu organisieren begann. An einem Sonntag, als sie erwarteten, daß ich in Weimar bleiben würde, beriefen sie in allen Parteibezirken Leipzigs Funktionärsversammlungen ein, zu denen sie ihre Redner sandten und verbreiteten in diesen Versammlungen eine regelrechte Kampfflugschrift gegen mich. Ich war aber am Abend zuvor aus Weimar zurückgekommen, und da ich sehr müde war, lag ich noch im Bett, als mein Telephon klingelte. Einer meiner Freunde rief aufgeregt ins Telephon: „Aber Curt, wo bist du denn, was machst du eigentlich?" - Ich antwortete ihm wahrheitsgemäß: „Ich bin im Bett", und dann erzählte er mir, was vorging. Ich wußte, wer die eigentliche Triebfeder dieser Gruppe war, ein Volkskammerabgeordneter, der schon vor der Revolution dem Landtag angehört hatte und als einziger mir in einer Parteiversammlung als Gegner der Rätediktatur entgegengetreten war. Ich fragte meinen Freund, in welchem Bezirk dieser Redner spräche. Blitzschnell zog ich mich an und fuhr hin. Er war mitten in seiner Rede gegen mich, als ich zur Tür hereinkam. Sein Gesicht war sehenswert, unwillkürlich fing er an zu stottern. Im Handumdrehen hatte in diesem Bezirk die Parteileitung das Spiel verloren. Nun fuhr ich von Bezirk zu Bezirk, wo meine Freunde sich mit den Rednern der Parteileitung herumschlugen. Der Handstreich, der einen Mißbilligungsbeschluß der Mehrheit des Bezirkes gegen mich herbeiführen sollte, brach völlig zusammen, als ich in den Lokalen erschien. Später wurde dieser innere Machtkampf um eine andere und wichtigere Fragestellung und mit anderen Mitteln wieder aufgenommen.

Am 7. Mai waren die Friedensbedingungen der Entente veröffentlicht worden, am 12. Mai protestierte Reichskanzler Scheidemann ${ }^{\mathbf{1 0 0}}$ in einer Kundgebung der Nationalversammlung in der Aula der Berliner Universität dagegen und legte sich in seiner Rede so fest, daß eine Unterzeichnung des Friedensvertrages durch eine von ihm geführte Regierung unmöglich wurde. Unsere Partei verfolgte diese Entwicklung mit der größten Aufmerksamkeit. Wir waren von vornherein zur Unterzeichnung des Friedensvertrages entschlossen, nicht nur, weil wir annahmen, daß die Herbeiführung des Friedens der oberste Wunsch der Mehrheit des Volkes war, sondern aus mancherlei anderen Gründen. Auf dem rechtesten Flügel der Partei wurde die Illusion genährt, daß die Entente einer Regierung, die von der wirklichen Kriegsopposition gebildet werden würde, Erleichterungen gewähren würde. Man glaubte dort an eine Interessengemeinschaft zwischen den Westmächten und den deutschen Politikern, die im Kriege den deutschen Militarismus bekämpft und diesen Kampf nach dem Kriege fortgesetzt hatten. Um nur zwei Namen zu nenen: der Abgeordnete Hugo Haase, der Vorsitzende der USPD, und Dr. Rudolf Breitscheid, der für kurze Zeit preußischer Minister gewesen war. Da im Juni 1919 die Probe aufs Exempel nicht gemacht werden konnte, wurde diese spezifische Illusion weitergetragen, bis sie später im Ruhrkampf zunächst einmal auf das Krasseste enttäuscht wurde. [...]

100 Philipp Scheidemann (1865-1939), Buchdrucker, Redakteur, 1903-1933 MdR (SPD), 1911 bis 1920 Mitglied des Parteivorstands, 1917-1918 neben Ebert Vorsitzender der SPD, Okt. 1918 Staatssekretär, 1918/19 im Rat der Volksbeauftragten, Februar-Juni 1919 Reichs-Ministerpräsident, 1920-1925 Oberbürgermeister von Kassel, 1933 Emigration nach Prag, später Kopenhagen. 
In gewissem Sinne stellte diese Illusion dieser USPD-Politiker nur einen Spezialfall der Illusionen der Regierungsmehrheit in der Nationalversammlung dar. Diese Regierungsmehrheit war, parteipolitisch gesehen, mit der Friedensresolutionsmehrheit des Reichstages vom Juli 1917, die schließlich die Regierung des Prinzen Max von Baden erzwungen und gebildet hatte, identisch. Trotz der harten Waffenstillstandsbedingungen war in dieser Mehrheit - der Weimarer Koalition aus Sozialdemokraten, Zentrum und Demokraten - und am stärksten in der Demokratischen Partei die Illusion lebendig, daß schließlich die Entente sich auf die Friedensresolution von 1917 besinnen und in Verhandlungen, in echten Verhandlungen mit der Regierung dieser Koalition einen Frieden gewähren würde, der sich dem Ideal eines Friedens ohne Annexionen und Reparationen wenigstens annäherte.

Der revolutionäre Flügel der USPD dagegen orientierte sich an den Vorbildern des Kampfes der Bolschewiki in Rußland um den Frieden. Er machte sich keine Illusionen, daß seine Regierung, noch dazu eine Diktaturregierung, wenn sie ins Leben treten sollte, größerem Wohlwollen der Entente begegnen würde als jede andere beliebige Regierung. In einer zu erwartenden Krise des Friedensschlusses erblickte er die Gelegenheit, seine Herrschaft zu errichten als Ausdruck des Friedenswillens des Volkes, wenn in dieser Krise die Macht wieder auf der Straße liegen würde, und dann wollte er die Macht gebrauchen zur Herbeiführung eines Systems des integralen Sozialismus. Dabei war es selbstverständlich, daß harte Friedensbedingungen Deutschland und Sowjetrußland enger aneinander führen würden. Seine Überlegungen schlossen die Ostorientierung der deutschen Politik in sich.

Die zweite revolutionäre Welle, die im März im Kampf um die Sozialisierung ihren Höhepunkt erreicht hatte, war von der Reichsregierung in elastischer Verteidigung aufgefangen worden mit dem Zugeständnis, gewisse sozialistische und sozialisierende Maßnahmen durchzuführen, so daß die Perspektive der Machteroberung im Kampfe um die Sozialisierung für den revolutionären Flügel der USPD zunächst in den Ifintergrund trat. Unmittelbar vor dem Versailler Diktat tagte der Sozialdemokratische Parteitag [10.-15. Juni 1919] in Berlin. Den Plänen des Reichswirtschaftsministers Wissell gemäß sprach er sich für die Sozialisierung aus und dafür, neben die politische demokratische Verfassung eine Wirtschaftsverfassung zu stellen, die sich auf die Räte stützen sollte. Auch proklamierte er die „Einheitsfront des Proletariats", wobei er sich ausdrücklich gegen die neue Lehre von der Diktatur der Minderheit aussprach. ${ }^{101}$ Wenn dieser Weg systematisch von der Sozialdemokratischen Partei fortgesetzt werden würde, so würden sich allenfalls Auseinandersetzungen um Ausma $\beta$ und Formen ergeben, aber keine ausgesprochen revolutionäre Situation, in der die USPD diktatorisch nach der Macht greifen konnte. Ganz anders aber war es, wenn kein Frieden zustande kam und die USPD mit der einfachen Parole „Wir werden den Frieden herbeiführen" nach der Macht greifen würde, selbst wenn sie dann wie Trotzki in Brest-Litowsk sich mit einem diktierten Gewaltfrieden abfinden müßte.

101 Im Mittelpunkt des SPD-Parteitags standen die Referate von Scheidemann und Bernstein zur Außenpolitik und von Hugo Sinzheimer und Max Cohen über Rätesystem und Reichsverfassung. In einer Resolution zur Parteieinigung hieß es: „Der Parteitag teilt den in vielen Anträgen zum Ausdruck gekommenen Wunsch nach der Einheitsfront des klassenbewußten Proletariats Deutschlands ... Der Parteitag lehnt das Streben nach einer nur mit den Mitteln des Terrorismus - und auch da nur für kurze Zeit - aufrechtzuerhaltenden Diktatur einer Minderheit ab." Protokoll über die Verhandlungen des Parteitages der Sozialdemokratischen Partei Deutschlands, abgehalten in Weimar vom 10. bis 15. Juni 1919, Berlin 1919, S.507. 
Solche Erwägungen waren realistischer als man aus der parteimäßigen Zusammensetzung der Nationalversammlung ablesen konnte, in der die USPD mit ihren $22 \mathrm{Ab}$ geordneten eine kleine, zahlenmäßig unbedeutende Gruppe darstellte. Wir wußten damals längst, daß unsere Partei darüber hinaus gewaltig anwuchs. Wir wußten, daß der mehrheitssozialistisch geführten Weimarer Koalition der Boden unter den Füßen schwankte, weil der Unterschied zwischen dem Kurs der Regierung und dem Willen der sozialdemokratischen Parteimitglieder immer offener hervortrat und weil die militärische Unterdrückungspolitik uns keineswegs unsere Anhänger entfremdete.

So warteten wir in größter Spannung, was nun in Weimar geschehen würde. Wenn sich die ganze Verwirrung und die Auflösung, die nun zunächst eintrat, nicht in Weimar, sondern in der Atmosphäre Berlins abgespielt hätte, wer weiß und wer kann sagen, was geschehen wäre? Denn was zunächst eintrat, war eine große politische Krise, in der wiederum mindestens stundenlang die Macht auf der Straße lag. Aber eben nicht auf der Straße in Berlin, sondern in Weimar.

Das Diktat von Versailles traf die Weimarer Koalition wie ein betäubender Schlag, alle Illusionen wurden grausam enttäuscht. Sie fühlte sich nackt und bloß gegenüber den nationalistischen Parteien der Rechten. Die Koalition zerbrach, die Reichsregierung zerbrach, das Bündnis zwischen der Reichsregierung und der Obersten Heeresleitung zerbrach gleichermaßen und damit das Vertrauen der Reichsregierung auf die Loyalität der neuen Militärmacht. Die Demokratische Partei trat aus der Reichsregierung und der Koalition aus. Von da an begann ihr unaufhaltsamer Niedergang, bis sie in den letzten Tagen der Weimarer Republik in der sogenannten Staatspartei verendete. ${ }^{102}$ Die Reichsregierung mußte auf der Grundlage einer Zweiparteienkoalition zwischen Sozialdemokraten und Zentrum neu gebildet werden. Reichskanzler Scheidemann trat zurück, ein neuer Mann mußte gefunden werden. Vor allem aber erhob sich die Frage, ob sich eine Mehrheit der Nationalversammlung für die Annahme des Friedensvertrags finden würde.

Vom 17. Juni bis zum 22. Juni morgens, an dem das Friedensultima:am ablief und die Nationalversammlung abstimmen mußte, blieb diese Frage in der Schwebe, ebenso die Frage, ob die Militärs der Regierung weiter Gefolgschaft leisten würden, wenn sie den Vertrag annahm. Nicht nur die Koalition, auch die einzelnen Fraktionen der Koalition fielen innerlich auseinander in Befürworter und Gegner der Annahme des Friedensvertrages, so daß es tagelang völlig unübersichtlich war, ob eine Annahmemehrheit zustande kommen und wie sie aussehen würde. Die Offiziere der um Weimar stehenden Truppen sowie die Führer der Freiwilligenkorps erklärten, daß sie ihre Posten niederlegen würden, falls die Reichsregierung den Vertrag annähme. Die Situationen wechselten in diesen Tagen von halber Stunde zu halber Stunde wie im Kaleidoskop. Alles erschien möglich: eine offene Meuterei der zum Schutze der Regierung und Nationalversammlung um Weimar stehenden Freiwilligentruppen, deren reaktionäre Gesinnung offenkundig war, ein von ihnen unterstützter Rechtsputsch, eine sehr schwache Annahmemehrheit nur aus Sozialdemokratie und Unabhängigen, ein Nichtzustandekommen einer Mehrheit und schließlich eine Machtergreifung durch die USPD, die allerdings nicht in Weimar vor sich gehen würde. $[. .$.

102 Durch vorübergehenden Zusammenschluß mit der „Volksnationalen Reichsvereinigung“ bzw. dem „Jungdeutschen Orden“ unter dem Namen „Deutsche Staatspartei" hatte die DDP 1930 den Wählerschwond erfolglos aufzuhalten versucht. 
Uns war klar, daß im Falle einer Ablehnung ein neues Ultimatum zu erwarten war und daß dann eine Annahmeregierung gebildet werden mußte, aber nicht in Weimar, sondern in Berlin unter völliger Beiseiteschiebung der Nationalversammlung. Der Reichspräsident war sich darüber im klaren, General Groener war sich ebenso darüber im klaren, trotz der Haltung Hindenburgs, und ebenso der Abgeordnete Erzberger ${ }^{108}$ in der Zentrumsfraktion. Ablehnung hätte die völlige Niederlage der alten Friedensresolutionsmehrheit und den Machtübergang an die Unabhängigen mit allen daraus entstehenden Konsequenzen bedeutet. Aber nach außen hin war das alles dank des dauernden Wechsels der Konstellationen in Weimar völlig undurchsichtig. Wir legten deshalb den größten Wert darauf, unsere Partei in allen Großstädten vorzubereiten. Wir hatten auf alle Fälle das Schattenkabinett, das beim Beginn der Nationalversammlung von uns organisiert worden war. Es war nötig, daß die Bevölkerung der großen Städte erfuhr, was vor sich ging. So fuhren wir zwischen dem 17. Juni und dem 21. Juni in alle Großstädte, ich selbst nach Leipzig und Frankfurt. ${ }^{104}$

In Weimar hatte sich inzwischen der Reichspräsident zur Bildung der Regierung Bauer [21. 6. 1919] gemeinsam mit dem Zentrum entschlossen, die Demokraten blieben draußen. Aber die Lage in den Fraktionen war nach wie vor kritisch. Es ging nicht nur darum, wie die einzelnen Abgeordneten stimmen, sondern auch darum, wie viele Abgeordnete sich der Verantwortung durch ihre Abreise von Weimar entziehen würden. Aus diesem Grunde stand am Weimarer Bahnhof ein doppeltes Auffangnetz, nämlich erstens die Polizei, die nur Abgeordnete und Personen mit Spezialausweisen zuließ und zweitens die Vertrauensmänner der Regierung, die jeden ankommenden oder abreisenden Abgeordneten registrierten und nach Möglichkeit nach seiner Haltung befragten. Am 21. abends verbreitete sich das Gerücht, daß eine Mehrheit gesichert sei, am 22. morgens war die neue Regierung überzeugt, daß die Mehheit für die Annahme größer sein werde als sie zunächst geglaubt hatte. Die Regierung hätte die zur Annahme nötigen Stimmen auch ohne unsere Stimmen aufgebracht - aber natürlich ist es eine Frage, wie es ausgesehen haben würde, wenn wir dagegen gestimmt oder an der Abstimmung nicht teilgenommen hätten. Die erwartete Situation, die uns an die Macht getragen hätte, war nicht eingetreten. Wir sollten bald erkennen, worum es bei den außerordentlich schweren Verhandlungen

103 Matthias Erzberger (1875-1921), Volksschullehrer, 1903-1921 MdR (Zentrum), 1918 Chef der Waffenstillstandskommission, Febr. - Juni 1919 Reichsminister o. P., Juni 1919 - März 1920 Reichsfinanzminister, 1921 Opfer eines Attentats rechtsradikaler Offiziere. Vgl. Klaus Epstein, Matthias Erzberger und das Dilemma der deutschen Demokratie, Berlin 1962; Theodor Eschenburg, Matthias Erzberger, München 1973.

104 Die Parteileitung der USPD veröffentlichte am 18. Juni 1919 einen Aufruf „An das arbeitende Volls", in dem unter Protest gegen die Friedensbedingungen der Alliierten und unter heftigen Angriffen auf die Reichsregierung die Anmahme des Ultimatums als unumgänglich bezeichnet wurde. „Getreu unseren sozialistischen und internationalen Grundsätzen legen wir im Verein mit den Sozialisten aller Länder gegen diese Vergewaltigung schärfsten Protest ein.“ . ., „Das arbeitende Volk darf sich über diese furchtbare Situation nicht täuschen lassen durch das nationalistische Geschrei der kapitalistisch-militaristischen Kreise und der unter ihrem Diktat stehenden ohnmächtigen Reichsregierung. Es darf sich nicht aufputschen lassen zu abenteuerlichen Aktionen gegen die Entente.“ . . ,Wir vertrauen auf den siegreichen Vormarsch der Arbeiterklasse und wissen, daß die fortschreitende proletarische Revolution den Vertrag von Versailles vernichten wird, wie sie die Verträge von Brest und Bulsarest beseitigt hat .. ." Freiheit, Nr. 282 v. 18. Juni 1919; unter der Uberschrift „An das Proletariat" auch in der LVZ v. 18. 6. 1919 (Dokumente u. Materialien Bd. VII, 1, S. 106-108). 
der beiden Koalitionspartner um die Neubildung der Reichsregierung gegangen war und daß wir dabei wieder verloren hatten, was wir geglaubt hatten, in der zweiten revolutionären Welle gewonnen zu haben. Am 8. Juli legte Erzberger der Nationalversammlung seinen großen Plan einer Reichsfinanzreform vor. Am gleichen Tage beriet das Reichskabinett über den nunmehr vorliegenden und vollendeten Gesamtplan des Reichswirtschaftsministers Wissell und seines Staatssekretärs von Moellendorff für Sozialisierung und Planwirtschaft. Das Reichskabinett lehnte den Plan ab. Der Reichswirtschaftsminister Wissell trat zurück und wurde durch den bisherigen Reichsernährungsminister Robert Schmidt ${ }^{105}$ ersetzt - einen Reichswirtschaftsminister zur Verhinderung jeder wirklichen Reichswirtschaftspolitik. Die Ablehnung von Wissells Plan war Inhalt der Koalitionsvereinbarung, es war der Preis, den das Zentrum für das Zustandekommen einer Annahmemehrheit verlangte. Das entscheidende Argument dabei - ob richtig oder falsch - lautete, daß ausgedehnte Gemeinwirtschaft im Konfliktfall der Entente den Zugriff auf öffentliches Vermögen und öffentliche Werte gestatten würde. Dieses Argument stand in der Folge jeder wirklichen Sanierung der Reichsfinanzen und jeder rechtzeitigen Stabilisierung der deutschen Währung im Wege bis zum Jahre 1924, nachdem der Ruhrkrieg ausgestanden war.

Erzbergers Plan zur Reichsfinanzreform war großzügig, imponierend und radikal. Ich arbeitete ihn eingehend durch, ich konnte ihn sachverständig beurteilen. Es gehörte für den Zentrumsminister sicher Mut dazu, diesen Plan vorzulegen, der von Einzelheiten abgesehen, wahrscheinlich selbst von der äußersten Linken angenommen worden wäre, wenn es sich je wirklich darum gehandelt hätte, ihn wirklich durchzuführen. Das aber geschah nicht aus dem gleichen Grunde, aus dem das Reichskabinett die Fortsetzung der von der sozialdemokratischen Fraktion verlangten und von der Regierung Scheidemann angenommenen Sozialisierungspolitik abgelehnt hatte. ${ }^{\mathbf{1 0 6}}$

Als die Tage der gespannten Erwartung und der Hoffnung auf Machtübernahme vorüber waren, stürzte ich mich zunächst intensiv in journalistische Arbeit. Ich bediente nicht nur die „Leipziger Volkszeitung“. Die Redaktion dex „Freiheit“ in Berlin hatte mich inzwischen beauftragt, als ihr Korrespondent bei der Nationalversammlung zu wirken. Es waren interessante Tage; denn neue politische Gewitterwolken stiegen herauf. Meine täglichen Berichte von etwa anderthalber Leitartikellänge machten viel Arbeit, besonders die Berichte über den Weitergang von Erzbergers Plänen, die sehr sachverständiger Beurteilung bedurften. Nach der ersten Unterzeichnung der Reichsverfassung fand die erste Lesung der Finanzgesetze in der

105 Robert Schmidt (1864-1943), Klaviermacher, 1893-1898 Redalkteur am Vorwärts, 1903-1918 Mitglied der Generalkommission der Gewerkschaften, 1893-1898 und 1903-1930 MdR (SPD), Febr. 1919 Reichsernährungsminister, Juli 1919 - August 1922 und 1929-1930 Reichswirtschaftsminister, 1923 Wiederaufbauminister.

${ }^{106}$ Die erfolgreich durchgeführte Finanzreform Frzbergers brachte nicht nur die Angleichung von Einnahmen und Ausgaben der öffentlichen Hand und größere Steuergerechtigkeit, sie bewirkte durch die Errichtung einer einheitlichen Reichsfinanzverwaltung und den Übergang der Steuerhoheit auf das Reich die entscheidende Stärkung der Reichsgewalt auf Kosten der Länder. Vgl. Franz Menges, Reichsreform und Finanzpolitik, Berlin 1971, S. 184 ff.; Wolfgang Benz, Süddeutschland in der Weimarer Republik, Berlin 1970, S. 185 f. Die Fehleinschätzung Geyers lrönnte darauf beruhen, daß Erzberger bei der Begründung am 8. 7.1919 die Finanzreform als Sozialisierungsersatz bezeichnete: "Gerechte Steuern stellen eine rasch wirkende vorzügliche Sozialisierung dar." Nationalversammlung, Sten. Ber. S. 1377. 
Nationalversammlung statt. Ich erinnere mich, daß ich sie sehr positiv bewertete, als ich abschätzen konnte, welcher Mut dazu gehörte und auf welchen Widerstand sie stoßen würden. Sie bildeten eine der wesentlichen Ursachen der alsbald gegen Erzberger hervortretenden Mordhetze. Was mich anbetrifft, so begründeten meine Berichte an die „Freiheit" meinen Ruf als finanzpolitischer Sachverständiger.

Schicksalsschwanger waren die parteipolitischen Auseinandersetzungen in der $\mathrm{Na}$ tionalversammlung nach der Annahme des Friedensvertrages. Die Regierungsfraktionen, die die Verantwortung auf sich genommen hatten, unternahmen nun den Versuch, die Verantwortung des Kaisers, der ehemaligen Obersten Heeresleitung und vor allem der Rechtsparteien aufzuzeigen. Die Rechte, die Morgenluft witterte, setzte sich zur Wehr, und sie konzentrierte ihre Angriffe auf die Person Erzbergers, der im Kriege zunächst ein wilder Annexionist gewesen war, um dann in der kritischen Stunde des Krieges zum Vater der Friedensresolution von $1917 \mathrm{zu}$ werden. Diese Kämpfe gipfelten in einer rednerischen Auseinandersetzung zwischen dem damals noch deutschnationalen Abgeordneten von Graefe ${ }^{107}$ und Erzberger.

Diese Auseinandersetzungen - über die ich dann eingehend meinen Zeitungen berichtete - hörte ich von der Journalistentribüne der Nationalversammlung aus, nicht von meinem Platz im Plenum, weil man oben viel besser beobachten und hören konnte. Ich stand den beiden Duellanten politisch außerordentlich kritisch gegenüber und verfolgte deshalb das Rededuell ungetrübt von Voreingenommenheit. Es war nicht schwer, Erzbergers Kriegspolitik anzugreifen, und von Graefes Rede war eine sorglich vorbereitete oratorische Glanzleistung. Während dieser schlanke, dunkelhaarige Nationalist mit ätzender Schärfe und vollendeten Formulierungen Anklage auf Anklage gegen Erzberger schleuderte, saß die massive Gestalt des Reichsfinanzministers offenbar gleichmütig auf ihrem Platz, obgleich es in dem elektrisch geladenen Saale fühlbar war, daß Graefes Rede stärksten Eindruck weit über die Fraktionen der Rechten hinaus machte. Ich hörte ihr zu mit den Ohren des geübten Redners, ich war gewissermaßen selber von dieser rhetorischen Profession, und als Graefe geendet hatte, meinte ich, die Rechte hätte der Regierung eine schwere Schlappe versetzt, und es würde Erzberger schwerfallen, wirksam zu antworten. Aber ich hatte mich getäuscht. Die massive Gestalt erhob sich sofort von ihrem Platz mit den verächtlichen Worten: „Ist das alles?" Und ging sofort zum erbitterten, massiven Angriff über und legte das Schuldkonto der Rechten so überzeugend offen, daß ich danach keinen $Z$ weifel daran hatte, daß die Rechte diese oratorische Auseinandersetzung verloren hatte. ${ }^{108}$ Aber hatte sie sie wirklich verloren? Ich habe eine Rede von der gleichen ätzenden Schärfe, demselben Glanz der Formulierungen und intellektuell fundiertem Angriffsgeist wie die Rede Graefes nur noch einmal gehört, und das war die unerhörte Rede von Helfferich ${ }^{109}$ gegen Rathenau im Reichstag am Tage vor Rathenaus Ermordung. Graefe war wohl im Rededuell unterlegen, aber seinen Angriffen folgte der politische Mord nach.

107 Albrecht von Graefe (1868-1933), Rittergutsbesitzer, 1899-1918 MdL Mecklenburg-Schwerin, 1912-1928 MdR (Kons./DNVP/Nationalsozialistische Freiheitspartei), 1922 Mitgrïnder der Deutschvölkischen Freiheitspartei.

108 Verhandlungen der Deutschen Verfassunggebenden Nationalversammlung, 66. Sitzung, 25. Juli 1919, Sten. Ber. S. 1912-1946.

109 Verhandlungen des Reichstags, 233. Sitzung, 23. Juni 1922, Sten.Ber. S. 7988 ff. Karl Helfferich (1872-1924), Volkswirt, seit 1908 im Vorstand der Deutschen Bank, 1915 Staatssekretär des Reichsschatzamtes, 1916-1917 des Reichsamts des Innern und Stellvertreter des Reichskanzlers, verantwortlich für die Kriegsfinanzpolitik, 1920-1924 MdR (DNVP). 
Wenn abends die Nationalversammlung ihre Sitzungen geschlossen hatte, arbeitete ich in den für die Presse hergerichteten Räumen der Nationalversammlung und telephonierte dann meine Berichte nach Leipzig und Berlin. Es war inzwischen Hochsommer, und ich habe damals gelernt, stundenlang auf Telephonverbindungen $\mathrm{zu}$ warten, ohne aus der Haut zu fahren, und was es bedeutet, in einer übermäßig heiBen Telephonzelle bei schlechter Verbindung eine halbe oder eine dreiviertel Stunde lang ins Telephon schreiend diktieren zu müssen.

An einem der letzten Sitzungstage der Nationalversammlung in Weimar, ehe die Sommerpause eintrat und die Nationalversammlung nach Berlin verlegt wurde, hatte ich mich an der Debatte beteiligt. Nach der Sitzung ging ich in die Presseräume, verfaßte meinen Bericht und telephonierte ihn. Ich hatte für den Abend eine Verabredung mit meinen Fraktionsfreunden in einem der Gesellschaftszimmer im ersten Stock des Weinhauses „Fürstenkeller". Als ich endlich dahin kam, todmüde von der Arbeit und der Hitze in der Telephonzelle, fand ich meine Freunde in sehr feuchtfröhlicher Stimmung vor. Ich setzte mich zu ihnen, und gleich danach wurde die Tür aufgerissen, und der neue Reichspressechef Ulrich Rauscher ${ }^{\mathbf{1 1 0}}$ erschien mit einer Reihe sozialdemokratischer Abgeordneter. Er war sichtlich bereits sehr stark betrunken. Er starrte uns erst mit maßloser Überraschung an, und dann sagte er: „Ei, ei, die Konkurrenz ist schon da“, was uns aus den verschiedensten Gründen zum Lachen brachte; denn in diesen Tagen waren wir ernstlich die Machtkonkurrenz. Weiter weiß ich von diesem Abend nicht viel. Meine Freunde tranken Ürziger Goldtropfen. Ich hatte kaum ein Glas getrunken, als ich den Kopf auf den Tisch legte und einschlief.

Nach der Vereidigung von Reichspräsident Ebert verschwand die Nationalversammlung im August sang- und klanglos aus Weimar, ${ }^{111}$ und ich fuhr nach Leipzig zurück.

110 Ulrich Rauscher (1884-1930), Journalist, im November 1918 als Sekretär Scheidemanns in die Reichskanzlei eingetreten, 1919-1920 Pressechef der Reichsregierung, 1922-1930 Gesandter in Warschau.

111 Die letzte Sitzung der Nationalversammlung in Weimar, bei der Reichspräsident Ebert den Eid auf die Reichsverfassung leistete, fand am 21. August 1919 statt. 